\title{
THE INFLUENCE OF FASTENER SPACING ON THE SLIP MODULUS BETWEEN COLD FORMED STEEL AND WOOD SHEATHING
}

by

WESTON LOEHR

B.S., Kansas State University, 2014

\begin{abstract}
A THESIS
submitted in partial fulfillment of the requirements for the degree

MASTER OF SCIENCE

Department of Civil Engineering College of Engineering

\author{
KANSAS STATE UNIVERSITY \\ Manhattan, Kansas
}

2016

Approved by:

Co-Major Professor Hani G Melhem, PhD, P.E.

Approved by:

Co-Major Professor Bill Zhang, PhD, P.E., S.E. 


\section{Copyright}

WESTON LOEHR

2016 


\begin{abstract}
Composite action is the joint behavior of two elements connected or bonded together. It is a phenomenon that is utilized in several applications throughout engineering. Previous studies have shown that cold formed steel (CFS) sheathed with structural wood panels exhibits a degree of partial composite action behavior. However currently in the design process, CFS and wood sheathing systems are considered separately in a non-composite manner due to the absence of sufficient supporting data. These systems can include the floors, roofs, and walls of a building. In order to determine the level of composite action present, the slip modulus is needed. The slip modulus describes the relationship between the shear force and the displacement exhibited by two elements in a composite system. The scope of this research is to determine the influence of fastener spacing on the slip modulus and provide a foundation of information to fully define the composite action between CFS and wood sheathing.
\end{abstract}




\section{Table of Contents}

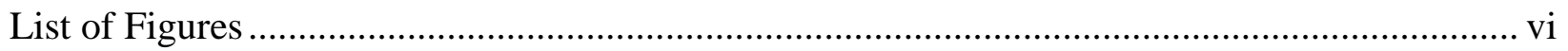

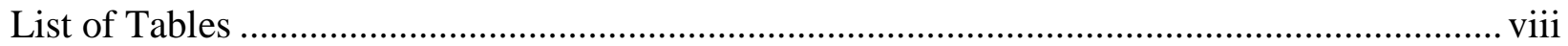

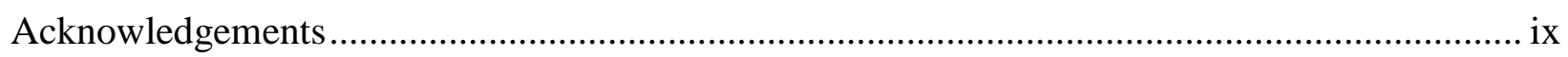

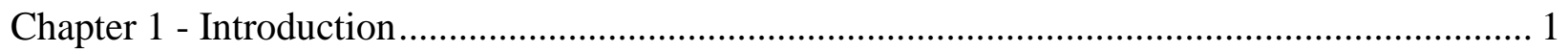

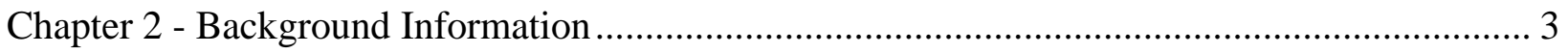

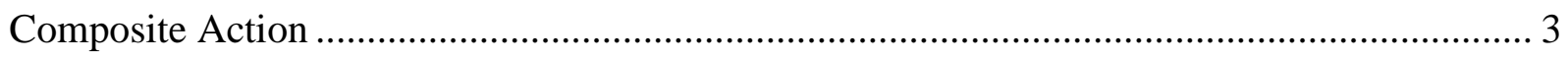

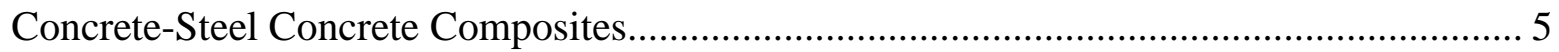

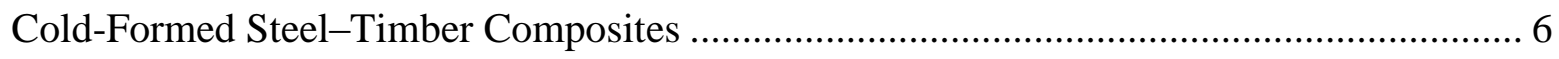

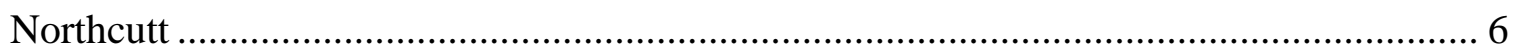

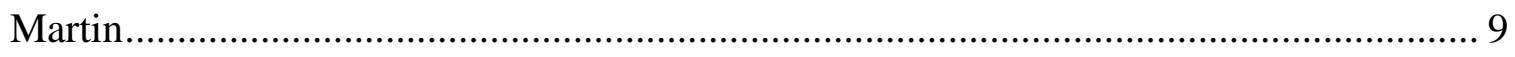

Curnutt and Faringthon ........................................................................................ 11

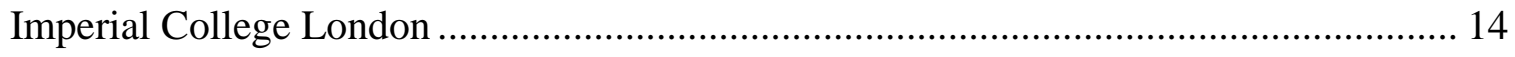

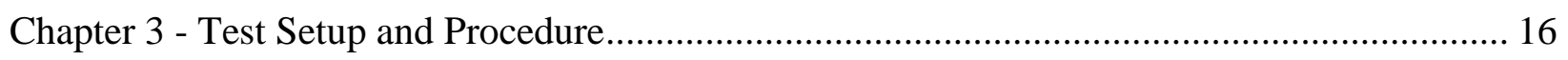

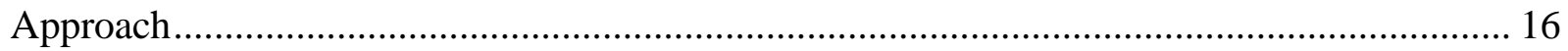

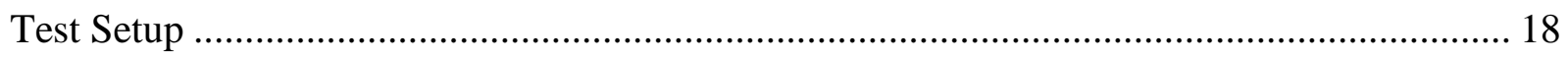

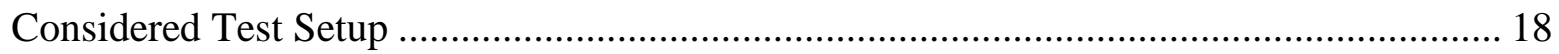

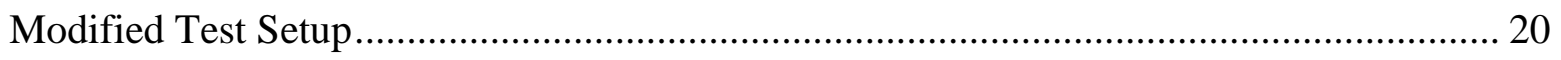

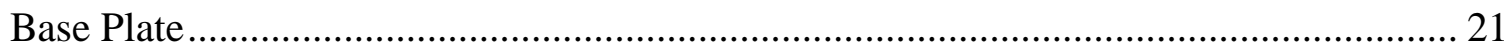

Slip Displacement Sensors................................................................................... 22

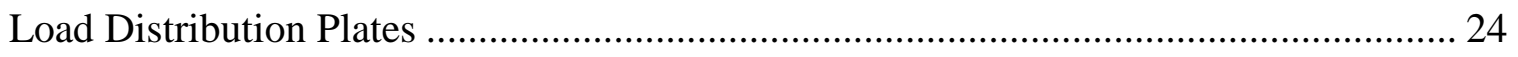

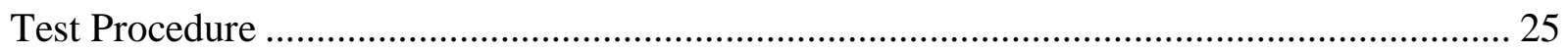

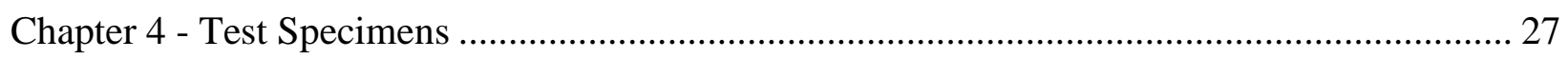


Material Selection

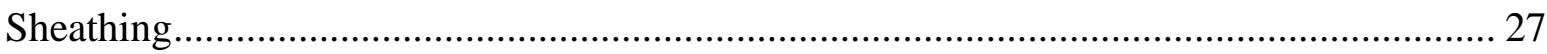

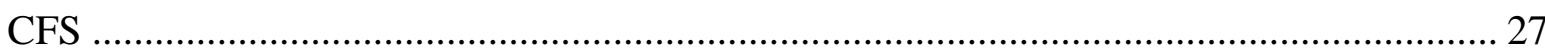

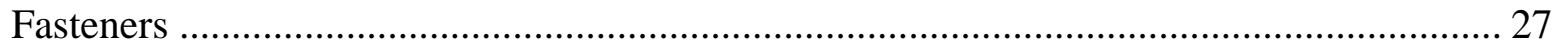

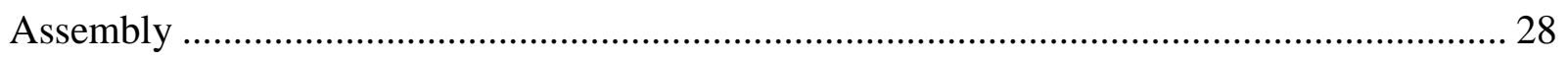

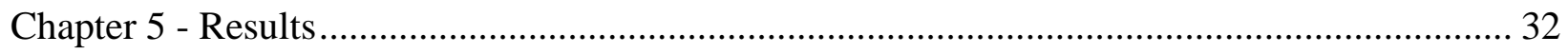

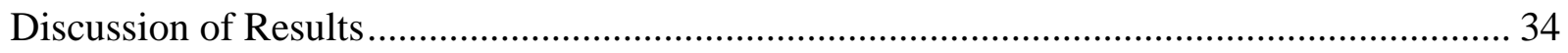

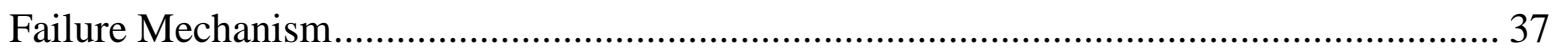

Slip Modulus and Normalized Slip Modulus........................................................ 38

Comparison of Results to Previous Studies .............................................................. 40

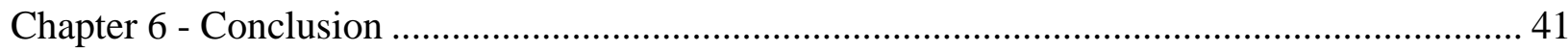

Recommendations for Future Research ................................................................ 42

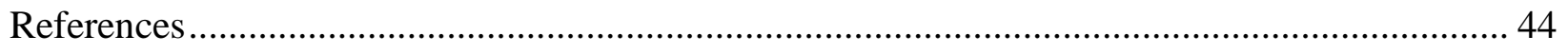

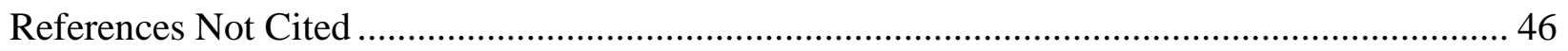

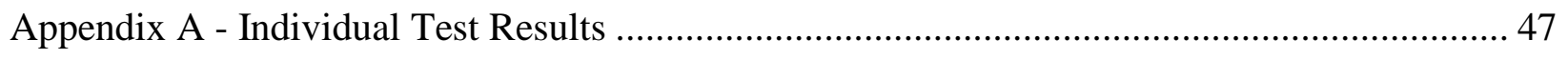

Appendix B - Shimadzu AG-IC Specifications Sheet .................................................. 52

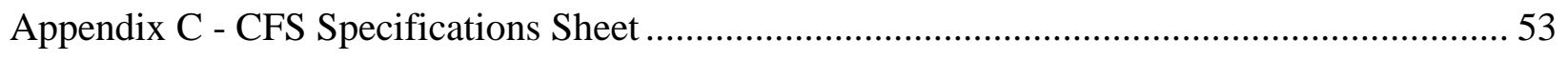

Appendix D - Celesco SP2-12 Specifications Sheet......................................................... 54 


\section{List of Figures}

Figure 2-1 Beam in Flexure with No Composite Action ..................................................... 3

Figure 2-2 Beam in Flexure with Full Composite Action .................................................... 4

Figure 2-3 Steel Reinforced Concrete Beam ............................................................... 5

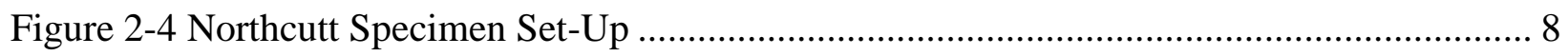

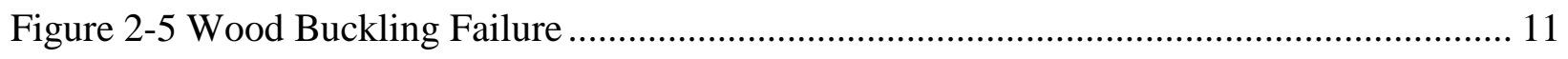

Figure 2-6 Typical Test Specimen ............................................................................. 12

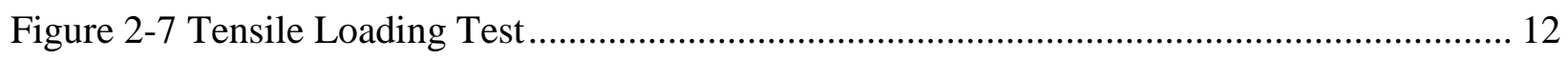

Figure 2-8 ICL Typical Cross Section and Loading Setup................................................ 14

Figure 3-1 Compression Test Setup........................................................................... 19

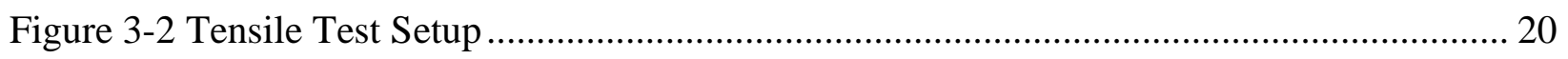

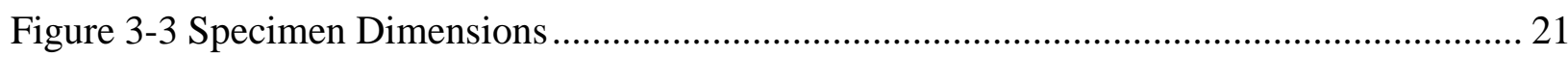

Figure 3-4 Base Plate Support Condition ….............................................................. 22

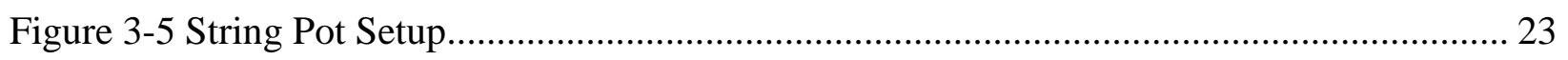

Figure 3-6 Back Metal Bracket and Magnet................................................................. 24

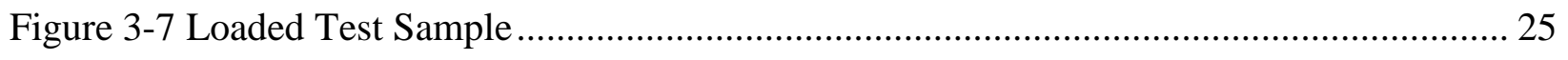

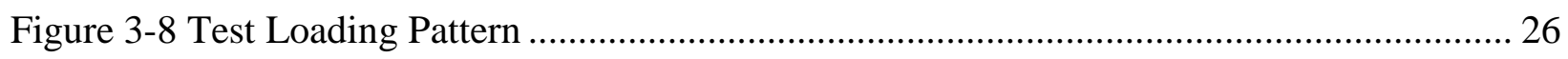

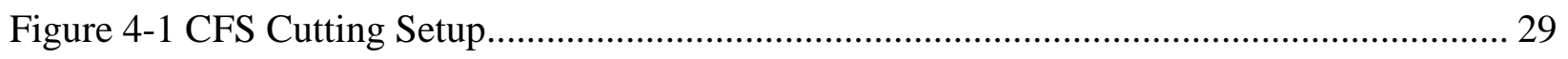

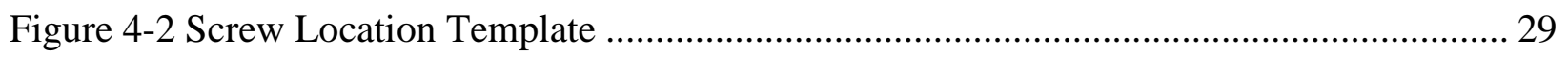

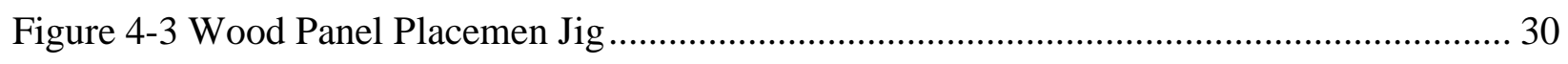

Figure 4-4 Wood Panel Being Attached ......................................................................... 30

Figure 5-1 Load Displacement Diagram for Five 6" Samples............................................... 34

Figure 5-2 Average Slip Response of a 6" Sample ............................................................ 35 
Figure 5-3 Average Slip Response of a 6" Sample up to 2000 lbs .... 36

Figure 5-4 Screw Tilting Mechanism and Failure 37

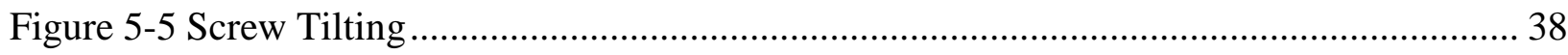

Figure 5-6 Screw Head After Failure ............................................................................ 38

Figure 5-7 Slip Modulus Compared To Fastener Spacing.................................................. 39

Figure 5-8 Normalized Slip Modulus Compared to Fastener Spacing ..................................... 39 


\section{List of Tables}

Table 2-1 Northcutt Slip Modulus and Recommended Normalized Slip Modulus Values........... 9

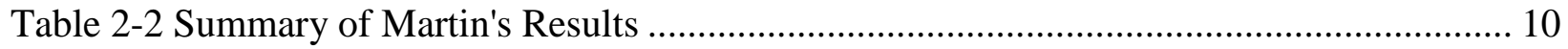

Table 2-3 Curnutt and Faringthon's Unpublished Results ............................................... 13

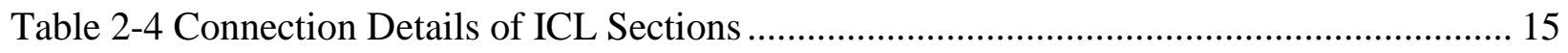

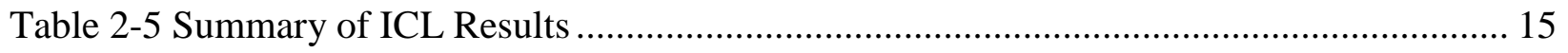

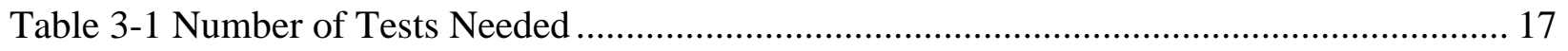

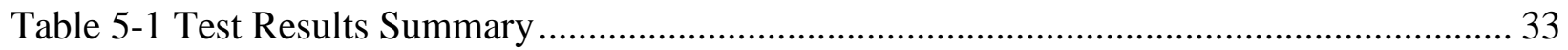

Table 5-2 Comparison of Results to Previous Studies....................................................... 40

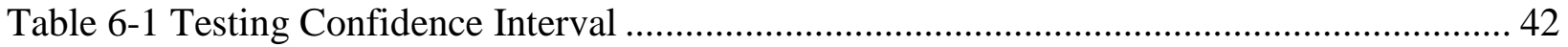




\section{Acknowledgements}

I would like to acknowledge my advisor Dr. Hani Melhem for his patience and guidance

throughout graduate studies. I would also like to thank Dr. Bill Zhang and Professor Kimberly

Kramer for their expertise, and Dr. Asad Esmaeily for serving on my committee.

My gratitude is extended out to Steve Thompson from Hi-Tech Interiors in Manhattan, KS for donating all of the cold-formed steel sections used in this study. 


\section{Chapter 1 - Introduction}

Cold-formed steel (CFS) is often thought of as a new product. However, the use of CFS began in the 1850's (6). Its use was primitive in the early years and had limited acceptance due to the lack of design standards and little knowledge of the material's behavior. It wasn't until 1946 when the first specification was published by AISI titled, "Specification for the Design of Light Gauge Steel Structural Members". A few years later, a design manual became available for engineers. In 1956, the second edition of AISI specifications was published and first adopted into building codes.

In the last couple of decades, CFS has seen an increased use in both commercial and residential construction. The demand growth for this material is caused by several factors. First, its high strength to weight ratio allows the architect and engineer versatility in the design process. Compared to timber, CFS can span longer distances without adding self-weight. Additionally, the material properties of steel do not significantly change with temperature or humidity variations typically encountered indoors, and it is not subject to decay when treated properly. Finally, cold formed steel's renewability makes it an environmentally friendly option, which is a growing concern in all industries.

One of the growing areas of application of cold-formed steel is in repetitive member assemblies. Sheathing materials such as gypsum, cement board, and wood panels are connected to an array of CFS members spaced closely together. The sheathing acts as a load distributing mechanism that transfers forces to the steel through surface contact, fasteners, or both. The steel is then responsible for carrying these forces to its supporting elements. Applications of these types of systems include floors, roofs, and walls. Currently in the design process, the sheathing and CFS members are considered separately (10). This approach does not accurately reflect the 
strength and stiffness of the system; it results in a larger number of members and an inefficient use of materials. In reality, the two materials in a CFS-sheathed system behave together in a composite manner.

Composite action occurs when two separate elements of different materials are bonded together in a way that makes them act as a single unit. The union of two different materials can result is a symbiotic relationship that can pair the strength of one material with the other's weakness. This concept has been widely studied and is exploited in several other areas of design and construction, such as reinforced concrete. However, limited research has been undertaken to investigate the composite behavior in CFS-wood sheathed systems. The aim of this investigation is to determine the effect of the fastener spacing on the slip modulus and composite action of a cold-formed steel member attached to wood sheathing. 


\section{Chapter 2 - Background Information}

Understanding the mechanics occurring within composite systems and the individual materials is crucial to study the composite effects on various types of assemblies.

\section{Composite Action}

Composite action is a well-known phenomenon used throughout engineering. It is when two members of different materials are bonded together in a way that they act as a single unit. In order for two elements to behave as one, a means to transfer the shear forces developed must be present. This can be done through a variety of mechanisms. Interlocking members, glue, and mechanical fasteners are the most common methods. The absence of a transfer mechanism results in the two materials behaving independently. To illustrate this type of behavior, Figure 2-1 shows a non-composite steel beam topped with a concrete slab loaded in flexure.
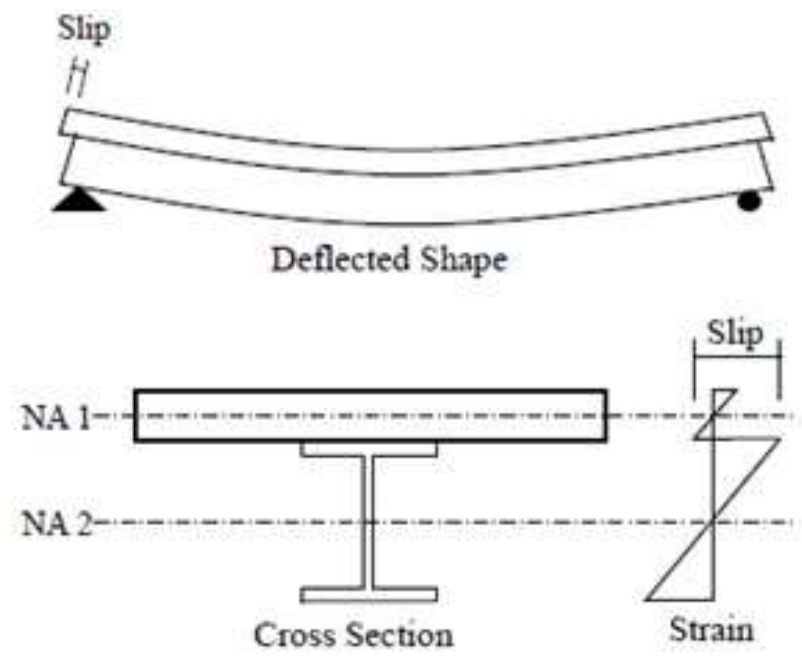

\section{Figure 2-1 Beam in Flexure with No Composite Action, Adapted from Martin (9)}

As the two materials deflect, the top portion is subjected to compressive stresses while the bottom has tensile stresses. The difference in these stresses creates horizontal shear in the members. Since there is no transfer of shear forces between the two members, there is a 
discontinuity in the stresses and strains of the two members. The effect is a displacement or slip between the two materials.

If a method of transferring shear forces between two materials is present, then composite action is possible. Figure 2-2 illustrates a beam loaded in flexure exhibiting full composite action. The two different materials have connectors transferring the full amount of horizontal shear developed at the contact surface and therefore deflect in unison. This produces a continuous distribution of strain amongst the two materials as well as a single neutral axis. This is advantageous because the resulting system response "is generally greater than the stiffness and strength of the members in the assembly acting alone." (2).

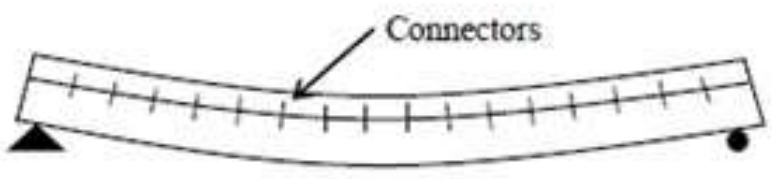

Deflected Shape

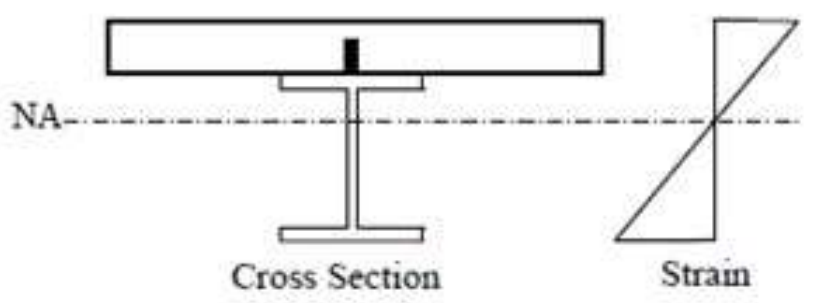

Figure 2-2 Beam in Flexure with Full Composite Action, Adapted from Martin (9)

However, composite systems often do not function in a fully composite behavior nor in a purely independent manner. These types of systems are classified as partially composite systems. "Partial composite action is the result of a non-rigid connection between elements which allows interlayer slip under load." (2). In other words, the fasteners are only able to transfer a portion of the horizontal shear, thus allowing a certain amount of movement between the two elements. 


\section{Concrete-Steel Concrete Composites}

Concrete-steel systems are the most common application of composite action. It is used in several structural elements such as beams, columns, and floors. Engineers combine these two materials because of their contrasting characteristics. Concrete is excellent in compression with a low cost, but it is prone to cracking under tensile stresses. On the other hand, steel is very strong in tension but is expensive relative to concrete. Employing composite action, engineers are able to produce better structural elements by optimizing each material according to its strength.

To best illustrate this, consider a reinforced concrete beam loaded in flexure as illustrated in Figure 2-3. Same as before, the top portion of the beam will experience compressive stresses while the bottom will have tensile stresses. Rather than construct a beam entirely of concrete, engineers can embed steel reinforcement (rebar) in the tensile region of the beam. The concrete efficiently resists the compressive stresses while relying on the steel to carry the majority or all of the tensile stresses. Rebar is often given a surface profile enabling it to grip and bond with the concrete poured around the steel. This provides a means for the stresses to be transferred between the two materials. The end result is a lighter, more cost effective beam than purely concrete or purely steel under certain conditions.

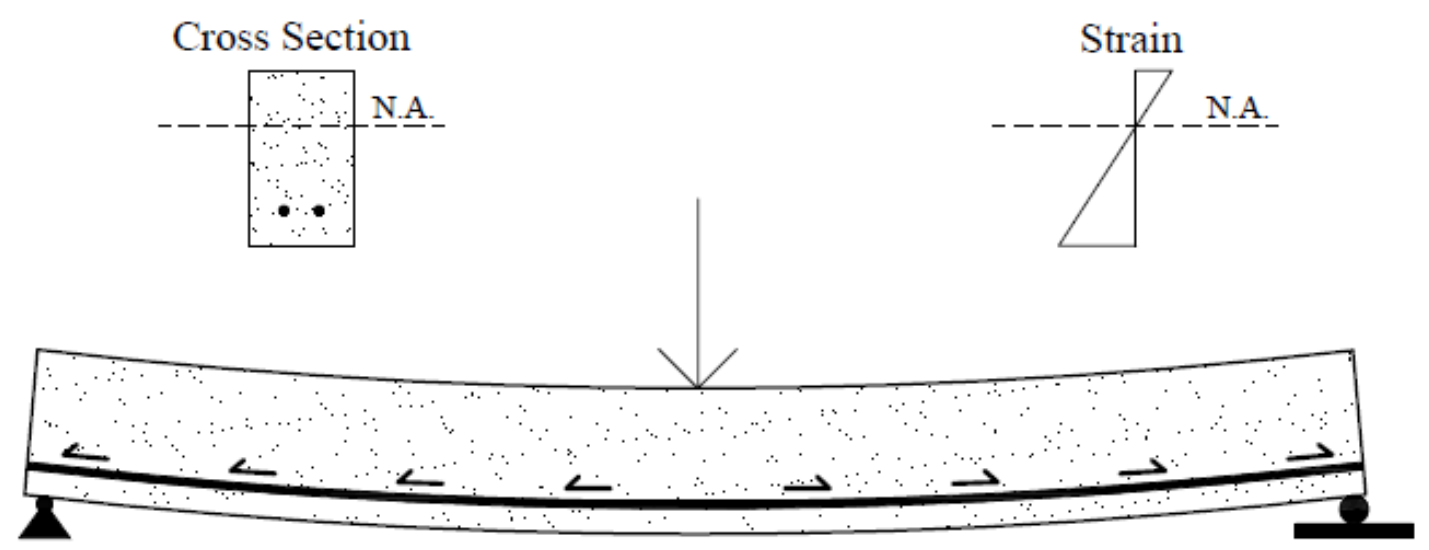

Figure 2-3 Steel Reinforced Concrete Beam 


\section{Cold-Formed Steel-Timber Composites}

A growing field in construction is the use of cold-formed steel with timber structural panels. The CFS members are arranged parallel to one another and are spaced at close intervals. Then structural wood panels (also referred to as wood sheathing) are connected to these members through mechanical fasteners. The result is a product similar to that of traditional wood framing with the steel replacing the timber wall studs, floor joists, or roof rafters. However, CFS-wood sheathing systems are often lighter and capable of resisting higher loads while maintaining the timely construction associated with timber structures. Since the CFS and structural panels are connected together, there is a prospect for composite action to be utilized. However, current design procedures neglect this opportunity and design the elements as two separate members.

\section{Northcutt}

In 2012, Amy Northcutt conducted a study (10) seeking to quantify the degree of composite action present in a CFS-timber sheathing system. The goal was to determine the change in the bending stiffness of an entire system compared to a single CFS member. To do this, the author performed compression (push) tests to measure the slip modulus of the connection as defined by ISO 6891 (7) using Equation 2-1. The modulus was then normalized to include the number of fasteners and their spacing by using Equation 2-2. Afterwards, the slip modulus was substituted into Equation 2-3 to calculate the shear bond coefficient. Finally, the effective bending stiffness was determined with Equation 2-4. 


\section{Equation 2-1 Slip Modulus}

$K=\frac{0.4 P_{U}}{V_{0.4}} \quad$ Where:

$0.4 P_{U}=40 \%$ of the expected ultimate load (lbs)

$V_{0.4}=$ the displacement or slip at $0.4 P_{U}$ (in.)

\section{Equation 2-2 Normalized Slip Modulus}

$K_{N}=\frac{K}{n s} \quad$ Where:

$K=$ the slip modulus (lbs/in.)

$n=$ number of fasteners

$s=$ fastener spacing (in.)

\section{Equation 2-3 Shear Bond Coefficient}

$\Upsilon=\frac{1}{1+\frac{\pi^{2} s E_{S} A_{s}}{K L^{2}}} \quad$ Where:

$\Upsilon=$ shear bond coefficient

$s=$ fastener spacing (in.)

$E_{s}=$ modulus of elasticity of sheathing (psi)

$A_{s}=$ area of sheathing $\left(\right.$ in..$\left.^{2}\right)$

$K=$ slip modulus (lbs/in.)

$L=$ length of member (in.)

\section{Equation 2-4 Effective Bending Stiffness}

$(E I)_{e f f}=E_{S} I_{S}+Y E_{S} A_{S} a_{1}^{2}+E_{j} I_{j}+E_{j} A_{j} a_{2}^{2} \quad$ Where:

$(E I)_{e f f}=$ effective bending stiffness of composite section $\left(\mathrm{lb} \cdot\right.$ in. $\left.^{2}\right)$

$E_{S} I_{S}=$ bending stiffness of sheathing $\left(\mathrm{lb} \cdot \mathrm{in} .{ }^{2}\right)$ 
$\Upsilon=$ shear bond coefficient

$E_{S} A_{S}=$ axial stiffness of sheathing (lb)

$a_{1}^{2}=$ distance between sheathing centroid and composite centroid (in.)

$E_{j} I_{j}=$ bending stiffness of CFS $\left(\mathrm{lb} \cdot\right.$ in. $\left.^{2}\right)$

$E_{j} A_{j}=$ axial stiffness of CFS (lb)

$a_{2}^{2}=$ distance between CFS centroid and composite centroid (in.)

A total of 12 tests were conducted, which were split equally into four series with different CFS thicknesses: 33 mil, 54 mil, 68 mil, and 97 mil (20 gauge, 16 gauge, 14 gauge, and 12 gauge respectively). The test specimens were composed of two 24 inch long $\times 6$ inch wide $\times 1 / 2$ inch thick plywood panels attached to the flanges of a 6 inch deep C-section. However, the 12 gauge section had 23/32 inch thick plywood to replicate common construction practice. The fasteners used were \#10 self-tapping screws spaced at a constant 12 inches. Two fasteners were installed per plywood panel. A typical sample is shown in Figure 2-4.

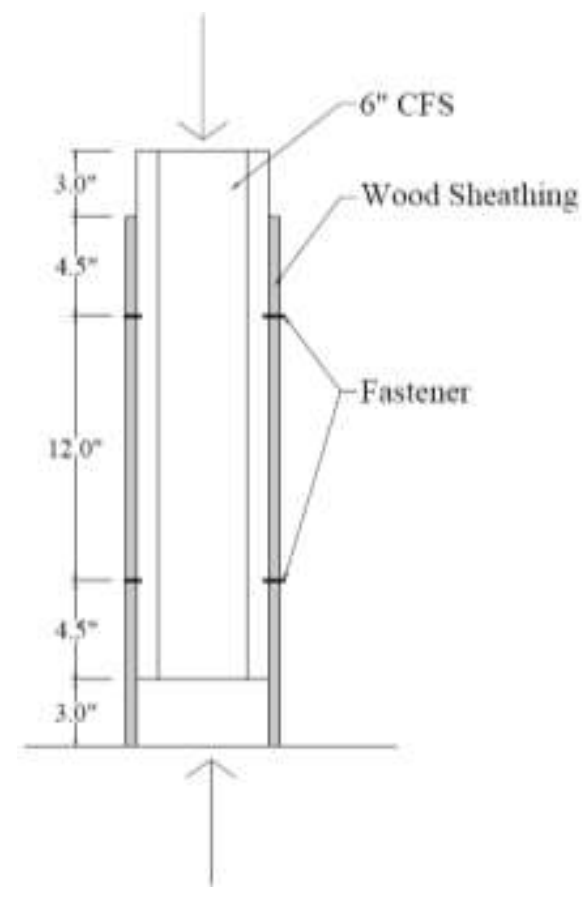

Figure 2-4 Northcutt Specimen Set-Up 
The push tests were conducted in accordance with ISO 6891 using an MTS testing machine with a transducer to record the slip deformation. A preliminary test was performed for each test series to establish the $0.4 P_{U}$ value and the loading rate. The primary failure mechanism observed during the testing was screw tilting. Exception occurred in the samples with the 12 gauge CFS channel, where shearing of the screw was the failure mode. The cause of this was attributed to the increased thickness of both the CFS and the plywood panel. Northcutt then calculated the normalized slip modulus and recommended following values shown in Table 2-1. The author neither recommended a normalized slip modulus value nor computed the effective stiffness for the T3 series because of its high amount of variance.

Table 2-1 Northcutt Slip Modulus and Recommended Normalized Slip Modulus Values

\begin{tabular}{|c|c|c|c|c|}
\hline $\begin{array}{c}\text { Test } \\
\text { Series }\end{array}$ & $\begin{array}{c}\text { Steel } \\
\text { Thickness } \\
\text { (gauge) }\end{array}$ & $\begin{array}{c}\text { Plywood } \\
\text { Thickness } \\
\text { (in.) }\end{array}$ & $\begin{array}{c}\text { Recommended Normalized } \\
\text { Slip Modulus } \\
\text { (lbs/in./in.) }\end{array}$ & $\begin{array}{c}\text { Effective } \\
\text { Stiffness } \\
\text { (\% Increase) }\end{array}$ \\
\hline $\mathrm{T} 1$ & 20 & $1 / 2$ & 140 & $63 \%$ \\
\hline $\mathrm{T} 2$ & 16 & $1 / 2$ & 560 & $40 \%$ \\
\hline $\mathrm{T} 3$ & 14 & $1 / 2$ & N.A. & N.A. \\
\hline $\mathrm{T} 4$ & 12 & $23 / 32$ & 640 & $59 \%$ \\
\hline
\end{tabular}

As the results show, the effective bending stiffness of a floor system was increased by an average of 54\% when compared to the CFS and plywood acting alone. The study clearly proved that partial composite action does exist in between CFS-timber sheathing systems. Northcutt concluded by acknowledging that the test results contained a high level of variation and recommends more research to be conducted.

\section{Martin}

In 2014, Geoff Martin built on Northcutt's research by further investigating the relationship between the slip modulus and CFS thickness (9). The study also began to look at the 
influence of fastener spacing. With these intentions, seven test series were established with three samples per series. The setup of the test samples mimicked Northcutt's specimens. The wood panels were 24 inch long $\times 6$ inch wide $\times 1 / 2$ inch thick birch plywood. However, no change was made to the 23/32 inch thick panels for the 12 gauge sections. The plywood panels were fastened to the flanges of the 6 inch C-section of CFS with \#10 self-tapping screws. Unlike Northcutt though, the number of fasteners installed depended on their spacing. The samples with $10 \mathrm{inch}$ spacing and 12 inch spacing had two fasteners per panel while the 6 inch and 8 inch had three. The series concerned with CFS thickness (T43, T54, and T97) used the same test setup as Northcutt illustrated in Figure 2-4 with distance between fasteners as 12 inches. The series related to fastener spacing (TF-6, TF-8, TF-10, and TF-12) employed 18 gauge CFS. The tests were conducted in accordance to ISO 6891 using a table top Shimadzu AG-IC Machine (see Appendix B - Shimadzu AG-IC Specifications Sheet) with two string potentiometers (pots) on each side to record the amount of slip. The results are summarized in Table 2-2.

Table 2-2 Summary of Martin's Results

\begin{tabular}{|c|c|c|c|c|}
\hline $\begin{array}{c}\text { Test } \\
\text { Series }\end{array}$ & $\begin{array}{c}\text { Steel Thickness } \\
\text { (Mils) }\end{array}$ & $\begin{array}{c}\text { Slip Modulus } \\
(\text { lbs/in) }\end{array}$ & $\begin{array}{c}\text { Normalized Slip Modulus } \\
\text { (lbs/in/in) }\end{array}$ & $\begin{array}{c}\text { Effective Stiffness } \\
\text { (\% Increase) }\end{array}$ \\
\hline T43 & 43 & 22442 & 468 & $20 \%$ \\
\hline T54 & 54 & 17659 & 368 & $14 \%$ \\
\hline T97 & 97 & 32470 & 676 & $6 \%$ \\
\hline TF6 & 43 & 28338 & 787 & $21 \%$ \\
\hline TF8 & 43 & 25933 & 540 & $20 \%$ \\
\hline TF10 & 43 & 16029 & 401 & $20 \%$ \\
\hline TF12 & 43 & 22442 & 468 & $20 \%$ \\
\hline
\end{tabular}

The primary failure mechanism observed during the testing was screw tilting, except one sample in the T97 series that had screw shear as the failure mode; in TF6 and TF8, buckling of the plywood panels was the cause of failure for each of the samples as shown in Figure 2-5. The 
increased stiffness was found to be less than that observed by Northcutt. Martin reiterated Northcutt's guidance for further testing to be conducted given the system's high level of variability. The author admits that construction quality may be partly to blame for the high deviation of results. Martin concludes by proposing the use of at least 15 test samples to obtain more definite results.

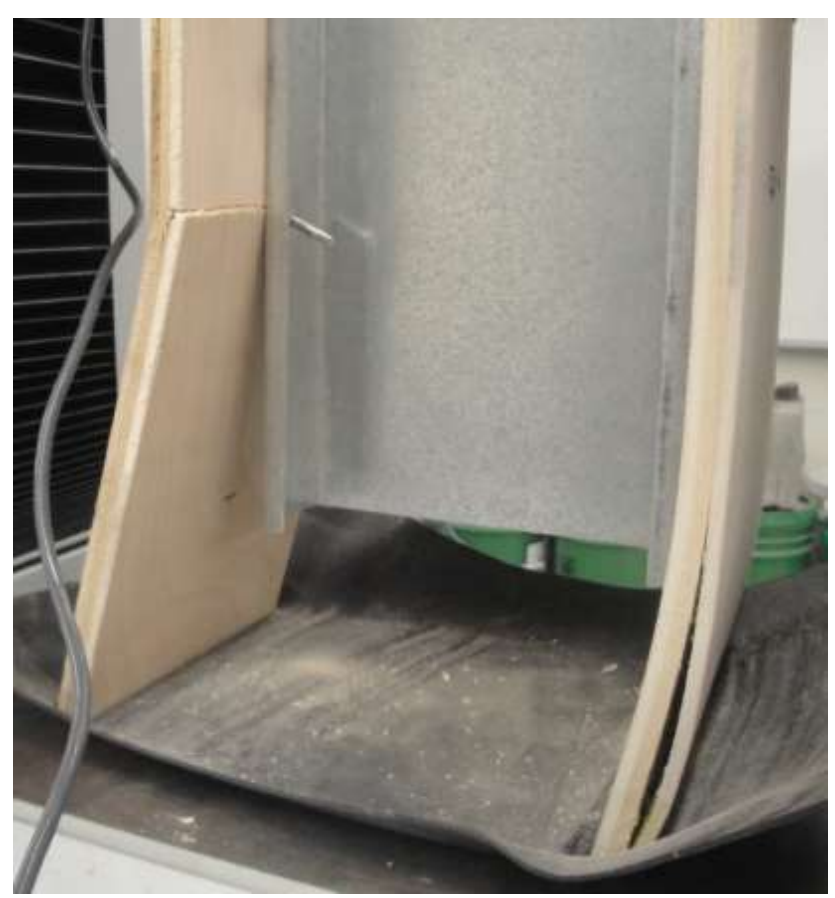

Figure 2-5 Wood Buckling Failure, used with permission by Martin (9)

\section{Curnutt and Faringthon}

In a 2015 unpublished study performed at Kansas State University (5), Austin Curnutt and Jonathan Faringthon attempted to resolve the instability issues and high levels of variance seen in the previous studies. Their focus was on refining the test setup to eliminate sources of inconsistencies and errors. The solution was to use a tensile (pull) test method rather than the compression method used by both Northcutt and Martin.

The investigation duplicated the test approach and setup used by Martin with a few exceptions. The CFS, plywood panels, and self-tapping screws were all identical to those in 
Martin's study. The same Shimadzu AG-IC Machine was used, but the compression heads were replaced with grip heads for tensile loading. Since only two grips can be installed, one on the top and one on the bottom, Curnutt and Faringthon were forced to have only a single wood panel attached to one of the flanges. To make this possible, a notch was cut out of the web of the CFS to create a location for the machine to grip the flange being tested. An illustration of a typical specimen is shown in Figure 2-6; an image of a specimen during a pull test is given in Figure $2-7$.

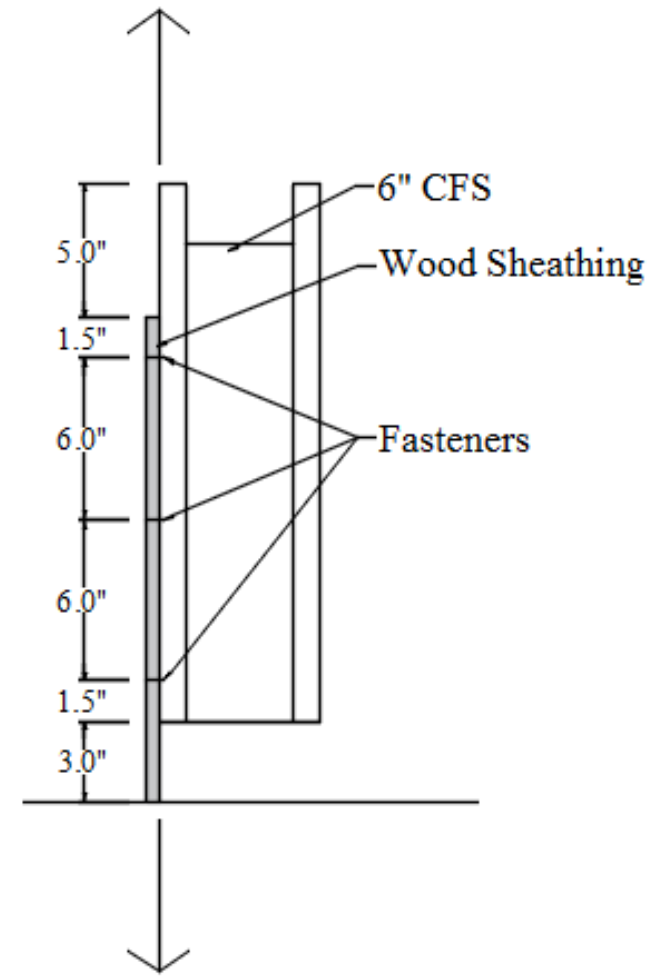

Figure 2-6 Typical Test Specimen

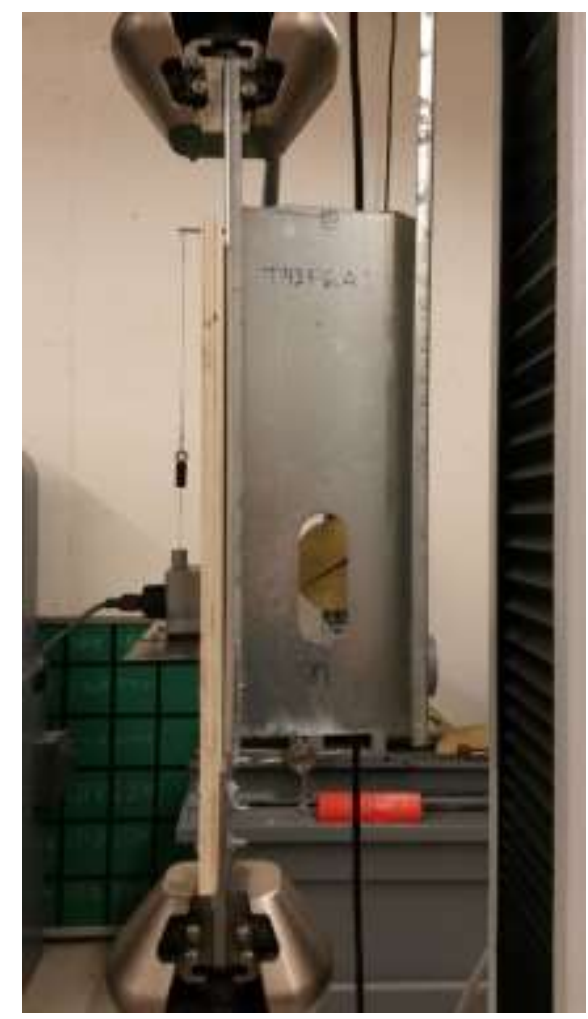

Figure 2-7 Tensile Loading Test

Photo Courtesy of Curnutt and Faringthon

Overall, the setup did not reduce the level of variance in the testing data. Five of the test series resulted in an increase in deviation while only two experienced a decrease in comparison to Martin. The results of Curnutt's and Faringthon's unpublished study are summarized in Table 2-3 on the following page. 
Table 2-3 Curnutt and Faringthon's Unpublished Results

\begin{tabular}{|c|c|c|c|c|c|c|c|c|c|}
\hline $\begin{array}{c}\text { Test } \\
\text { Series }\end{array}$ & $\begin{array}{c}\text { Steel } \\
\text { Gauge (mils) }\end{array}$ & $\begin{array}{c}\text { Plywood } \\
\text { Thickness }\end{array}$ & $\begin{array}{l}\text { Fastener } \\
\text { Spacing }\end{array}$ & $\begin{array}{c}\text { Fasteners per } \\
\text { Specimen }\end{array}$ & $\begin{array}{c}\text { Max } \\
\text { Force (lb) }\end{array}$ & $\begin{array}{c}\text { Slip @ Max } \\
\text { Force (in) }\end{array}$ & $\begin{array}{c}\mathbf{4 0 \%} \\
P_{\text {est }}(\mathrm{lb})\end{array}$ & $\begin{array}{c}\text { Slip at } 40 \% \\
\text { Pest }_{\text {(lb) }}\end{array}$ & $\begin{array}{l}\text { Failure } \\
\text { Mode }\end{array}$ \\
\hline \multirow{6}{*}{$\mathrm{T} 43 \mathrm{~F} 12$} & 43 & $1 / 2^{\prime \prime}$ & 12 & 2 & 1472.5 & 0.4777 & 589.8 & 0.0530 & Screw Tilt \\
\hline & 43 & $1 / 2^{\prime \prime}$ & 12 & 2 & 1456.7 & 0.5376 & 582.7 & 0.0374 & Screw Tilt \\
\hline & 43 & $1 / 2^{\prime \prime}$ & 12 & 2 & 1630.6 & 0.4859 & 652.2 & 0.1076 & Screw Tilt \\
\hline & 43 & $1 / 2^{\prime \prime}$ & 12 & 2 & 1706.4 & 0.4469 & 682.6 & 0.0628 & Screw Tilt \\
\hline & 43 & $1 / 2^{\prime \prime}$ & 12 & 2 & 1395.9 & 0.4148 & 558.4 & 0.0575 & Screw Tilt \\
\hline & 43 & $1 / 2^{\prime \prime}$ & 12 & 2 & 1449.3 & 0.4501 & 579.7 & 0.0760 & Screw Tilt \\
\hline \multirow{3}{*}{ T54F12 } & 54 & $1 / 2^{\prime \prime}$ & 12 & 2 & 1341.8 & 0.4978 & 536.7 & 0.0279 & Screw Tilt \\
\hline & 54 & $1 / 2^{\prime \prime}$ & 12 & 2 & 1425.8 & 0.2982 & 570.3 & 0.0283 & Screw Tilt \\
\hline & 54 & $1 / 2^{\prime \prime}$ & 12 & 2 & 1685.7 & 0.4781 & 674.3 & 0.0357 & Screw Tilt \\
\hline \multirow{3}{*}{ T97F12 } & 97 & $1 / 2^{\prime \prime}$ & 12 & 2 & 1375.9 & 0.2201 & 550.4 & 0.0283 & Screw Shear \\
\hline & 97 & $1 / 2 "$ & 12 & 2 & 1380.1 & 0.3195 & 552.0 & 0.0407 & Screw Shear \\
\hline & 97 & $1 / 2^{\prime \prime}$ & 12 & 2 & 1833.95 & 0.2509 & 733.6 & 0.0177 & Screw Shear \\
\hline \multirow{3}{*}{ T43F6 } & 43 & $1 / 2^{\prime \prime}$ & 6 & 3 & 2470.8 & 0.5097 & 988.3 & 0.0641 & Screw Tilt \\
\hline & 43 & $1 / 2^{\prime \prime}$ & 6 & 3 & 2347.2 & 0.3959 & 938.9 & 0.0337 & Screw Tilt \\
\hline & 43 & $1 / 2^{\prime \prime}$ & 6 & 3 & 1834.3 & 0.5118 & 733.7 & 0.0760 & Screw Tilt \\
\hline \multirow{3}{*}{ T43F8 } & 43 & $1 / 2^{\prime \prime}$ & 8 & 2 & 1658.3 & 0.3692 & 663.3 & 0.0320 & Screw Tilt \\
\hline & 43 & $1 / 2 "$ & 8 & 2 & 1421.9 & 0.4493 & 568.8 & 0.0394 & Screw Tilt \\
\hline & 43 & $1 / 2^{\prime \prime}$ & 8 & 2 & 1568.8 & 0.4805 & 627.5 & 0.0587 & Screw Tilt \\
\hline \multirow{3}{*}{$\mathrm{T} 43 \mathrm{~F} 10$} & 43 & $1 / 2 "$ & 10 & 2 & 1738.4 & 0.4608 & 695.4 & 0.0776 & Screw Tilt \\
\hline & 43 & $1 / 2 "$ & 10 & 2 & 2036.3 & 0.5331 & 814.5 & 0.0694 & Screw Tilt \\
\hline & 43 & $1 / 2^{\prime \prime}$ & 10 & 2 & 1530.1 & 0.4822 & 612.0 & 0.0719 & Screw Tilt \\
\hline
\end{tabular}




\section{Imperial College London}

At the Imperial College London (ICL) in 2015, Kyvelou, Gardner, and Nethercot performed full scale tests on CFS-timber composites (8). The aim of their project was to examine the amount of composite action that exists within a typical floor section. Through the course of the study, four full scale floor sections were constructed and tested along with one test of just bare CFS joists. The cross sectional configuration and loading setup are shown in Figure 2-8.
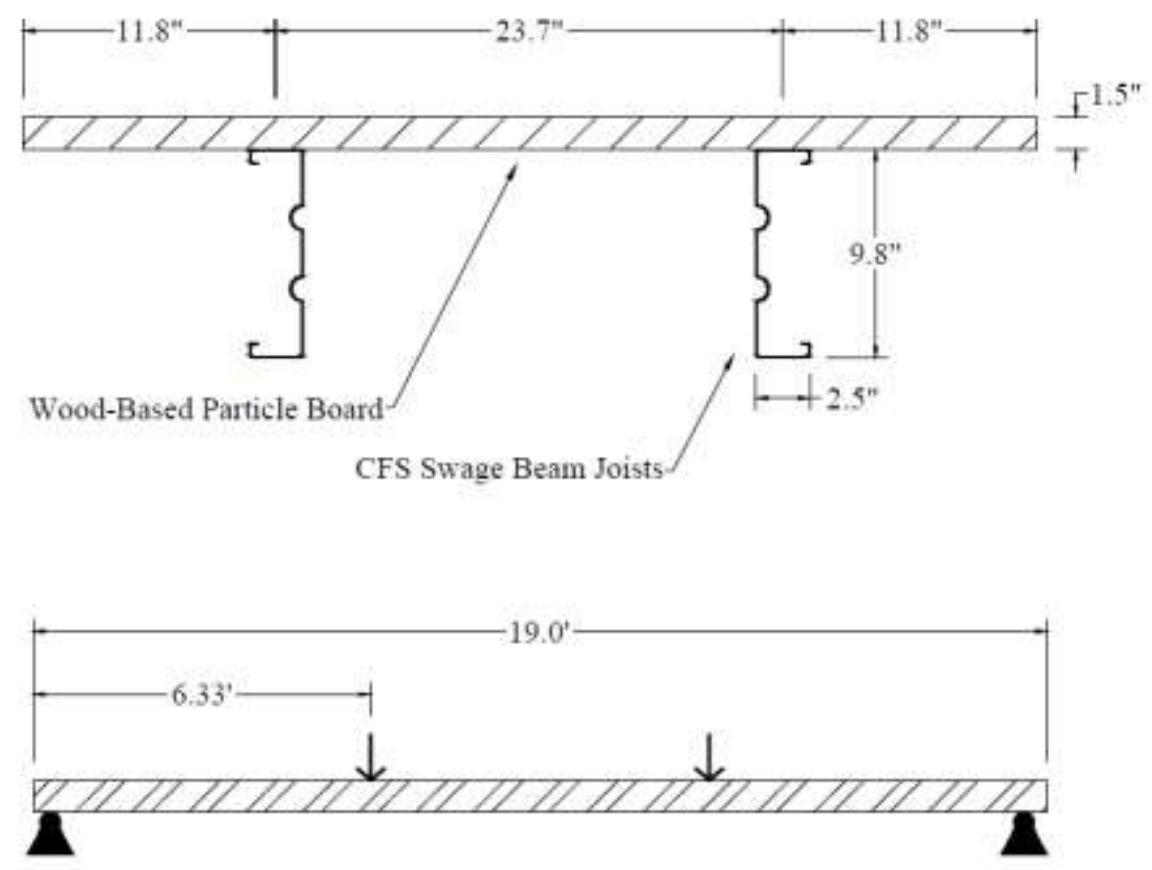

Figure 2-8 ICL Typical Cross Section and Loading Setup

The assembly spanned 19 feet and was loaded equally at the third points. Each section contained a different level of shear connection capacity, which is described in Table 2-4 on the following page. Numerous strain gauges and linear variable differential transformers (LVDT's) were placed throughout the entire setup. As part of the investigation, a theoretical, mechanical analysis of the system assuming a full shear transfer between the wood panel and the CFS joists was performed using area transformation. The experimental results were then compared to the theoretical analysis and to the bare CFS joists. The results are summarized in Table 2-5. 
Table 2-4 Connection Details of ICL Sections

\begin{tabular}{|c|l|c|}
\hline Test No. & Type of Shear Connection & Fastener Spacing (in.) \\
\hline 1 & N.A. (bare CFS joists) & - \\
\hline 2 & Self-tapping screws & 23.6 \\
\hline 3 & Self-tapping screws & 5.9 \\
\hline 4 & Self-tapping screws, wood glue at wood panel joints & 5.9 \\
\hline 5 & $\begin{array}{l}\text { Self-tapping screws, wood glue at wood panel joints, } \\
\text { epoxy resin at the beam-board interface }\end{array}$ & 3.9 \\
\hline
\end{tabular}

Table 2-5 Summary of ICL Results

\begin{tabular}{|c|c|c|c|c|}
\hline \multirow{2}{*}{$\begin{array}{c}\text { Test } \\
\text { No. }\end{array}$} & \multicolumn{2}{|c|}{ Experimental vs. Bare Steel } & \multicolumn{2}{c|}{ Experimental vs. Theoretical } \\
\cline { 2 - 5 } & Moment Capacity & Flexural Stiffness & Moment Capacity & Flexural Stiffness \\
\hline 1 & 1.00 & 1.00 & 0.43 & 0.58 \\
\hline 2 & 1.05 & 1.07 & 0.45 & 0.62 \\
\hline 3 & 1.45 & 1.14 & 0.61 & 0.66 \\
\hline 4 & 1.50 & 1.41 & 0.64 & 0.82 \\
\hline 5 & 1.99 & 1.42 & 0.85 & 0.82 \\
\hline
\end{tabular}

As believed, an increase in moment capacity and flexural stiffness was observed as the connection between the two materials became more rigid. It is important to notice the increased performance when the fastener spacing is reduced from nearly 24 inches to about 6 inches. This shows positive correlation between the distance between fasteners and the amount of composite action exhibited. The findings of the ICL study reveals a significant advantage of composite action in CFS-wood panel flooring systems. A 99\% increase in moment capacity and a $42 \%$ increase in stiffness compared to bare steel are possible if nearly full shear transfer is obtained. 


\section{Chapter 3 - Test Setup and Procedure}

Previous research concluded that composite action exists between CFS-wood sheathing systems. It also helped identify several potential factors that influence the slip modulus between cold-formed steel and wood sheathing. These factors include:

1. Fastener type

2. Fastener diameter

3. Fastener spacing

4. Sheathing type

5. Sheathing thickness

6. CFS thickness

However to better understand the effects of the different variables on the slip modulus, extensive research needs to be conducted for each of the factors.

\section{Approach}

The aim of this investigation is to further study the fastener spacing-slip modulus relationship. To accomplish this, two sub-goals were established. The first was to refine the testing method to reduce inconsistencies between tests performed. The second was to complete an adequate number of tests to obtain results with a level of confidence greater than $85 \%$.

Fastener spacings of 6 inches, 8 inches, 10 inches, and 12 inches were selected based on Martin's research (9) and the unpublished research by Curnutt and Faringthon (5). Throughout this study, the other five variables were held constant. Once the spacings were selected, statistical analysis was performed on each of the previous studies to provide guidance on how many tests would need to be conducted to get conclusive results. Equation 3-1 was applied to the 
data from Martin's and Curnutt \& Faringthon's research, and the results are summarized in Table

3-1. An average error of $\pm 10 \%$ was used for the calculations.

Equation 3-1 Sample Size Needed for One, Continuous Outcome

$$
\begin{aligned}
& n=\left(\frac{\sigma * Z}{E}\right)^{2} \quad \text { Where: } \\
& n=\text { number of tests needed } \\
& \sigma=\text { known standard deviation of study } \\
& Z=\text { confidence level } \\
& E=\text { allowable margin of error }
\end{aligned}
$$

\begin{tabular}{|c|c|c|c|}
\hline $\begin{array}{l}\text { Fastener } \\
\text { Spacing }\end{array}$ & $\begin{array}{l}\text { Confidence } \\
\text { Level }\end{array}$ & $\begin{array}{c}\text { Martin } \\
(\# \text { Tests Needed) }\end{array}$ & $\begin{array}{c}\text { Curnutt and Faringthon } \\
\quad(\# \text { Tests Needed })\end{array}$ \\
\hline \multirow{4}{*}{ 6" } & $80 \%$ & 12 & 23 \\
\hline & $85 \%$ & 15 & 29 \\
\hline & $90 \%$ & 19 & 38 \\
\hline & $95 \%$ & 27 & 54 \\
\hline \multirow{4}{*}{$8 "$} & $80 \%$ & 5 & 17 \\
\hline & $85 \%$ & 7 & 21 \\
\hline & $90 \%$ & 9 & 27 \\
\hline & $95 \%$ & 13 & 39 \\
\hline \multirow{4}{*}{$10 "$} & $80 \%$ & 13 & 1 \\
\hline & $85 \%$ & 16 & 1 \\
\hline & $90 \%$ & 21 & 1 \\
\hline & $95 \%$ & 30 & 1 \\
\hline \multirow{4}{*}{$12 ”$} & $80 \%$ & 16 & 22 \\
\hline & $85 \%$ & 21 & 28 \\
\hline & $90 \%$ & 27 & 36 \\
\hline & $95 \%$ & 38 & 52 \\
\hline
\end{tabular}

Table 3-1 Number of Tests Needed 
Based on this information, it was decided to perform 15 tests for each fastener spacing striving for an $85 \%$ confidence interval. Each test series would also have three preliminary tests to establish the maximum capacity and the loading rate, and to refine the test setup if needed. Refer to Chapter 4 for test specimen details.

\section{Test Setup}

In order to determine an effective test setup and test method to analyze the effect of mechanical fastener spacing on the slip modulus between CFS and wood sheathing, IS0 6891 (7) and AISI Test Standard for Cold-Formed Steel Connections (1) were consulted for guidance. Neither standard directly governs the connection between CFS and wood sheathing. ISO 6891 is used for the "determination of the strength and deformation characteristics of [timber] joints made with mechanical fasteners" (7). The standard discusses the loading pattern and procedure while providing little guidance towards the test apparatus. Conversely, the AISI standard is applicable to "connections for use in cold-formed steel diaphragms" and discusses the test apparatus. A combination of the two test standards was utilized for this study.

\section{Considered Test Setup}

Two different test modes were considered for the investigation. First was a compression loading condition, which is illustrated in Figure 3-1. Prior research by Northcutt (10) and Martin (9) utilized this type of test setup. The configuration is easy to assemble and provides two slip surfaces for testing with each specimen. However, the setup presented some issues. Chiefly, the buckling failure of the wood material at the base of the specimen. During six out of the 27 trials performed in Martin's study, the wood either buckled laterally or began to split apart. The lateral shifting of the wood material was shown in Figure 2-5. The accuracy of results in a trial in which buckling occurred cannot be guaranteed. The wood failure could influence the effective stiffness 
between the wood, fastener, and CFS. For this reason, alternative setups and approaches were investigated.

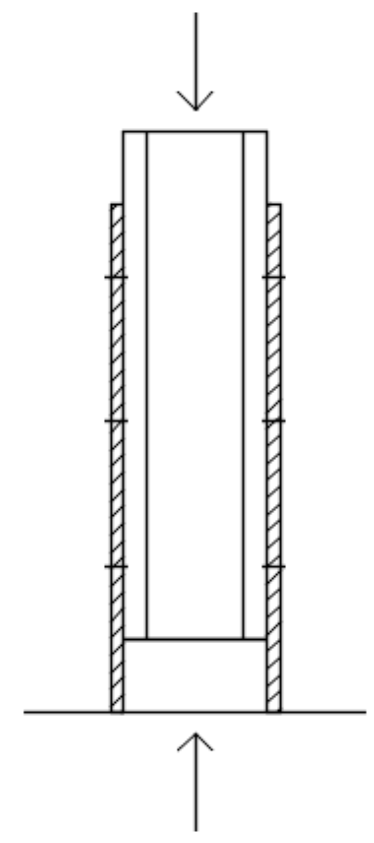

\section{Figure 3-1 Compression Test Setup}

The other test setup considered was a tensile loading condition as shown in Figure 3-2. This type of setup was used by Curnutt and Faringthon. The tensile setup eliminated the buckling issues previously experienced by both Northcutt and Martin. However, the setup required the CFS to be cut with a plasma cutter to provide a surface for the machine to grip the specimen along the flange of the CFS. Consequently, the configuration provided only one flange for the wood sheathing to be connected and tested. Other limitations are also present.The total strength allowed during one test is restricted by the grip strength of the machine jaws and the yield limit of the remaining steel after the cut. This method also required more time for the added step in the preperation of such specimens. 


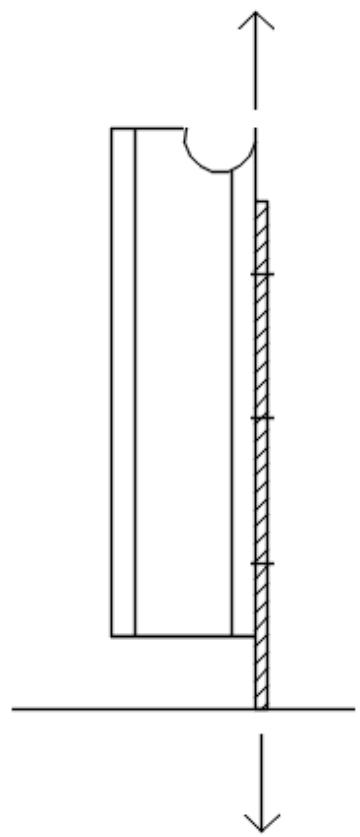

\section{Figure 3-2 Tensile Test Setup}

\section{Modified Test Setup}

After weighing the costs and benefits of each setup, the decision was made to use the compression test method and to resolve the buckling issues. One solution was the addition of a base support to limit the amount of rotation of the wood panel at the base of the specimen. Another was to reduce the length from the bottom of the specimen to the first fastener from 7.5 inches (refer to Figure 2-6) to 6 inches. Figure 3-3 illustrates the configuration and dimensions of the specimens with 6 inch, 8 inch, 10 inch, and 12 inch fastener spacing.

A total of 12 preliminary tests were conducted to examine setup modifications and to determine loading rates and stopping values for the test procedure. The tests were performed using a Shimadzu AG-IC machine similar to the one used by previous researchers. The final setup used for the four different test series is described in the following pages. 


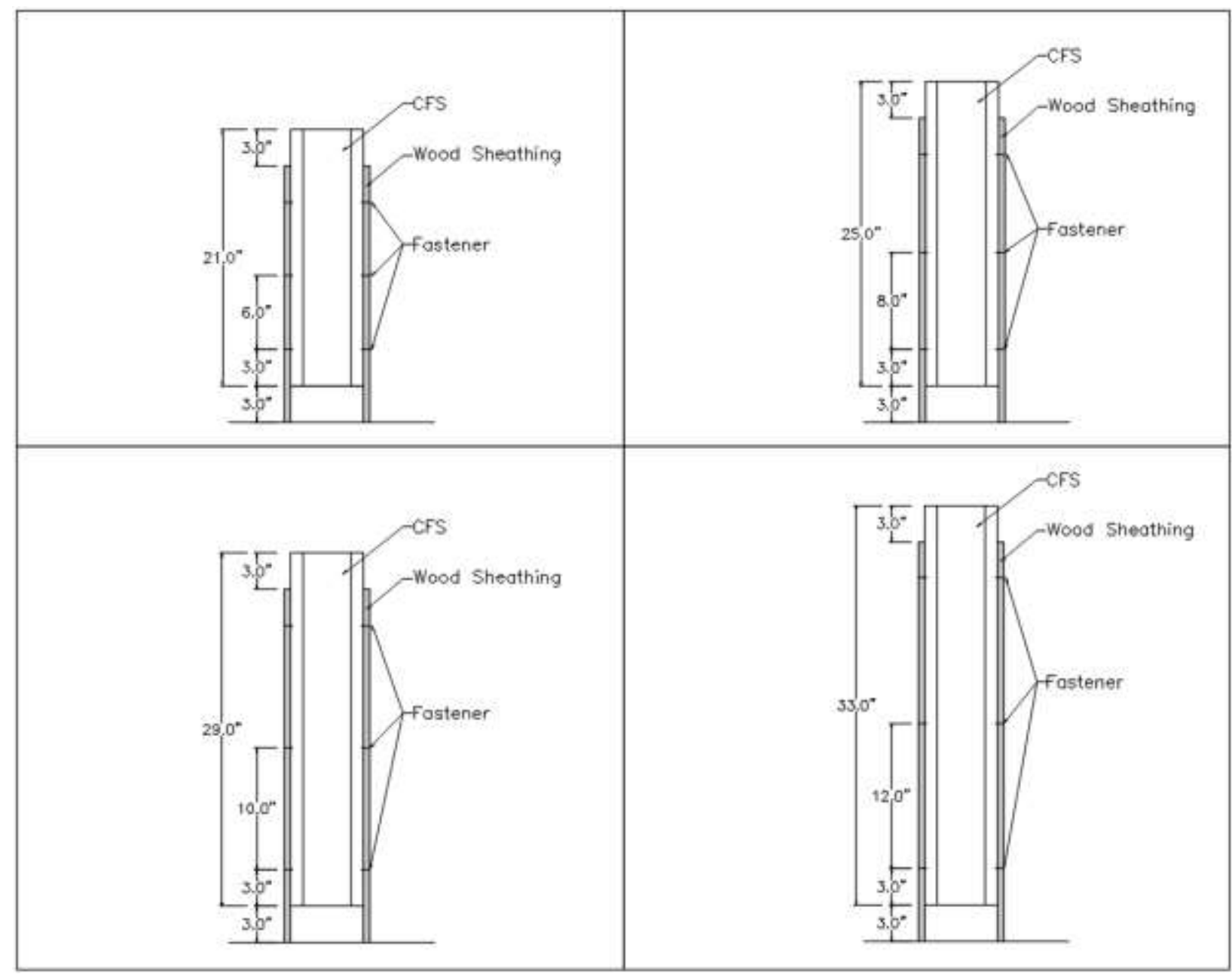

\section{Figure 3-3 Specimen Dimensions}

\section{Base Plate}

In order to prevent lateral buckling of the wood material, a bottom plate was fabricated to hold the specimen at the base. The wooden plate had two slots running front to back that held the bottom ends of the two pieces of wood sheathing. To prevent a moment from being applied at the support, the slots were cut 1/8 inch larger than the sheathing thickness, which allowed for a rotation of up to $2^{\circ}$. The base plate was bolted to the Shimadzu Testing machine to prevent the 
specimen or support from moving laterally. The base plate provided an extra benefit of ensuring every specimen was centered directly under the loading ram in each test.

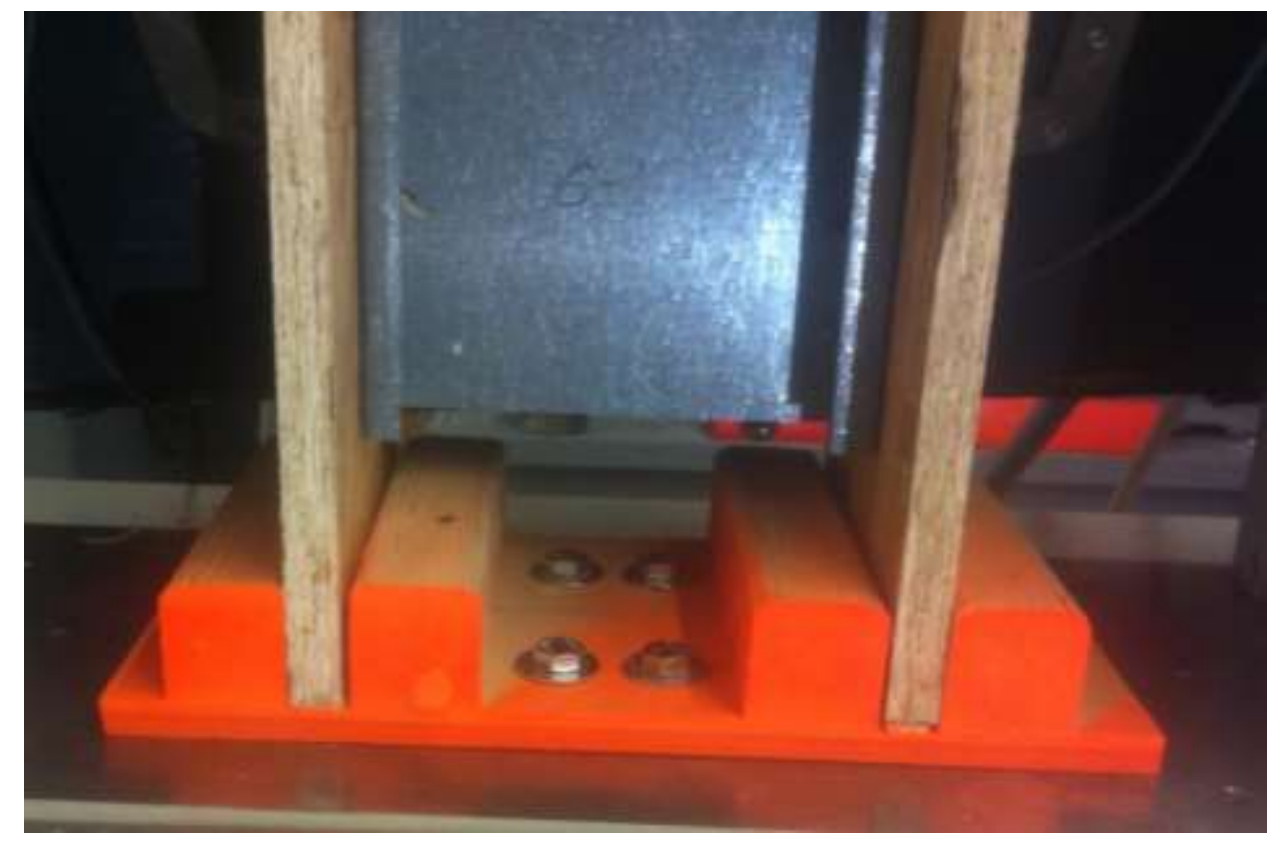

Figure 3-4 Base Plate Support Condition

\section{Slip Displacement Sensors}

Celesco SP2-12 Compact String Pot (see Appendix D - Celesco SP2-12 Specifications Sheet for more information) sensors were used to measure the relative displacement of the steel compared to the wood sheathing. The string potentiometers (pots) were calibrated, and their accuracy was found to be within $\pm 0.5 \%$ when tested against the Shimadzu Testing machine, which has an accuracy of \pm 0.0004 inches (Appendix B - Shimadzu AG-IC Specifications Sheet). Two sensors were used during testing; one for each side of the specimen. For each sensor, one end was connected to the sheathing and the other to the metal flange. The body of the string pots were fastened to an L-shaped, metal bracket so that the sensor would be oriented in the proper direction. It was connected to the bracket so that the sensor's string would be in the center of the wood material, which lined up with the middle of the CFS flange. The metal bracket also 
provided a method of attaching the sensors with accuracy and consistency among all the specimens. The string pot sensor configuration is illustrated in Figure 3-5.

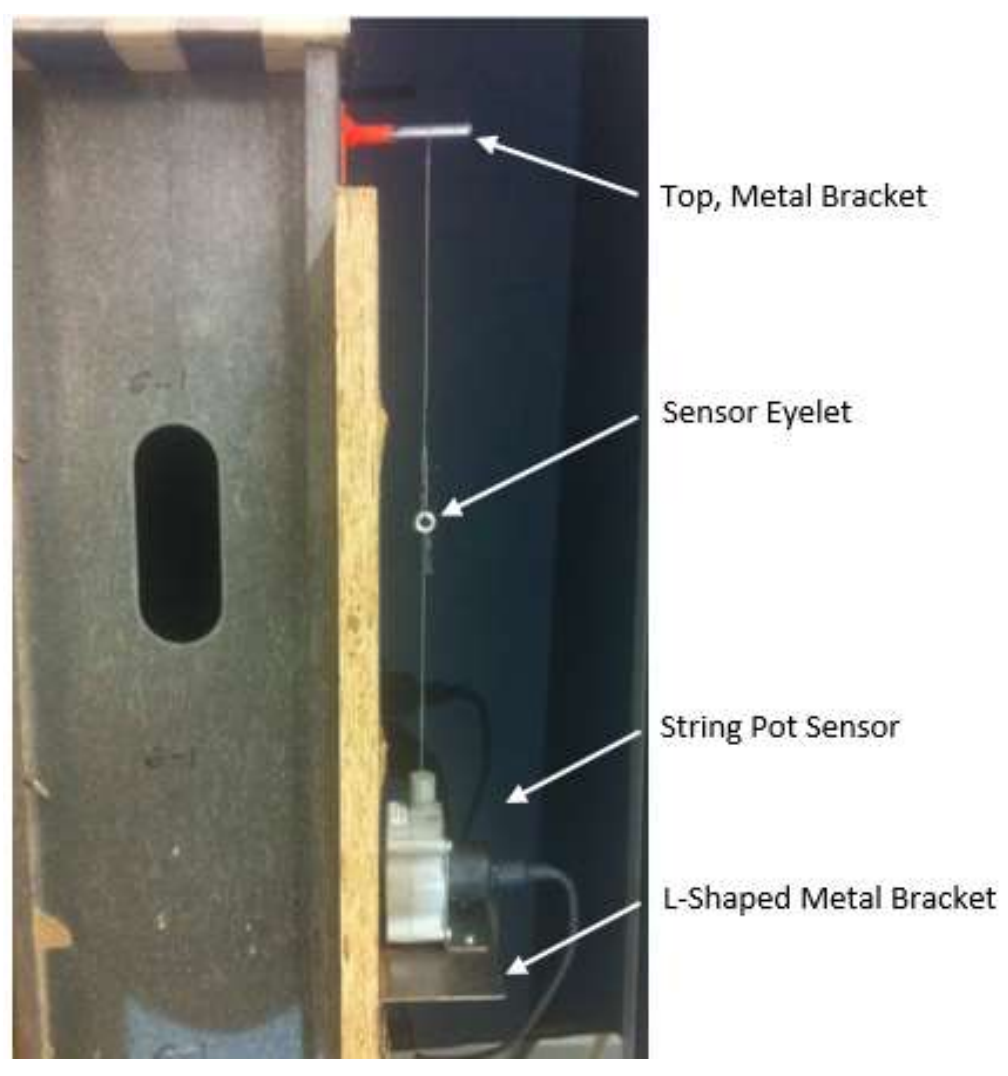

Figure 3-5 String Pot Setup

A steel wire was attached through the eyelet at the end of the device measuring string. The steel wire had a loop on the other end that slipped onto another fabricated metal bracket. The top, metal bracket was U-shaped and hugged the back and the two flanges of the CFS member. The metal bracket has two metal rods protruding from the sides to hold the sensor's string at the middle of each of the CFS flanges. The bracket was held on to the web of the CFS with an Eclipse toggle switch magnet as shown in Figure 3-6.

A concern was brought up that the magnet might move during testing from the tension in the sensor's string and the combined weight of the metal bracket and magnet. The magnet has a clamping strength of 176 pounds. The coefficient of static friction between steel and galvanized 
steel is 0.5 . The force required to move the magnet from its static position would be 85 pounds, far exceeding the amount of tension created in the string.

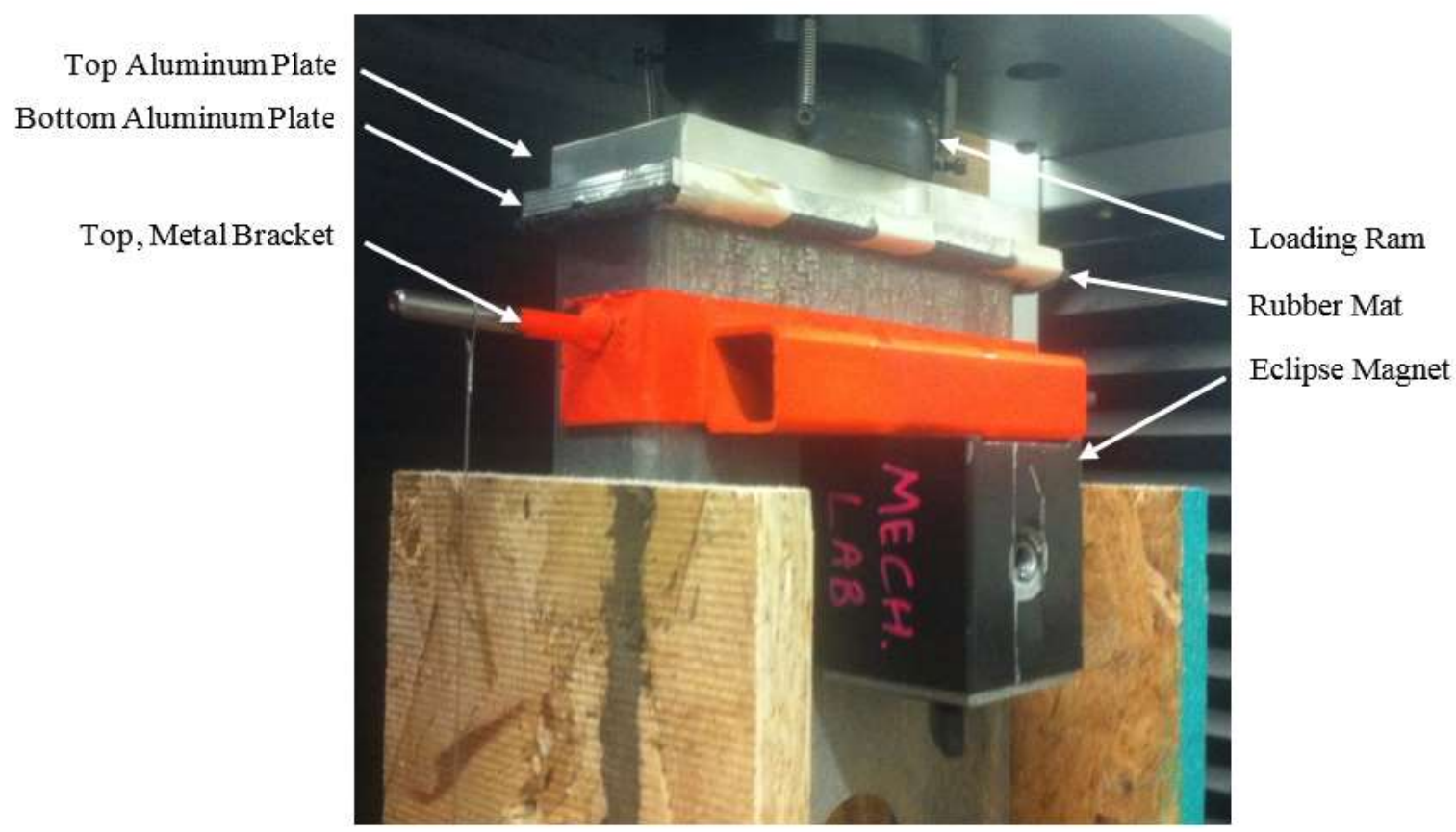

\section{Figure 3-6 Back Metal Bracket and Magnet}

\section{Load Distribution Plates}

At the top of each specimen, plates were used to distribute the load from the Shimadzu Testing machine to the specimen. Initially during the preliminary testing, a single $6.5 \mathrm{inch} \times 2.5$ inch $\times 0.25$ inch (width $\times$ depth $\times$ thickness) aluminum plate was placed atop of 0.25 inches plywood that sat on top of the CFS member. The wood uniformly spread the load across the surface of the steel reducing any potential stress concentrations. However, the wood began to split after a few tests and the aluminum plate started to deform. To fix this, an additional 6 inch $\times$ 2 inch $\times 0.5$ inch aluminum plate was added between the loading ram and the original aluminum plate, and a 1/16 inch piece of rubber mat was glued and taped to the bottom of the smaller aluminum plate to replace the plywood. The mat was replaced after each test series so that the CFS did not have a chance to dig in and cut through the rubber. 


\section{Test Procedure}

First, the Shimadzu Testing machine was prepared for testing by installing the compression ram device and bolting on the custom fabricated base plate. The machine remained unaltered with this setup for the duration of the entire testing activity. Next, a specimen was loaded onto the base plate and a level was used to check that the specimen was plumb with regards to the Shimadzu Testing machine. Pieces of printer paper were used as shims to correct any specimens that were out of plumb. The string pot sensors were then connected to the sheathing on both sides of the specimen below the middle screw with a pair of vice-grip clamps. Afterwards, the top bracket was attached to the web of the CFS with the toggle switch magnet. The wire of the string pot sensors were then slipped onto the rods of the bracket. The strings were leveled to be plumb with regards to the wood sheathing. The final step prior to beginning the experiment was to place the aluminum plates on top of the specimen. Figure 3-7 shows a loaded sample in the Shimadzu Testing machine.

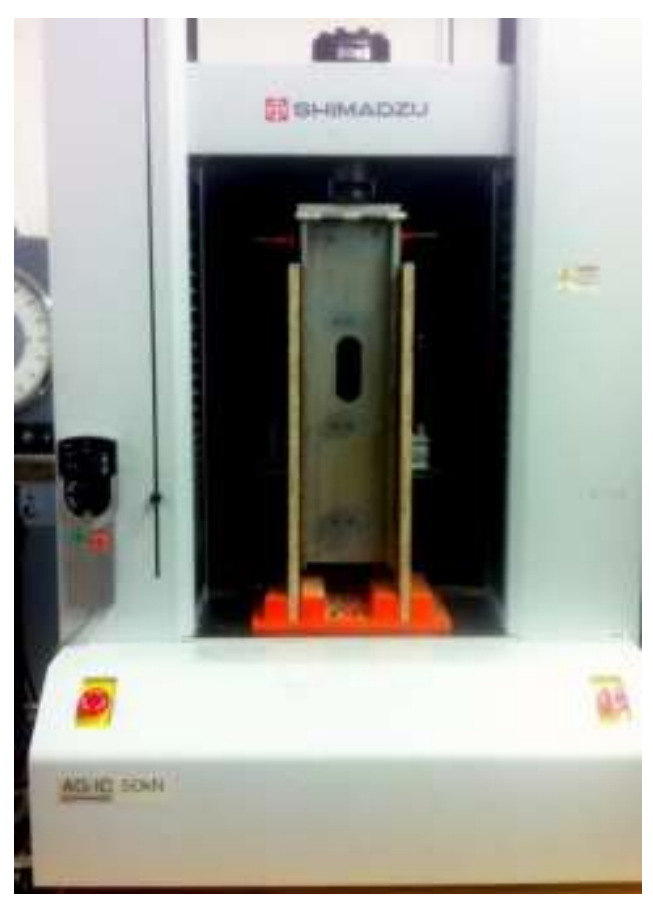

Figure 3-7 Loaded Test Sample 
The testing machine was controlled through a computer running Trapezium X, which can create a custom loading pattern. The specimen was loaded as follows:

1. Load the specimen at a rate of 800 pounds per minute

2. At 1600 pounds, hold stroke for 30 seconds

3. Release load at a rate of 800 pounds per minute

4. At 800 pounds, hold stroke for 30 seconds

5. Reload specimen at a rate of 800 pounds per minute until failure

Failure was considered to occur when the compression ram stroke reaches 0.60 inches. This amount of displacement by the loading ram ensured the peak strength, capacity decline, and failure were recorded. Figure 3-8 graphically shows the loading pattern.

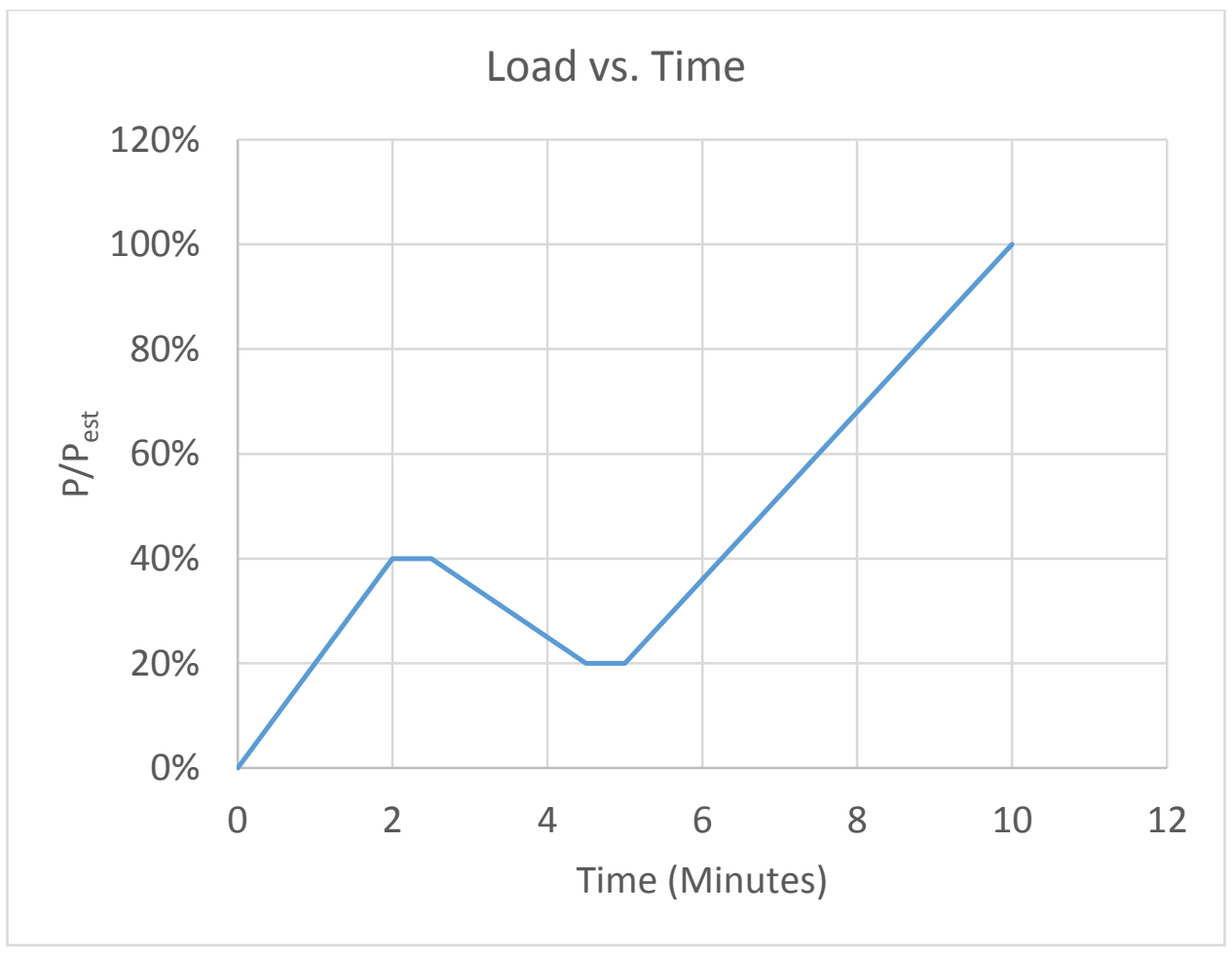

Figure 3-8 Test Loading Pattern 


\section{Chapter 4 - Test Specimens}

\section{Material Selection}

Great consideration was given in the selection of the materials used for testing. The materials used needed to be both locally available as well as common to the industry.

\section{Sheathing}

Oriented strand board (OSB) is a prevalent type of wood structural sheathing used in flooring systems. It is also common for walls and roofs where a CFS-wood sheathing systems may also be used. The thickness selected was 19/32 inch with a 40/20 span rating; this was chosen based on its flexural properties. OSB with this thickness is the thinnest size that can be used with 24 inch on center supports, provided it has a 1.5 inch thick layer of lightweight concrete poured on top (11). Concrete toppings are commonly used in commercial applications to improve fire resistance and sound insulation properties of the floor system. Without a topping, 40/20 rated 19/32 inch OSB can have maximum support spacing of 20 inch (11), but a 16 inch spacing is more likely in a residential setting.

\section{CFS}

The cold-formed steel section used was 600S162-43. This corresponds to 6 inch stud section with 1.625 inch wide flanges and 0.5 inch stiffener lips. The specified yield stress was 33 ksi. The thickness is 43 mils ( 0.043 inch) or 18 gauge steel. The cold-formed steel was donated by Hitech Interiors. A specifications sheet for the CFS is included in Appendix C.

\section{Fasteners}

There are several features to be considered in selecting the proper fastener to be used as "[it] is necessary to assure the proper performance of the connections used in cold formed steel construction" (3). First is the point type of the fastener. Self-drilling screws are the most 
common type used since they drill their own hole in the material eliminating the need for predrilled holes. For this study, \#3 point was chosen based on availability and the thickness of the CFS used.

The head style of the fastener is the next feature to be considered. Fasteners are normally required to be flush with the sheathing to provide a smooth surface for the flooring finish used. Two types of heads are designed for this: flat heads and wafer heads. After consulting with the local CFS supplier, flat head fasteners were used as they were deemed more common in construction.

Following the point style and head type, a decision has to be made on the diameter and thread count of the fastener. To be consistent with Martin's and Northcutt's research, \#10-24 screws were selected. The final step in determining the fastener specification is the overall length of the screw. AISI S200 specifies that the fastener length must be long enough so that at least three threads be exposed past the connected materials (3). A length of 1-1/2 inches was used to ensure the screws had an adequate thread length to comply with this standard.

\section{Assembly}

Consistency was a point of emphasis in the construction of the test specimens. With so many tests being performed and previously observed high variability in performance, extra measures were taken to maintain consistency in the fabrication of the samples. Consequently, several custom devices and jigs were created to construct the specimens.

The first step in the assembly of the test specimens was to cut all of the CFS to the exact needed lengths. A horizontal band saw with a fine, toothed blade was used to perform all of the cuts. A stop was set up to ensure the lengths were consistent for all the samples in a single test series. A wooden block and a reverse, bolt clamp were placed in the web of the CFS to prevent 
the saw's clamp from deforming the flanges. Special care was taken to reduce the vibration in the CFS due to the moving saw blade. An illustration of the setup is shown in Figure 4-1.

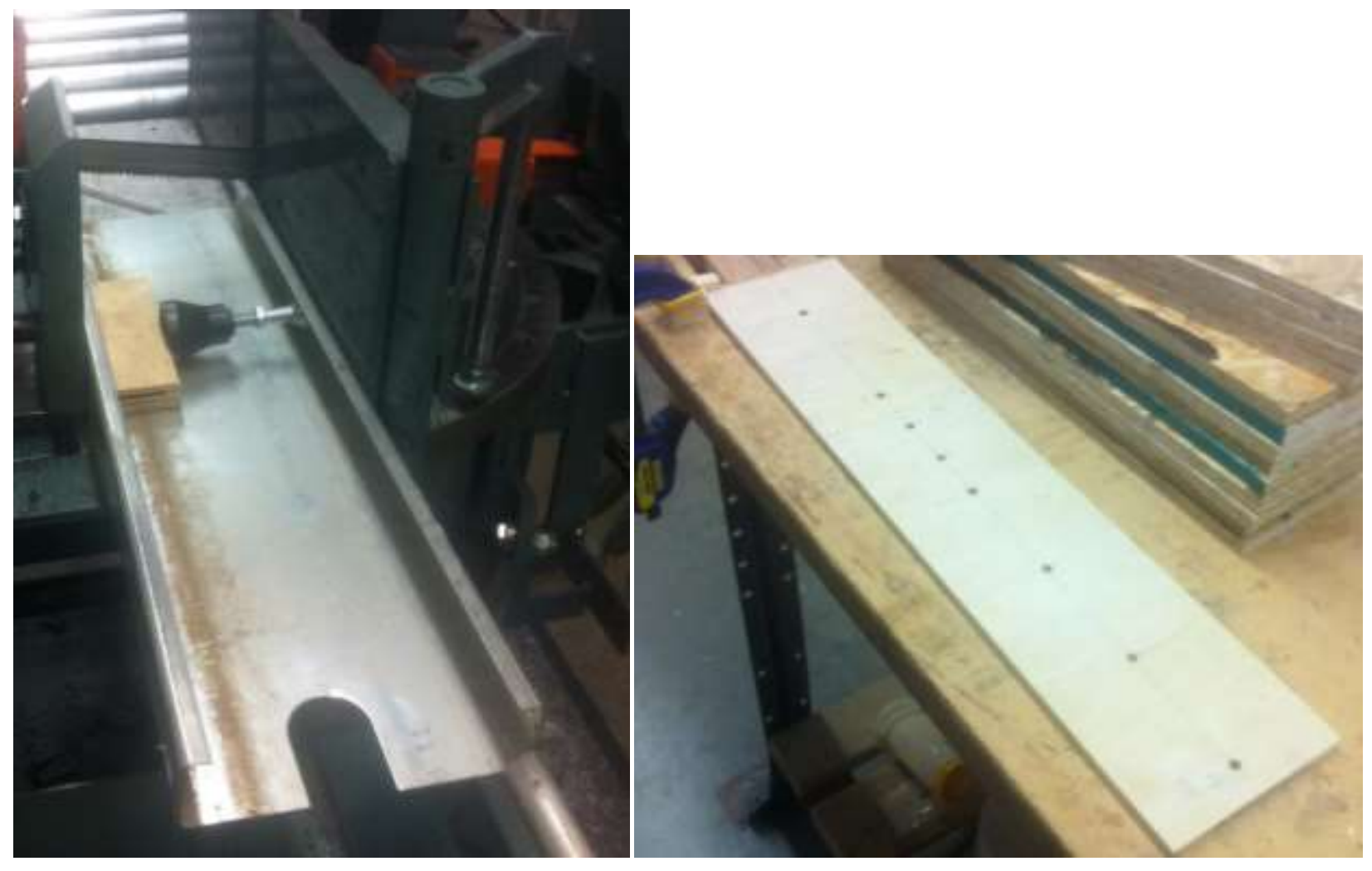

Figure 4-1 CFS Cutting Setup

Figure 4-2 Screw Location Template

The next step in the construction process was to cut the wooden side panels. The panels were ripped to width using a table saw and then cut to exact specimen lengths using a compound miter saw. Similar to cutting the CFS, a stop was installed on the miter saw to provide uniform lengths. After all of the panels were cut, markings for the screw locations were applied using a wooden template shown in Figure 4-2.

After all of the wood and metal pieces were cut and marked, they were fastened together with the \#10-24 self-tapping screws. Measures were taken to ensure that the fasteners were placed directly in the middle of the CFS flange. To do this, a jig was constructed that hugged the CFS end. The jig held the CFS piece upright for easier construction, created more surface for the 
wood panel to rest on, and provided the 3 inch offset between the wood panels and the steel end. The jig was used in conjunction with a C-shaped, steel channel that acted as a guide in the longitudinal direction of the samples. Spacers were placed between the steel channel and the CFS. The wood panel was placed on top of the CFS and butted up against the steel channel and the end jig. Once the panel was in the correct location, clamps were placed on each end to prevent the apparatus from moving during the installation of the screws. In a construction setting, workers often stand on the wood sheathing directly above the area on which they are working. Their weight "clamps" the panel to the steel preventing any movement. The clamps also prevented the wood from "jacking" during installation.

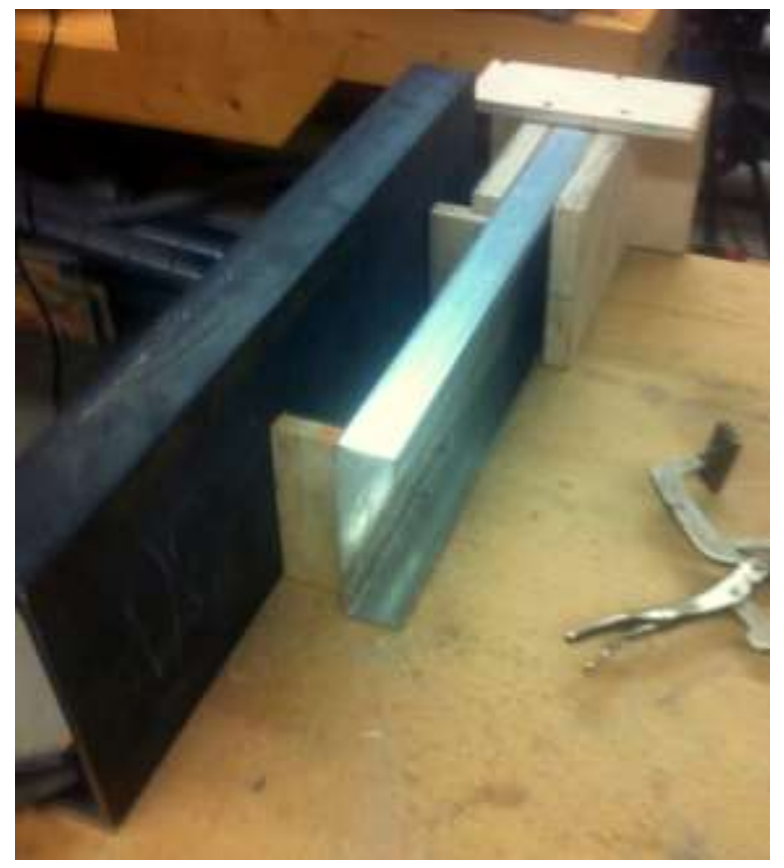

Figure 4-3 Wood Panel Placemen Jig

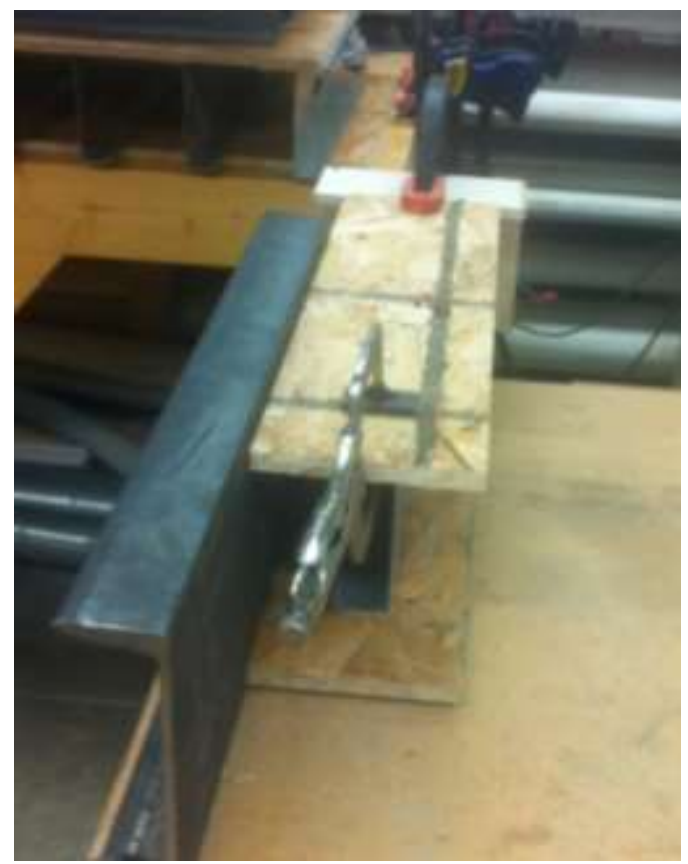

Figure 4-4 Wood Panel Being Attached

A drywall screw-gun was used to drive the fasteners into the specimens. The screw gun has a variable depth adjustment feature that releases the screw at a preselected depth. Structural wood sheathing attached to steel often requires the head of the fastener to be flush with the exposed surface of the wood. On the other hand, the fastener cannot be overdriven into the wood. 
A shear capacity reduction of almost $10 \%$ can occur if a fastener is overdriven by as little as $1 / 16$ inch (12). The depth adjustment feature was essential to set the screws to the correct depth each time. 


\section{Chapter 5 - Results}

The results for each test series are summarized in Table 5-1. The slip modulus $(K)$ is calculated using Equation 2-1 and the normalized slip modulus $\left(K_{N}\right)$ using Equation 2-2. Both are repeated here for convenience. The slip modulus calculations were based on 1900 lbs rather than the corresponding $40 \%$ maximum load for each test series. This was determined by rounding the average value of $0.4 P_{U}$ for all samples tested $(1893 \mathrm{lbs})$ not including the preliminary tests.

\section{Equation 2-1 Slip Modulus}

$K=\frac{0.4 P_{U}}{V_{0.4}} \quad$ Where:

$0.4 P_{U}=40 \%$ of the expected ultimate load (lbs)

$V_{0.4}=$ the displacement or slip at $0.4 P_{U}$ (in.)

\section{Equation 2-2 Normalized Slip Modulus}

$$
\begin{aligned}
& K_{N}=\frac{K}{n s} \quad \text { Where: } \\
& K=\text { the slip modulus (lbs/in.) } \\
& n=\text { number of fasteners } \\
& s=\text { fastener spacing (in.) }
\end{aligned}
$$

Samples 10-11 and 12-13 were omitted from calculations due to their vastly different results. Each of these specimens had self-tapping screws break during the fabrication process. As a result, small holes had to be predrilled to install fasteners at those locations. This is believed to have caused the samples to behave differently than the others samples. See Appendix A for the detailed results of each individual sample. 
Table 5-1 Test Results Summary

\begin{tabular}{|c|c|c|c|c|c|c|c|c|}
\hline $\begin{array}{l}\text { Spacing } \\
\text { (in) }\end{array}$ & Statistic & $\begin{array}{c}\text { P Max } \\
(\mathrm{lbs})\end{array}$ & $\begin{array}{c}\text { D Max } \\
\text { (in.) }\end{array}$ & $\begin{array}{c}\text { P } 40 \% \\
(\mathrm{lbs})\end{array}$ & $\begin{array}{l}\text { D } 40 \% \\
\text { (in.) }\end{array}$ & $\begin{array}{l}\text { D @ } 1900 \\
\text { (in.) }\end{array}$ & $\begin{array}{l}\text { Slip Modulus } \\
\quad \text { (lbs/in.) }\end{array}$ & $\begin{array}{c}\text { Normalized Slip } \\
\text { Modulus (lbs/in./in.) }\end{array}$ \\
\hline \multirow{5}{*}{6} & Average & 4836 & 0.4620 & 1934 & 0.0118 & 0.0118 & 182,043 & 5,057 \\
\hline & Standard Deviation & 372 & 0.0202 & 149 & 0.0041 & 0.0046 & 61,258 & 1,702 \\
\hline & C.O.V. & $8 \%$ & $4 \%$ & $8 \%$ & $34 \%$ & $39 \%$ & $34 \%$ & $34 \%$ \\
\hline & Maximum & 5308 & 0.5084 & 2123 & 0.0196 & 0.0206 & 296,181 & 8,227 \\
\hline & Minimum & 3928 & 0.4346 & 1571 & 0.0052 & 0.0064 & 92,017 & 2,556 \\
\hline \multirow{5}{*}{8} & Average & 4757 & 0.4459 & 1903 & 0.0126 & 0.0127 & 158,902 & 3,310 \\
\hline & Standard Deviation & 317 & 0.0287 & 127 & 0.0030 & 0.0035 & 40,854 & 851 \\
\hline & C.O.V. & $7 \%$ & $6 \%$ & $7 \%$ & $24 \%$ & $27 \%$ & $26 \%$ & $26 \%$ \\
\hline & Maximum & 5264 & 0.4819 & 2106 & 0.0180 & 0.0217 & 256,156 & 5,337 \\
\hline & Minimum & 4253 & 0.3665 & 1701 & 0.0076 & 0.0074 & 87,757 & 1,828 \\
\hline \multirow{5}{*}{10} & Average & 4744 & 0.4710 & 1898 & 0.0163 & 0.0150 & 149,754 & 2,496 \\
\hline & Standard Deviation & 391 & 0.0304 & 156 & 0.0081 & 0.0054 & 78,333 & 1,306 \\
\hline & C.O.V. & $8 \%$ & $6 \%$ & $8 \%$ & $50 \%$ & $36 \%$ & $52 \%$ & $52 \%$ \\
\hline & Maximum & 5375 & 0.5198 & 2150 & 0.0369 & 0.0253 & 379,111 & 6,319 \\
\hline & Minimum & 3995 & 0.4015 & 1598 & 0.0042 & 0.0050 & 75,221 & 1,254 \\
\hline \multirow{5}{*}{12} & Average & 4590 & 0.4507 & 1836 & 0.0152 & 0.0153 & 135,480 & 1,882 \\
\hline & Standard Deviation & 257 & 0.0222 & 103 & 0.0069 & 0.0048 & 42,817 & 595 \\
\hline & C.O.V. & $6 \%$ & $5 \%$ & $6 \%$ & $46 \%$ & $31 \%$ & $32 \%$ & $32 \%$ \\
\hline & Maximum & 4963 & 0.4946 & 1985 & 0.0371 & 0.0261 & 225,662 & 3,134 \\
\hline & Minimum & 3883 & 0.4154 & 1553 & 0.0088 & 0.0084 & 72,906 & 1,013 \\
\hline
\end{tabular}




\section{Discussion of Results}

The response of the CFS-wood composite is best depicted through load-slip curves.

Figure 5-1 shows the behavior of samples 6-1 through 6-5. The specimens experienced similar relationships between force and slip up to $2500 \mathrm{lbs}$ of load. After $2500 \mathrm{lbs}$, the responses began to level off and diverge. However, the response curves still remained similar reaching a peak load and a slight reduction in strength before failure. Again, failure for a sample was considered to be after the loading ram had displaced 0.6 inches, enough to capture the peak strength and the decline.

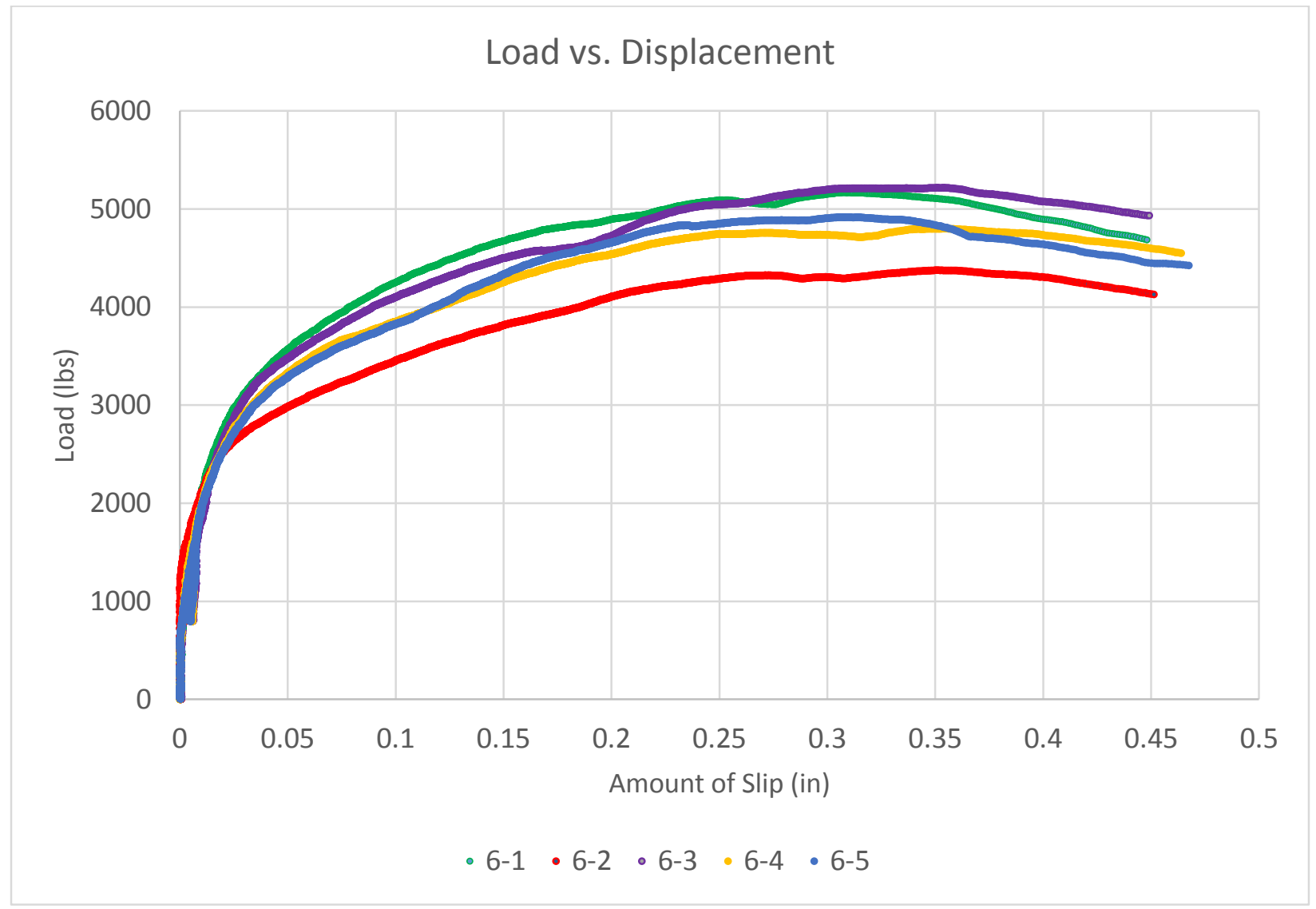

Figure 5-1 Load Displacement Diagram for Five 6" Samples

To obtain a "typical" response of a CFS-wood sheathing system, a load-displacement diagram was created averaging the load and slip of all of the 6 inch series. The result is shown in 
Figure 5-2. After the initial portion, the curve begins to slowly level off until it is nearly flat. This transition is attributed to the crushing of the wood fibers. As the wood crushes, its ability to resist additional loading and deformation decreases similar to the yielding of steel. It is important to note that the graph does not depict the decline in the capacity of the system up to and past the peak capacity.

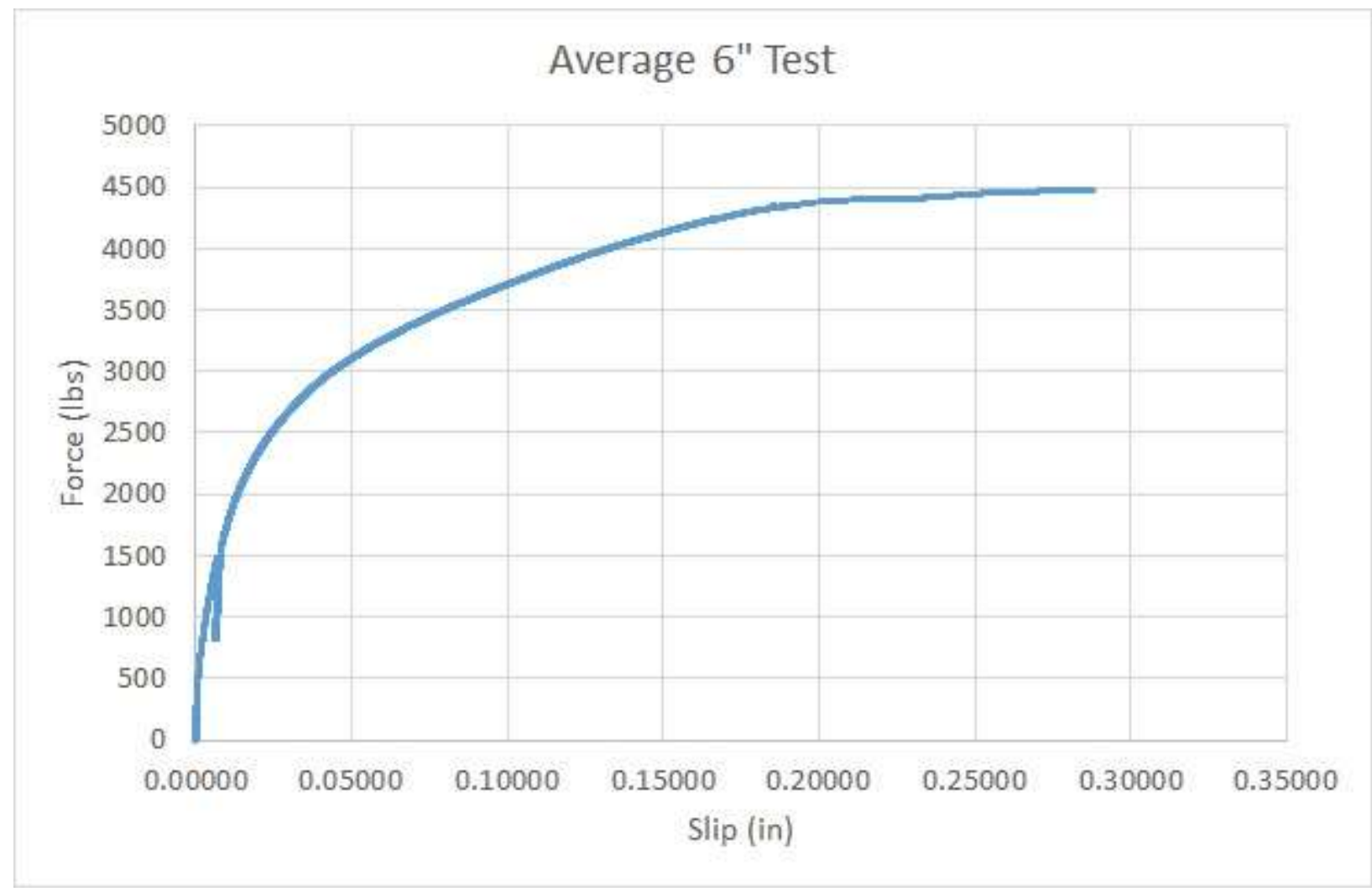

Figure 5-2 Average Slip Response of a 6" Sample

A closer look at the typical response up to $2000 \mathrm{lbs}$ in Figure 5-3 reveals two noteworthy characteristics. The first is the response at initial loading. The slope of the curve is steep until about $500 \mathrm{lbs}$ and then begins to level off. The probable cause of this is the friction between the steel and the wood surfaces. Once the friction is overcome and enough settlement has taken place, bearing on the fastener becomes the primary load path. The other main feature is the loop that occurs between $800 \mathrm{lbs}$ and $1600 \mathrm{lbs}$. The loop shows the reaction during the pause, 
unloading, and reloading cycle of the test. Interestingly, it appears the system does not recover in a perfectly elastic manner. The projection of the unloading path shown by the green, dotted line suggests some permanent slip has taken place by $1600 \mathrm{lbs}$. This may be caused by the overcoming of friction and transition into fastener bearing.

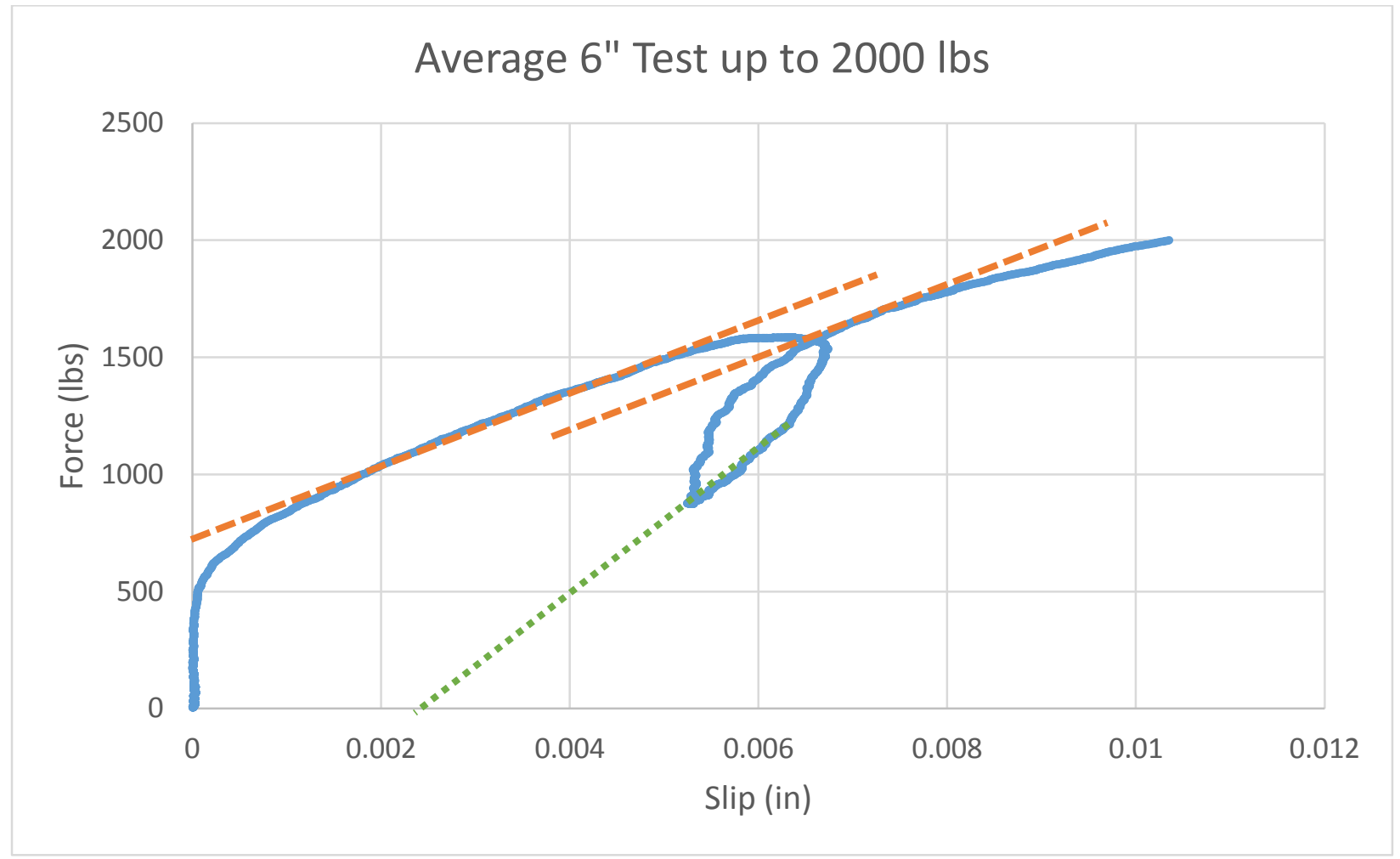

Figure 5-3 Average Slip Response of a 6" Sample up to $2000 \mathrm{lbs}$

The maximum load for each specimen decreased slightly as the fastener spacing increased. The slip between the CFS and the wood sheathing also generally increased. This is attributed to the local behavior of the sample between two fasteners acting as a column. The longer length allows for more rotation at the two ends. The increased rotation accentuated the screw tilt failure mechanism. 


\section{Failure Mechanism}

The failure mechanism for each sample was screw tilting. The forces induced in the screw can be idealized as a force acting at the centroid of the steel, an opposite triangular stress distribution from the wood, and a concentrated force acting on the head of the screw (4). Figure 5-4 shows the idealized diagram of the forces acting upon the fastener and the movement that occurs as a result.
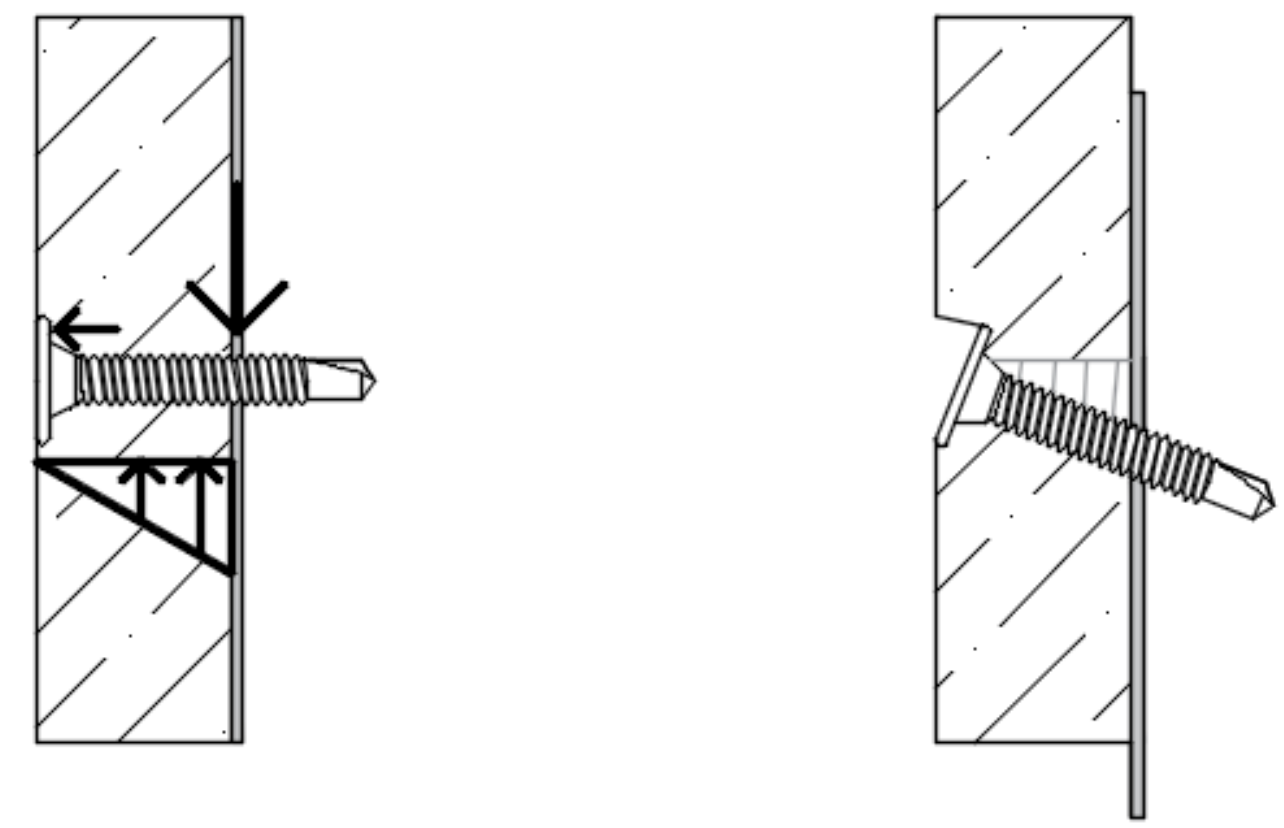

\section{Figure 5-4 Screw Tilting Mechanism and Failure}

As the load increases, the sheathing begins to crush at the extreme fibers adjacent to the steel and at the head of the fastener. Once the wood crushes, the rotation becomes more prominent causing more crushing. The end result is a fastener that has rotated and withdrawn into the sheathing. Figure 5-5 reveals the final angle of the screw after testing. It is important to reiterate that the fasteners were originally installed at $90^{\circ}$. The crushing of the wood fibers and the pull through of the fastener head is shown in Figure 5-6. 


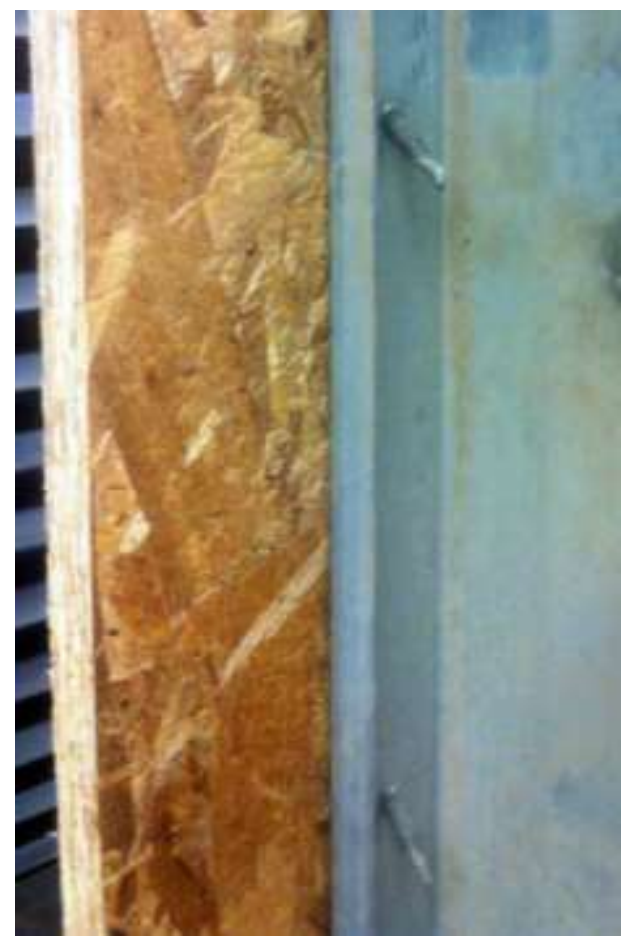

Figure 5-5 Screw Tilting

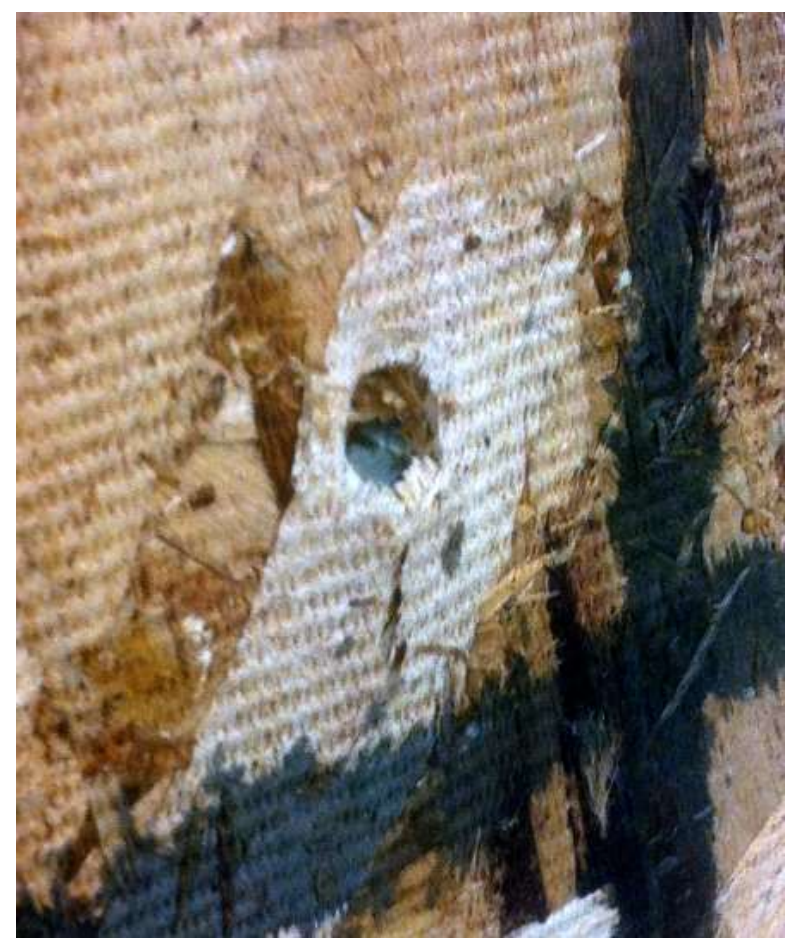

Figure 5-6 Screw Head After Failure

\section{Slip Modulus and Normalized Slip Modulus}

The amount of slip between the wood sheathing and the CFS increased as the fastener spacing increased as hypothesized. In contrast, the slip modulus and the normalized slip modulus decreased as the distances between screws increased. The reason for this is the reduced stiffness of the fastener connection, which is exemplified by the amount of slip experienced. The average and minimum slip modulus and normalized slip modulus compared to the fastener spacing are displayed in Figure 5-7 and Figure 5-8 respectively. Trend lines are included to better exhibit the occurring relationship. The method of least squares was used to find the curve that best fit the data points. The equation for each trend line along with the $\mathrm{R}^{2}$ value are given directly above the curve. 


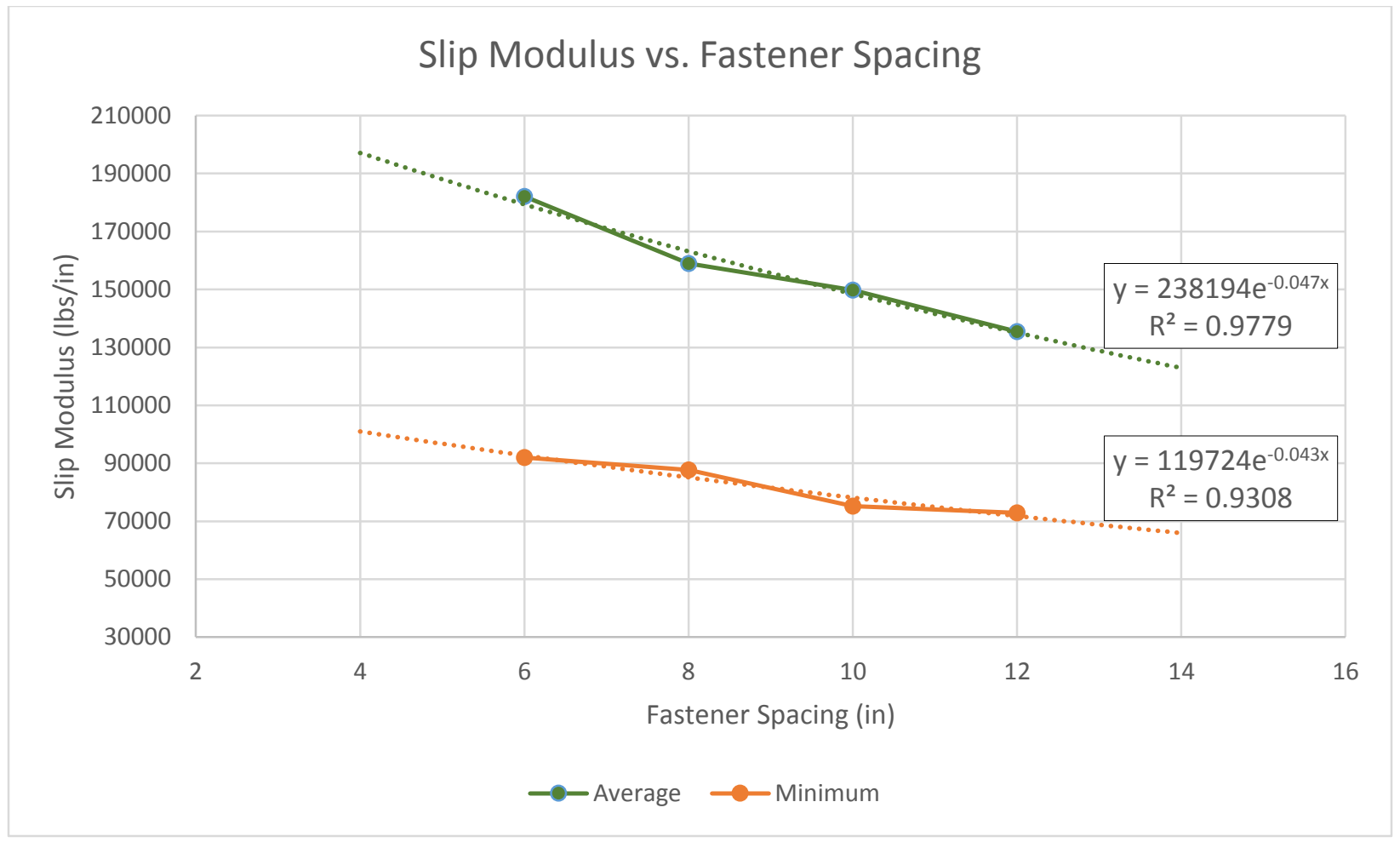

Figure 5-7 Slip Modulus Compared To Fastener Spacing

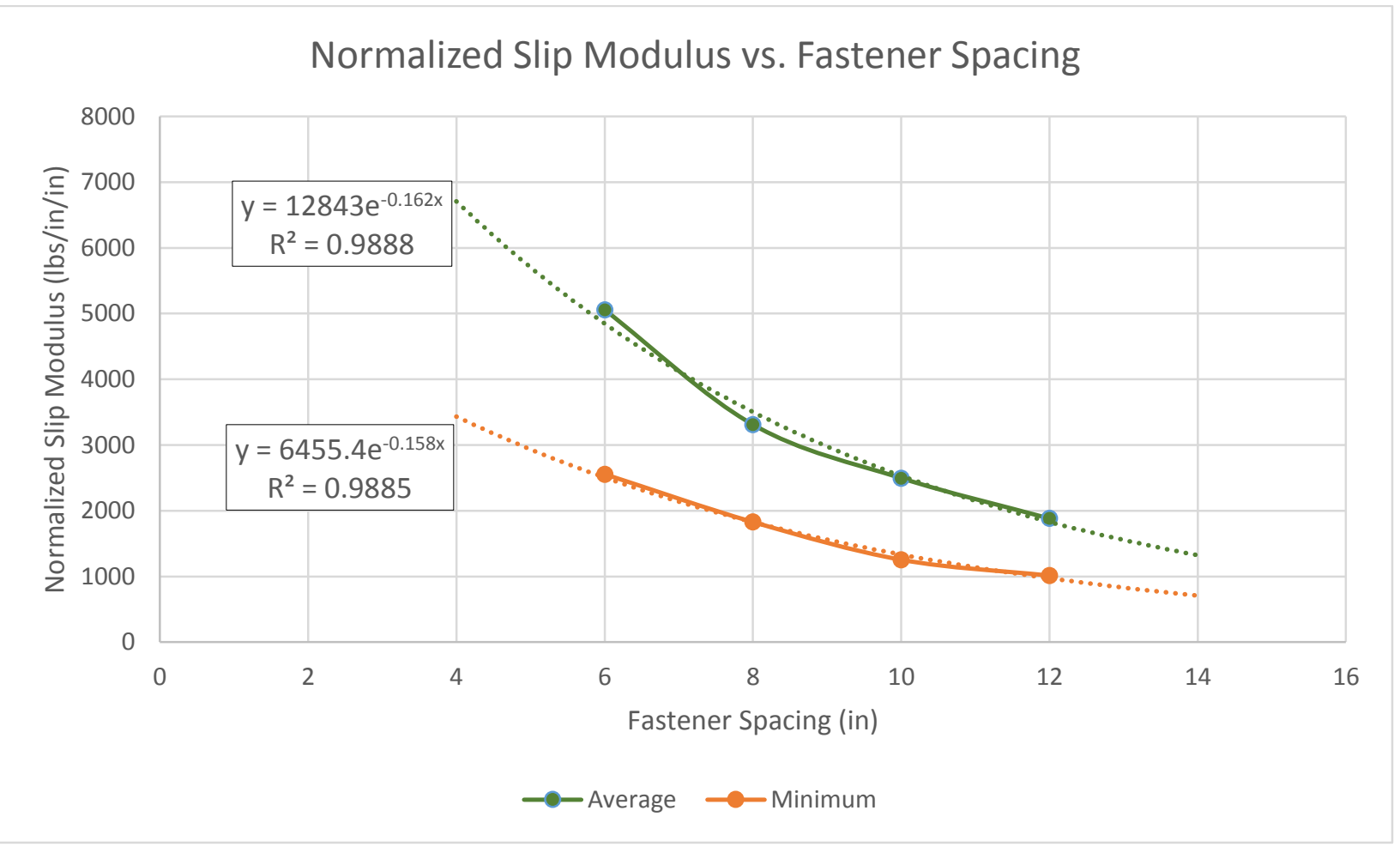

Figure 5-8 Normalized Slip Modulus Compared to Fastener Spacing 


\section{Comparison of Results to Previous Studies}

It is difficult to compare the results of this study to the results of the previous studies performed by Martin and Curnutt and Faringthon. There are two significant differences in the sample setup of this study and the studies done previously: the fasteners and the sheathing. Martin's and Curnutt and Faringthon's samples were both made with 1/2 inch birch plywood and self-tapping \#10-16 hex-head screws. As mention earlier, this investigation used 19/32 inch OSB for the sheathing and self-tapping \#10-24 flat-head screws. These two differences created stark contrast between this investigation and those done previously. Table 5-2 is a comparison of the final results amongst the studies. One common ground between all of these investigations is the screw tilting failure mode.

Table 5-2 Comparison of Results to Previous Studies

\begin{tabular}{|l|c|c|c|c|c|c|}
\hline Study & \multicolumn{2}{|c|}{ Martin } & \multicolumn{2}{c|}{ Curnutt \& Faringthon } & \multicolumn{2}{c|}{ Loehr } \\
\hline $\begin{array}{l}\text { Fastener } \\
\text { Spacing }\end{array}$ & $\begin{array}{c}\text { Sheathing } \\
\text { Thickness }\end{array}$ & $\begin{array}{c}\mathrm{K}_{\mathrm{N}} \\
(\mathrm{lbs} / \mathrm{in} / \mathrm{in})\end{array}$ & $\begin{array}{c}\text { Sheathing } \\
\text { Thickness }\end{array}$ & $\begin{array}{c}\mathrm{K}_{\mathrm{N}} \\
(\mathrm{lbs} / \mathrm{in} / \mathrm{in})\end{array}$ & $\begin{array}{c}\text { Sheathing } \\
\text { Thickness }\end{array}$ & $\begin{array}{c}\mathrm{K}_{\mathrm{N}} \\
(\mathrm{lbs} / \mathrm{in} / \mathrm{in})\end{array}$ \\
\hline $6 "$ & $1 / 2^{\prime \prime}$ & 787 & $1 / 2^{\prime \prime}$ & 423 & $19 / 32^{\prime \prime}$ & 5057 \\
\hline $8^{\prime \prime}$ & $1 / 2^{\prime \prime}$ & 540 & $1 / 2 "$ & 980 & $19 / 32^{\prime \prime}$ & 3310 \\
\hline $10^{\prime \prime}$ & $1 / 2^{\prime \prime}$ & 401 & $1 / 2 "$ & 955 & $19 / 32^{\prime \prime}$ & 2496 \\
\hline $12^{\prime \prime}$ & $1 / 2^{\prime \prime}$ & 468 & $1 / 2 "$ & 487 & $19 / 32^{\prime \prime}$ & 1882 \\
\hline
\end{tabular}

Northcutt's test specimens differed greatly from the ones used in this study. A comparison between the two results would be less meaningful, and therefore it is omitted. 


\section{Chapter 6 - Conclusion}

The aim of this investigation was to determine the effect of fastener spacing on the slip modulus between CFS and OSB sheathing. Compression tests were performed on specimens with 6 inch, 8 inch, 10 inch and 12 inch distances between fasteners; each spacing had 15 tests

for a total of 60 conducted tests. The specimens were composed of an 18 gauge stud section with 19/32 inch thick OSB attached to each flange. The fasteners were \#10-24 self-tapping screws. It is clear from the results that an increase in the spacing between the screws leads to an increased slip between the CFS and the sheathing. Consequently, the slip modulus and normalized slip modulus increase as fastener spacing decreases.

The accuracy of the results were improved in comparison to previous studies. The modified test setup and attention to uniformity during the fabrication process are the main causes for this improvement. Accordingly, the results have a level of confidence greater than $80 \%$ on the average amount of slip experienced for each test series. The 6 inch test series barely missed the $85 \%$ goal set out at the beginning of the investigation. Consequently, the slip modulus and normalized slip modulus results also have high levels of confidence with the exception of the 10 inch test series. Table 6-1 breaks down the confidence interval for the amount of slip, slip modulus, and the normalized slip modulus for each fastener spacing. The values were obtained by using Equation 3-1 rearranged for the confidence interval $(\mathrm{Z})$ and again using a $\pm 10 \%$ value for the marginal error. 
Table 6-1 Testing Confidence Interval

\begin{tabular}{|c|c|c|c|}
\hline $\begin{array}{c}\text { Fastener } \\
\text { Spacing }\end{array}$ & Slip & Slip Modulus & $\begin{array}{c}\text { Normalized Slip } \\
\text { Modulus }\end{array}$ \\
\hline $6 "$ & $84 \%$ & $88 \%$ & $88 \%$ \\
\hline $8 ”$ & $92 \%$ & $93 \%$ & $93 \%$ \\
\hline $10 ”$ & $86 \%$ & $77 \%$ & $77 \%$ \\
\hline $12 ”$ & $89 \%$ & $89 \%$ & $89 \%$ \\
\hline
\end{tabular}

\section{Recommendations for Future Research}

After completion of this investigation, there are several recommendations for future research concerning the composite action in CFS-wood sheathing systems.

1. Supplementary tests ought to be conducted on the 10 inch fastener spacing in an attempt to increase the confidence interval for the slip modulus and normalized slip modulus.

2. Further research should be carried out concerning different types of fasteners, fastener diameters, types of sheathing, sheathing thickness, and CFS thickness. Priority should be given to CFS thickness and sheathing thickness as these are most likely going to have the largest effect on the slip modulus of a CFS-wood sheathing system.

3. A different test setup will probably need to be used when testing thinner sheathing (less than 19/32 inch thick) in order to prevent the wood panel from buckling prior to connection failure.

4. Full scale tests of CFS-wood sheathing composites would be beneficial to confirm the amount of partial composite action experienced compared to the theoretical values.

5. Minimum values should be used for the slip modulus and the normalized slip modulus for determining the increased capacity and stiffness. This will provide 
conservatism for the system. However, this may result in undesired conservativism during seismic events as stiffer elements attract higher forces. The material may not be able to handle the unexpected loading.

6. Research should be conducted regarding cyclic loading of the samples. 


\section{References}

1) AISI, (2008). Cold-Formed Steel Design Manual. AISI S905-13. American Iron and Steel Institute.

2) ASTM Standard D6555 - 03 (2014), "Standard Guide of Evaluating Systems Effects in Repetitive-Member Wood Assemblies,” ASTM International, West Conshohocken, PA, www.astm.org.

3) CFSEI, (2011). Screw Fastener Selection for Cold-Formed Steel Frame Construction. (Tech Note F102-11). Washington, D.C.

4) Corner, S. M. (2014). Screw-Fastened Cold-Formed Steel-to-Steel Shear Connection Behavior and Models (Unpublished master's thesis). Virginia Polytechnic Institute and State University. Retrieved April 7, 2016, from https://theses.lib.vt.edu/theses/available/etd-12212014235617/unrestricted/Corner_SMW_T_2014.pdf

5) Curnutt, A., \& Faringthon, J. (n.d.). Cold-Formed Steel (CFS) and Plywood Sheathing Slip Modulus [Scholarly project].

6) History. (n.d.). Retrieved March 14, 2016, from http://www.cfsei.org/history

7) ISO, (1983). Timber Structures - Joints Made With Mechanical Fasteners. (Ref. No. ISO 6891-1983). International Organization for Standardization.

8) Kyvelou, P., Gardner, L., \& Nethercot, D. A. (2015). Composite Action Between ColdFormed Steel Beams and Wood-Based Floorboards. International Journal of Structural Stability and Dynamics, 15(08), 1540029. Retrieved September 10, 2015. 
9) Martin, G. (2014). Investigation of the slip modulus between cold-formed steel and plywood sheathing (Unpublished master's thesis). Kansas State University. Retrieved September 4, 2015, from https://krex.k-state.edu.

10) Northcutt, A. (2012). Slip modulus of cold-formed steel members sheathed with wood structural panels (Master's Thesis). Retrieved from K-State Research Exchange.

11) OSB Design and Application Guide (Publication). (n.d.). Retrieved December 12, 2015, from TECO website: http://www.tecotested.com/techtips/pdf/osbdesignapplicationguide

12) Reduction In Shear Capacity Due To Overdriven Fateners (Tech.). (2008, January).

Retrieved February 23, 2016, from TECO website:

http://www.tecotested.com/techtips/pdf/tt_overdrivenfasteners 


\section{References Not Cited}

1) Lakkavalli, B., \& Liu, Y. (2006). Experimental study of composite cold-formed steel Csection floor joists. Journal of Constructional Steel Research, 62(10), 995-1006. Retrieved September 24, 2015, from Science Direct.

2) Steel Market Development Institute. (2010). [Brochure]. Author. Retrieved March 03, 2016, from http://www.smdisteel.org/ /media/Files/SMDI/Construction/Construction Overview of CFS Apps in Bldg Const - 2010 Update.pdf?la=en

3) Vieira, L. C., \& Schafer, B. W. (2012). Lateral stiffness and strength of sheathing braced cold-formed steel stud walls. Engineering Structures, 37, 205-213. Retrieved October 1, 2015, from www.sciencedirect.com.

4) Vieira, L., Schifferaw, Y., \& Schafer, B. (2011). Experiments on sheathed cold-formed steel studs in compression. Journal of Constructional Steel Research, 67(10), 1554-1566. Retrieved September 15, 2015, from Science Direct.

5) Xu, L., \& Tangorra, F. (2007). Experimental investigation of lightweight residential floors supported by cold-formed steel C-shape joists. Journal of Constructional Steel Research, 63(3), 422-435. Retrieved September 28, 2015, from Science Direct. 


\section{Appendix A - Individual Test Results}

The results of the individual tests are summarized in Table A-1, Table A-2, Table A-3, and Table A-4. The slip modulus $(K)$ is calculated using Equation 2-1 and the normalized slip modulus $\left(K_{N}\right)$ using Equation 2-2. Following each table is a plot of the amount of slip at the considered $0.4 P_{U}$ compared to the average, one standard deviation interval, and two standard deviation interval. The slip modulus calculations were based on $1900 \mathrm{lbs}$ rather than the corresponding $40 \%$ maximum load for each test series. This was determined by rounding the average of the $0.4 P_{U}$ values for all the samples tested $(1893 \mathrm{lbs})$.

Samples 10-11 and 12-13 were omitted from calculations due to their vastly different results. Each of these specimens had self-tapping screws break when being constructed. As a result, small holes had to be predrilled to install fasteners at those locations. This is believed to have caused the samples to behave differently than the others samples. 
Table A-1 6-Inch Fastener Spacing Test Results

\begin{tabular}{|c|c|c|c|c|c|c|c|}
\hline Sample & $\begin{array}{c}\text { P Max } \\
\text { (Ibs) }\end{array}$ & $\begin{array}{c}\text { D Max } \\
\text { (in.) }\end{array}$ & $\begin{array}{c}\text { P 40\% } \\
\text { (lbs) }\end{array}$ & $\begin{array}{c}\text { D 40\% } \\
\text { (in.) }\end{array}$ & $\begin{array}{c}\text { D @ 1900 } \\
\text { (in.) }\end{array}$ & $\begin{array}{c}\text { Slip Modulus } \\
\text { (lbs/in) }\end{array}$ & $\begin{array}{c}\text { Normalized Slip } \\
\text { Modulus (Ibs/in/in) }\end{array}$ \\
\hline $6-1$ & 5170 & 0.4533 & 2068 & 0.0098 & 0.0074 & 256,156 & 7,115 \\
\hline $6-2$ & 4379 & 0.4551 & 1752 & 0.0052 & 0.0064 & 296,181 & 8,227 \\
\hline $6-3$ & 5220 & 0.4523 & 2088 & 0.0120 & 0.0106 & 178,826 & 4,967 \\
\hline $6-4$ & 4802 & 0.4667 & 1921 & 0.0092 & 0.0086 & 220,414 & 6,123 \\
\hline $6-5$ & 4919 & 0.4739 & 1968 & 0.0102 & 0.0096 & 197,454 & 5,485 \\
\hline $6-6$ & 3928 & 0.5084 & 1571 & 0.0096 & 0.0166 & 114,190 & 3,172 \\
\hline $6-7$ & 4480 & 0.4711 & 1792 & 0.0182 & 0.0206 & 92,017 & 2,556 \\
\hline $6-8$ & 4758 & 0.4396 & 1903 & 0.0082 & 0.0084 & 225,662 & 6,268 \\
\hline $6-9$ & 5139 & 0.4597 & 2056 & 0.0120 & 0.0102 & 185,839 & 5,162 \\
\hline $6-10$ & 4821 & 0.4410 & 1929 & 0.0150 & 0.0146 & 129,833 & 3,606 \\
\hline $6-11$ & 4834 & 0.4817 & 1934 & 0.0164 & 0.0160 & 118,472 & 3,291 \\
\hline $6-12$ & 4739 & 0.4819 & 1896 & 0.0072 & 0.0082 & 231,166 & 6,421 \\
\hline $6-13$ & 5261 & 0.4346 & 2104 & 0.0122 & 0.0088 & 215,404 & 5,983 \\
\hline $6-14$ & 4780 & 0.4723 & 1912 & 0.0196 & 0.0196 & 96,712 & 2,686 \\
\hline $6-15$ & 5308 & 0.4390 & 2123 & 0.0122 & 0.0110 & 172,323 & 4,787 \\
\hline Average & 4836 & 0.4620 & 1934 & 0.0118 & 0.0118 & 182,043 & 5,057 \\
\hline Std Dev & 372 & 0.0202 & 149 & 0.0041 & 0.0046 & 61,258 & 1,702 \\
\hline
\end{tabular}

$6^{\mathrm{u}}$ Fastener Spacing

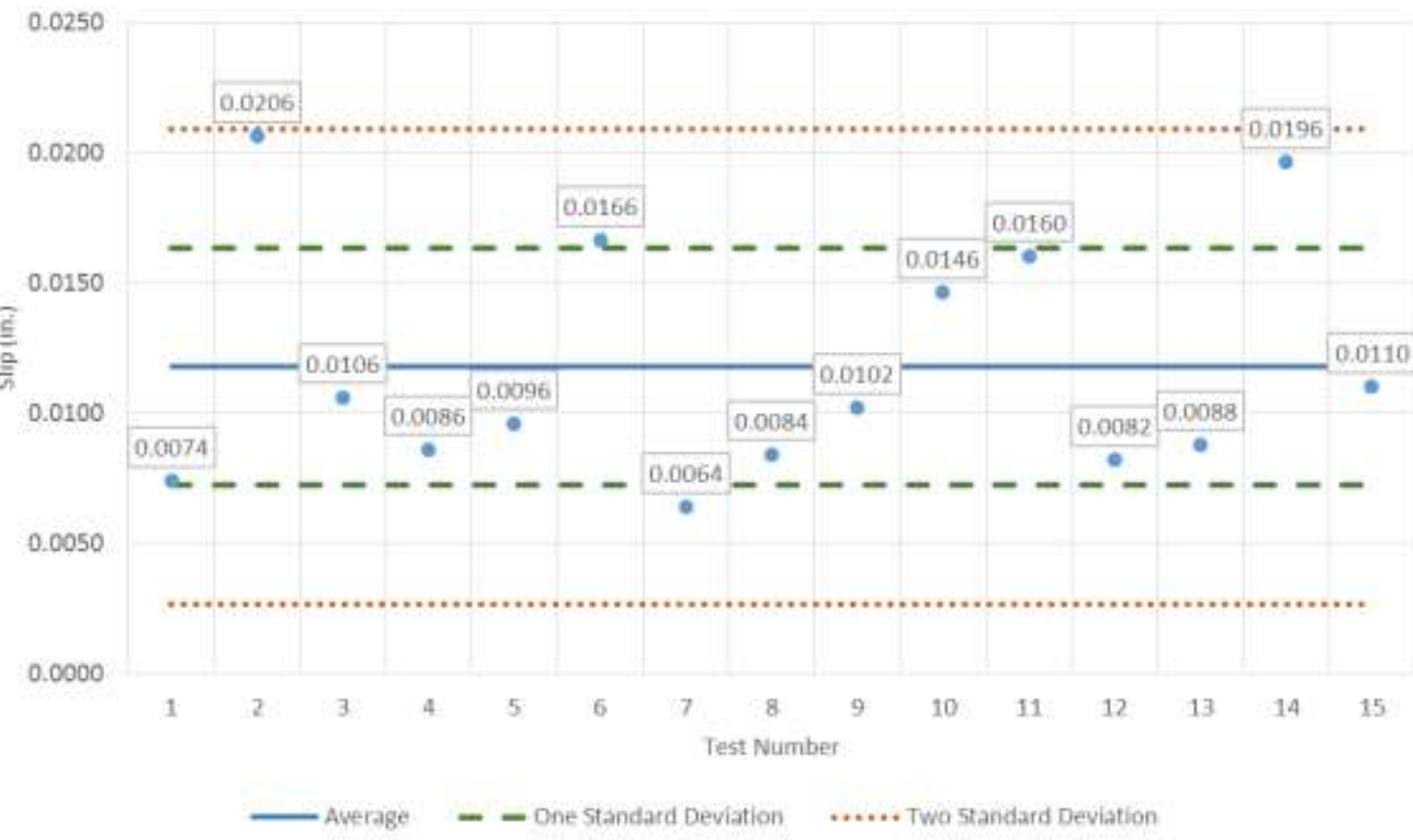

Figure A-1 6-Inch Fastener Spacing Slip at 1900 lbs 
Table A-2 8-Inch Fastener Spacing

\begin{tabular}{|c|c|c|c|c|c|c|c|}
\hline Sample & $\begin{array}{c}\text { P Max } \\
\text { (lbs) }\end{array}$ & $\begin{array}{c}\text { D Max } \\
\text { (in.) }\end{array}$ & $\begin{array}{c}\text { P 40\% } \\
\text { (lbs) }\end{array}$ & $\begin{array}{c}\text { D 40\% } \\
\text { (in.) }\end{array}$ & $\begin{array}{c}\text { D @ 1900 } \\
\text { (in.) }\end{array}$ & $\begin{array}{c}\text { Slip Modulus } \\
\text { (lbs/in) }\end{array}$ & $\begin{array}{c}\text { Normalized Slip } \\
\text { Modulus (Ibs/in/in) }\end{array}$ \\
\hline $8-1$ & 4716 & 0.4667 & 1887 & 0.0144 & 0.0146 & 129,833 & 2,705 \\
\hline $8-2$ & 4966 & 0.4424 & 1986 & 0.0118 & 0.0106 & 178,826 & 3,726 \\
\hline $8-3$ & 4584 & 0.4621 & 1833 & 0.0090 & 0.0100 & 189,556 & 3,949 \\
\hline $8-4$ & 4253 & 0.4306 & 1701 & 0.0170 & 0.0217 & 87,757 & 1,828 \\
\hline $8-5$ & 4954 & 0.4819 & 1982 & 0.0110 & 0.0094 & 201,655 & 4,201 \\
\hline $8-6$ & 5064 & 0.4460 & 2026 & 0.0094 & 0.0074 & 256,156 & 5,337 \\
\hline $8-7$ & 4310 & 0.4392 & 1724 & 0.0100 & 0.0114 & 166,277 & 3,464 \\
\hline $8-8$ & 4590 & 0.4771 & 1836 & 0.0134 & 0.0146 & 129,833 & 2,705 \\
\hline $8-9$ & 4572 & 0.3665 & 1829 & 0.0134 & 0.0146 & 129,833 & 2,705 \\
\hline $8-10$ & 4782 & 0.4434 & 1913 & 0.0116 & 0.0114 & 166,277 & 3,464 \\
\hline $8-11$ & 5017 & 0.4198 & 2007 & 0.0124 & 0.0118 & 160,640 & 3,347 \\
\hline $8-12$ & 5264 & 0.4669 & 2106 & 0.0142 & 0.0114 & 166,277 & 3,464 \\
\hline $8-13$ & 4278 & 0.4450 & 1711 & 0.0076 & 0.0108 & 175,515 & 3,657 \\
\hline $8-14$ & 5028 & 0.4709 & 2011 & 0.0160 & 0.0148 & 128,078 & 2,668 \\
\hline $8-15$ & 4983 & 0.4302 & 1993 & 0.0180 & 0.0162 & 117,010 & 2,438 \\
\hline Average & 4757 & 0.4459 & 1903 & 0.0126 & 0.0127 & 158,902 & 3,310 \\
\hline Std Dev & 317 & 0.0287 & 127 & 0.0030 & 0.0035 & 40,854 & 851 \\
\hline
\end{tabular}

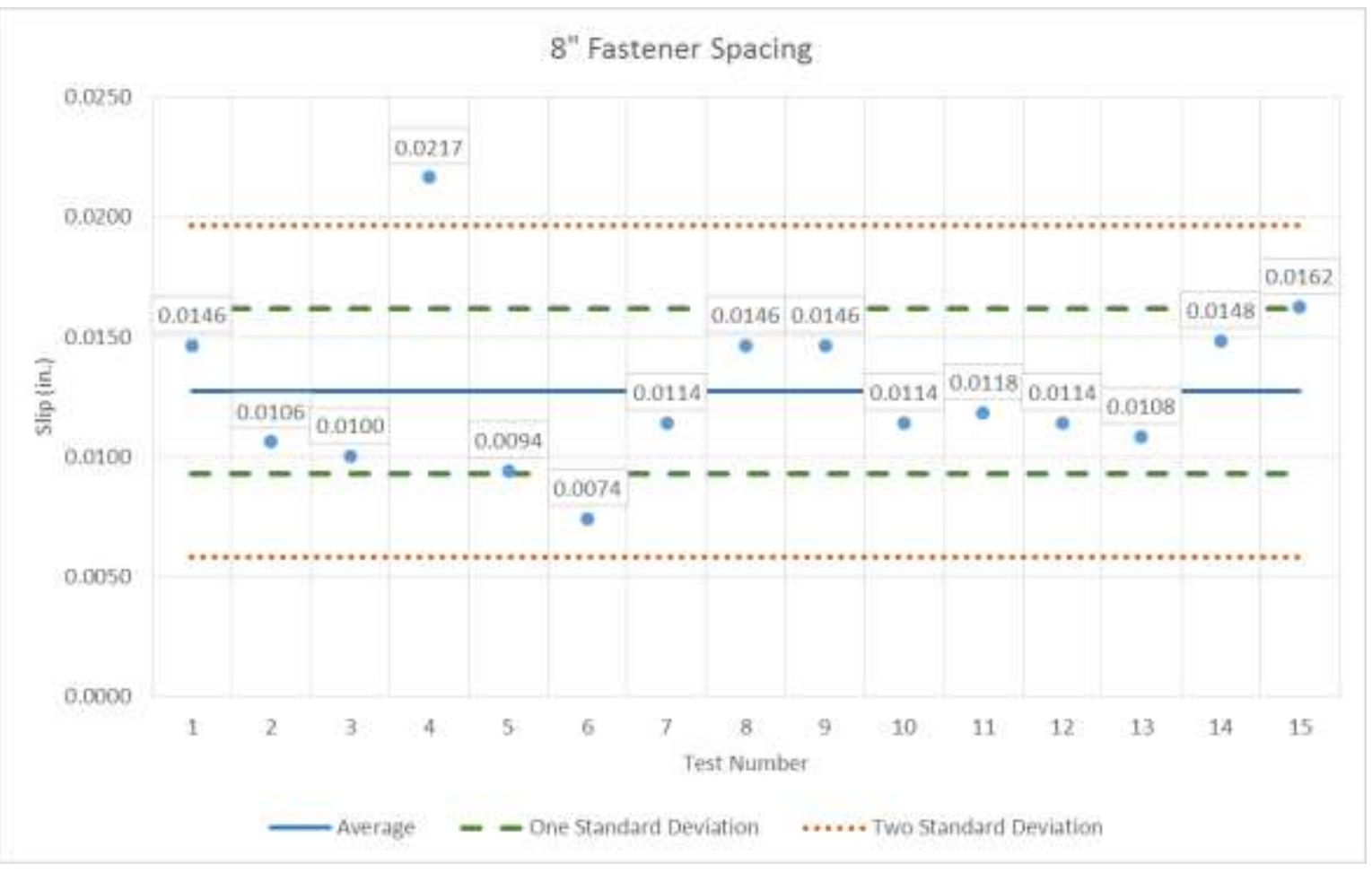

Figure A-2 8-inch Fastener Spacing Slip at 1900 lbs 
Table A-3 10-Inch Fastener Spacing

\begin{tabular}{|c|c|c|c|c|c|c|c|}
\hline Sample & $\begin{array}{c}\text { P Max } \\
\text { (lbs) }\end{array}$ & $\begin{array}{c}\text { D Max } \\
\text { (in.) }\end{array}$ & $\begin{array}{c}\text { P 40\% } \\
\text { (lbs) }\end{array}$ & $\begin{array}{c}\text { D 40\% } \\
\text { (in.) }\end{array}$ & $\begin{array}{c}\text { D @ 1900 } \\
\text { (in.) }\end{array}$ & $\begin{array}{c}\text { Slip Modulus } \\
\text { (lbs/in) }\end{array}$ & $\begin{array}{c}\text { Normalized Slip } \\
\text { Modulus (Ibs/in/in) }\end{array}$ \\
\hline $10-1$ & 4438 & 0.4378 & 1775 & 0.0042 & 0.0050 & 379,111 & 6,319 \\
\hline $10-2$ & 4923 & 0.4581 & 1969 & 0.0160 & 0.0156 & 121,510 & 2,025 \\
\hline $10-3$ & 3995 & 0.4922 & 1598 & 0.0116 & 0.0164 & 115,583 & 1,926 \\
\hline $10-4$ & 4308 & 0.4723 & 1723 & 0.0138 & 0.0180 & 105,309 & 1,755 \\
\hline $10-5$ & 4519 & 0.4464 & 1807 & 0.0100 & 0.0110 & 172,323 & 2,872 \\
\hline $10-6$ & 4736 & 0.4705 & 1895 & 0.0136 & 0.0136 & 139,379 & 2,323 \\
\hline $10-7$ & 4569 & 0.4964 & 1828 & 0.0198 & 0.0202 & 93,839 & 1,564 \\
\hline $10-8$ & 5216 & 0.4723 & 2086 & 0.0092 & 0.0082 & 231,166 & 3,853 \\
\hline $10-9$ & 5138 & 0.4879 & 2055 & 0.0122 & 0.0104 & 182,265 & 3,038 \\
\hline $10-10$ & 4742 & 0.5198 & 1897 & 0.0130 & 0.0118 & 160,640 & 2,677 \\
\hline $10-11$ & 4853 & 0.4956 & 1941 & 0.0369 & $* *$ & $* *$ & $* *$ \\
\hline $10-12$ & 5081 & 0.4015 & 2033 & 0.0293 & 0.0253 & 75,221 & 1,254 \\
\hline $10-13$ & 4278 & 0.5044 & 1711 & 0.0168 & 0.0212 & 89,413 & 1,490 \\
\hline $10-14$ & 4991 & 0.4653 & 1996 & 0.0192 & 0.0176 & 107,702 & 1,795 \\
\hline $10-15$ & 5375 & 0.4444 & 2150 & 0.0184 & 0.0154 & 123,088 & 2,051 \\
\hline Average & 4744 & 0.4710 & 1898 & 0.0163 & 0.0150 & 149,754 & 2,496 \\
\hline Std Dev & 391 & 0.0304 & 156 & 0.0081 & 0.0054 & 78,333 & 1,306 \\
\hline
\end{tabular}

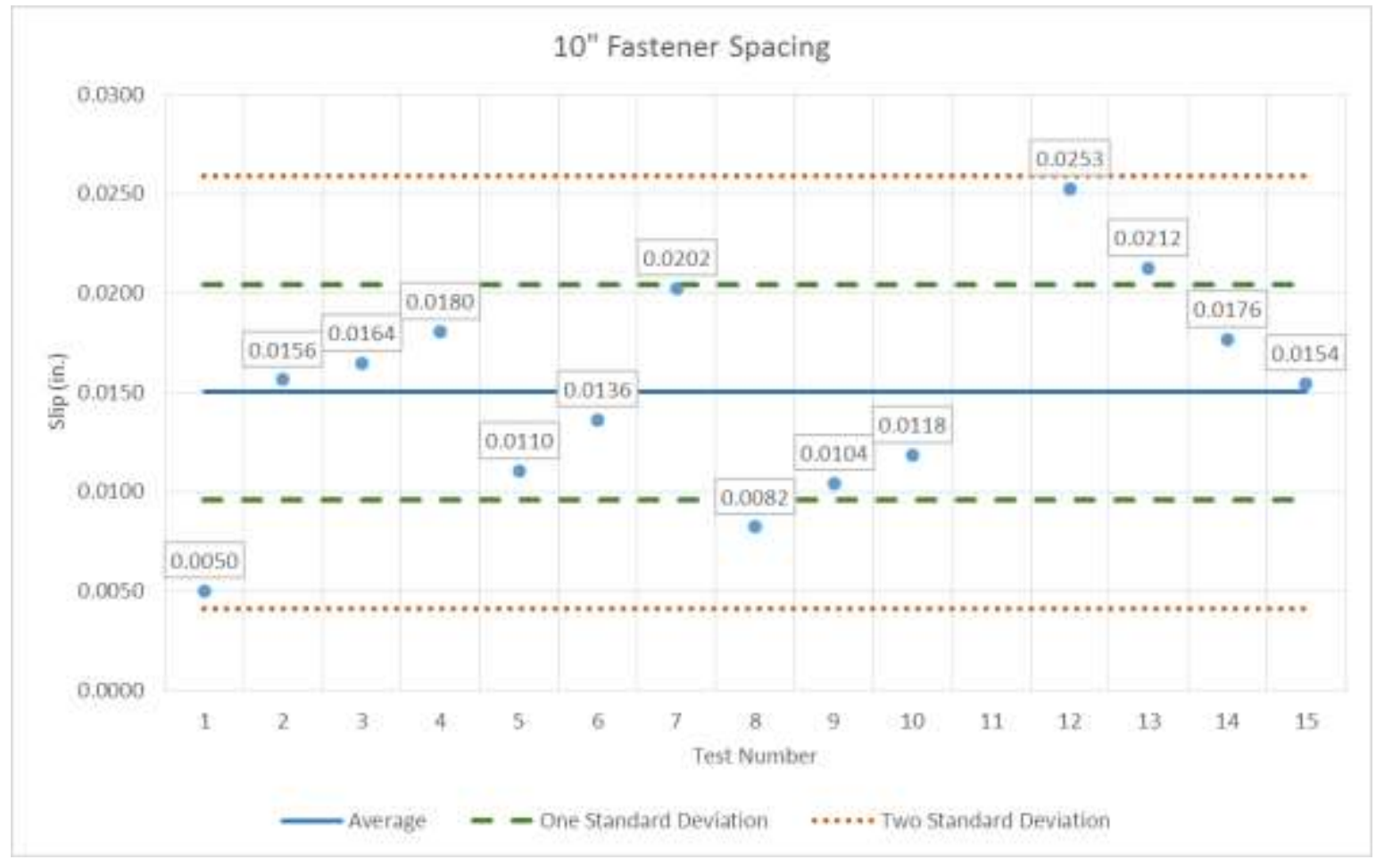

Figure A-3 10-Inch Fastener Spacing Slip at 1900 lbs 
Table A-4 12-Inch Fastener Spacing

\begin{tabular}{|c|c|c|c|c|c|c|c|}
\hline Sample & $\begin{array}{c}\text { P Max } \\
\text { (lbs) }\end{array}$ & $\begin{array}{c}\text { D Max } \\
\text { (in.) }\end{array}$ & $\begin{array}{c}\text { P 40\% } \\
\text { (lbs) }\end{array}$ & $\begin{array}{c}\text { D 40\% } \\
\text { (in.) }\end{array}$ & $\begin{array}{c}\text { D @ 1900 } \\
\text { (in.) }\end{array}$ & $\begin{array}{c}\text { Slip Modulus } \\
\text { (Ibs/in) }\end{array}$ & $\begin{array}{c}\text { Normalized Slip } \\
\text { Modulus (Ibs/in/in) }\end{array}$ \\
\hline $12-1$ & 4828 & 0.4238 & 1931 & 0.0170 & 0.0170 & 111,503 & 1,549 \\
\hline $12-2$ & 4678 & 0.4404 & 1871 & 0.0162 & 0.0162 & 117,010 & 1,625 \\
\hline $12-3$ & 4963 & 0.4334 & 1985 & 0.0104 & 0.0084 & 225,662 & 3,134 \\
\hline $12-4$ & 4651 & 0.4513 & 1860 & 0.0118 & 0.0128 & 148,090 & 2,057 \\
\hline $12-5$ & 4604 & 0.4154 & 1842 & 0.0088 & 0.0102 & 185,839 & 2,581 \\
\hline $12-6$ & 4512 & 0.4330 & 1805 & 0.0132 & 0.0146 & 129,833 & 1,803 \\
\hline $12-7$ & 4576 & 0.4593 & 1830 & 0.0090 & 0.0096 & 197,454 & 2,742 \\
\hline $12-8$ & 4230 & 0.4537 & 1692 & 0.0094 & 0.0132 & 143,603 & 1,994 \\
\hline $12-9$ & 4549 & 0.4603 & 1820 & 0.0124 & 0.0146 & 129,833 & 1,803 \\
\hline $12-10$ & 4760 & 0.4719 & 1904 & 0.0168 & 0.0170 & 111,503 & 1,549 \\
\hline $12-11$ & 4748 & 0.4352 & 1899 & 0.0138 & 0.0138 & 137,359 & 1,908 \\
\hline $12-12$ & 3883 & 0.4883 & 1553 & 0.0138 & 0.0261 & 72,906 & 1,013 \\
\hline $12-13$ & 4596 & 0.4946 & 1838 & 0.0371 & $* *$ & $* *$ & $* *$ \\
\hline $12-14$ & 4528 & 0.4456 & 1811 & 0.0182 & 0.0212 & 89,413 & 1,242 \\
\hline $12-15$ & 4745 & 0.4541 & 1898 & 0.0194 & 0.0196 & 96,712 & 1,343 \\
\hline Average & 4590 & 0.4507 & 1836 & 0.0152 & 0.0153 & 135,480 & 1,882 \\
\hline Std Dev & 257 & 0.0222 & 103 & 0.0069 & 0.0048 & 42,817 & 595 \\
\hline
\end{tabular}

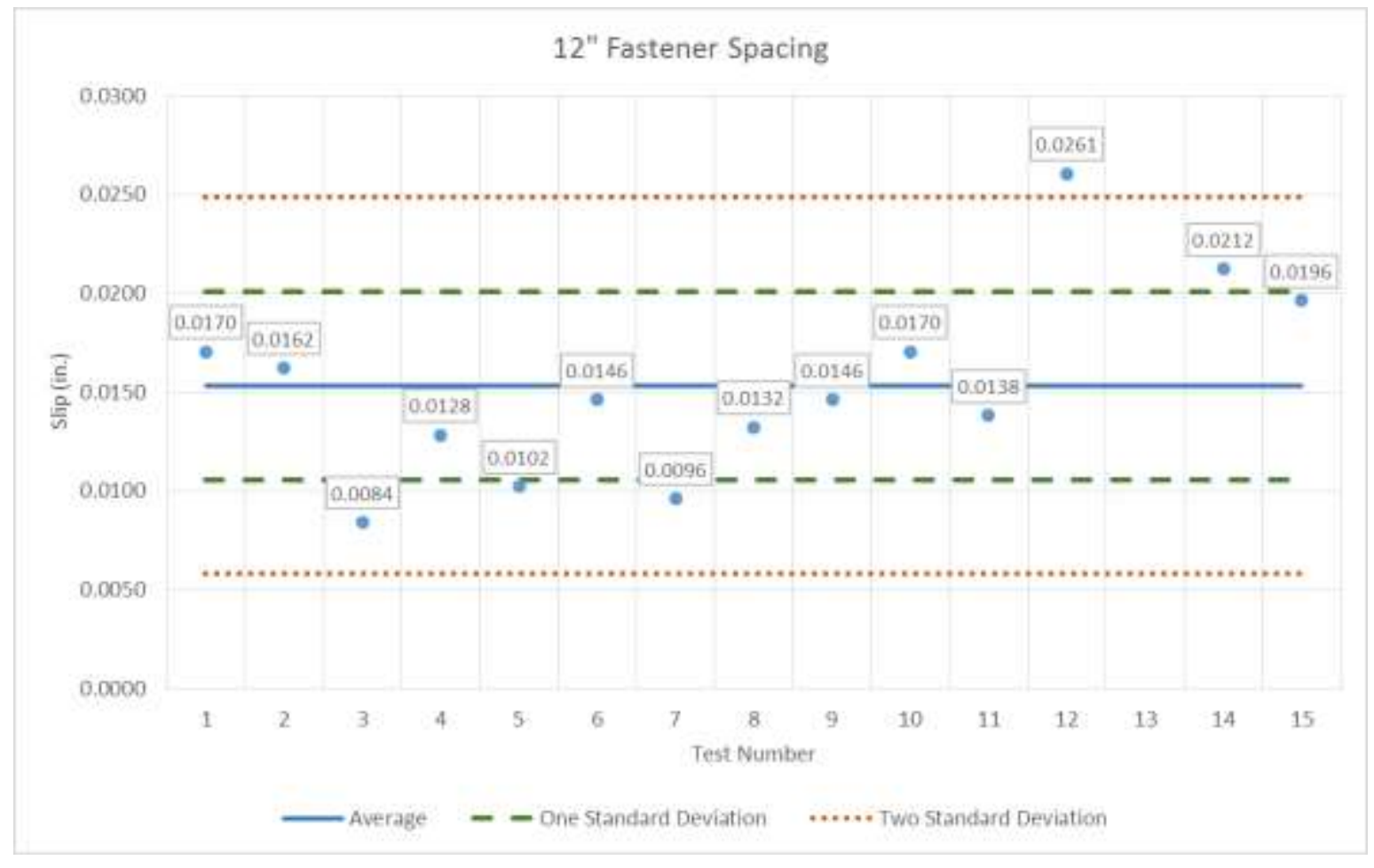

Figure A-4 12-Inch Fastener Spacing Slip at $1900 \mathrm{lbs}$ 


\section{Appendix B - Shimadzu AG-IC Specifications Sheet}

\section{Specifications for Autograph AG-IC}

\begin{tabular}{|c|c|c|c|}
\hline \multirow{2}{*}{ Model } & \multirow{2}{*}{\begin{tabular}{|c|} 
AG-IC Table-Top Type \\
AG-20kN/50kNICD \\
\end{tabular}} & \multicolumn{2}{|c|}{ AG-IC Floor Type } \\
\hline & & AG-100kNIC & AG-250kN/300kNIC \\
\hline Maximum Load Capacity & $20 \mathrm{kN} / 50 \mathrm{kN}$ & $100 \mathrm{kN}$ & $250 / 300 \mathrm{kNIC}$ \\
\hline \multirow{2}{*}{ Test Force Precision } & \multicolumn{2}{|c|}{ 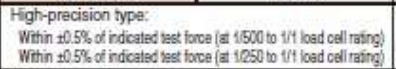 } & 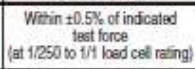 \\
\hline & \multicolumn{2}{|c|}{ 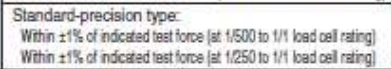 } & $\begin{array}{c}\text { Within } 11 \% \text { of indicated } \\
\text { fest furce } \\
\text { (at } 1 / 250 \text { to t/f load cel rifing) }\end{array}$ \\
\hline 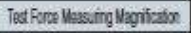 & \multicolumn{3}{|c|}{$\times 1,2,5,10,20,50,100$ (7 ranges, automatic range switching) } \\
\hline Calibration & \multicolumn{3}{|c|}{ Automatic calibration (calbration test force: tensile and compression) } \\
\hline $\begin{array}{l}\text { Crosshead - Table Distance } \\
\text { (Tensile Stroke) }\end{array}$ & $\begin{array}{c}20 \mathrm{kN}: \text { Max, } 1060 \mathrm{~mm} \\
50 \mathrm{kN}: \text { Max, } 1060 \mathrm{~mm}) \\
(605 \mathrm{~mm})\end{array}$ & $\begin{array}{l}\text { Max. } 1250 \mathrm{~mm} \\
(760 \mathrm{~mm})\end{array}$ & $\begin{array}{l}\text { Max. } 1440 \mathrm{~mm} \\
(600 \mathrm{~mm})\end{array}$ \\
\hline Test Speed (mm/min) (1) & 0.0005 to 1000 & 0.0005 to 1000 & 0.0005 to 500 \\
\hline Retum Speed (mm/min) & 1100 & 1100 & 550 \\
\hline Speed Accuracy ('2) & \multicolumn{3}{|c|}{ $\pm 0.1 \%$} \\
\hline $\begin{array}{l}\text { Crosshead Speed and } \\
\text { Permitted Test Force }\end{array}$ & $\begin{array}{c}20 \mathrm{kN} 50 \mathrm{kN} \\
\text { across entire speed range }\end{array}$ & $\begin{array}{l}100 \mathrm{kN} \\
\text { across entire speed range }\end{array}$ & 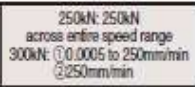 \\
\hline Effective Test Width & $450 \mathrm{~mm}$ & \multicolumn{2}{|c|}{$575 \mathrm{~mm}$} \\
\hline Displacement Accuracy & \multicolumn{3}{|c|}{ Within $\pm 0.1 \%$ indicated value ( $( \pm 0.01 \mathrm{~mm}$ for indicated value up to $10 \mathrm{~mm}$ ) } \\
\hline Crosshead Control & \multicolumn{3}{|c|}{$\begin{array}{l}\text { Single test control, cycle test control, manual control } \\
\text { - Cycle test control pemits test force cycles, stroke cycles, deformation cycles } \\
\text { (extensometer is optional), or a combination of these. }\end{array}$} \\
\hline Date Capture Pate & \multicolumn{3}{|c|}{$\mathrm{BOOHz}$} \\
\hline
\end{tabular}

("1) Set to any speed.

(2) Crosshead speed accuracy is calculated from the crosshead travel within a prescribed time at a constant speed between $0.5 \mathrm{~mm} / \mathrm{min}$ and $500 \mathrm{~mm} / \mathrm{min}$.

\begin{tabular}{|c|c|c|c|}
\hline \multirow{2}{*}{ Model } & \multirow{2}{*}{\begin{tabular}{c|} 
AG-IC Table-Top Type \\
AG-20kN/50kNICD
\end{tabular}} & \multicolumn{2}{|c|}{ AG-IC Floor Type } \\
\hline & & AG-100kNIC & AG-250kN/300kNIC \\
\hline Maximum Load Cspacity & $20 \mathrm{kN} / 50 \mathrm{kN}$ & $100 \mathrm{kN}$ & $250 / 3006$ NIC \\
\hline Standard Functions & \multicolumn{3}{|c|}{$\begin{array}{l}\text { - Automatic reading of load cell characteristic values } \\
\text { - Auto / tull-auto test force range switching } \\
\text { - Crosshead position fine adjustrment } \\
\text { - Test force display function } \\
\text { - Stroke display function } \\
\text { - External analog output (2 channels), Extemal analog input (2 channels) } \\
\text { - Internal amps: } 3 \text { ports (One of them is used for the test force amp.) } \\
\text { - PS-232C interface } \\
\text { - Recorder output } \\
\text { - Autornatic test foroe / strain control } \\
\text { - Test force auto-zeroing } \\
\text { - Test force auto-calibration } \\
\text { - Break detetetion } \\
\text { - Auto-return } \\
\text { - Crosshead speed settings } \\
\text { - Cycle number display } \\
\text { - Stress value display } \\
\text { - Displacement gauge value display function }\end{array}$} \\
\hline Frame rigidity & $120 \mathrm{kN} / \mathrm{mm}$ & $300 \mathrm{kN} / \mathrm{mm}$ & Min, $400 \mathrm{kN} / \mathrm{mm}$ \\
\hline $\begin{array}{l}\text { Dimensions (mm) } \\
\text { (Standard Type) } \\
\text { (Width } \times \text { Dept } \times \text { Height) }\end{array}$ & $845 \times 500 \times 1625$ & $1170 \times 750 \times 2162$ & $1170 \times 750 \times 2412$ \\
\hline $\begin{array}{l}\text { Weight } \\
\text { (Standard Type) }\end{array}$ & \begin{tabular}{l|}
$280 \mathrm{~kg}$ \\
(tester main unit) \\
$20 \mathrm{~kg}$ \\
(measurement controler)
\end{tabular} & $800 \mathrm{~kg}$ & $900 \mathrm{~kg}$ \\
\hline $\begin{array}{l}\text { Installation } \\
\text { Conditions }\end{array}$ & \multicolumn{2}{|c|}{$\begin{array}{l}\text { Temperature: } 5^{\circ} \mathrm{C} \text { to } 40^{\circ} \mathrm{C} \\
\text { Humidity: } 20 \% \text { to } 80 \% \text { (no condensation) } \\
\text { Power supply voltage fluctuations: within } \pm 10 \% \\
\text { Vibratons. frequency } 5 \mathrm{~Hz} \text { max, ampiltude } 5 . \mu \mathrm{m} \text { mex. } \\
\text { Type } \mathrm{D} \text { grounding ( } 100 \mathrm{\Omega} \text { max.) }\end{array}$} & 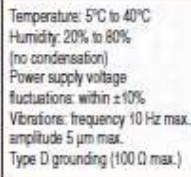 \\
\hline Power Requirements & $\begin{array}{l}\text { Single phase } \\
200-230 \mathrm{VAC} \\
50-60 \mathrm{~Hz} \\
4.0 \mathrm{kVA}(1.5 \mathrm{~kW})\end{array}$ & $\begin{array}{l}\text { Three phase } \\
200-230 \mathrm{VAC} \\
50-60 \mathrm{~Hz} \\
6.0 \mathrm{kVA}(1.6 \mathrm{~kW})\end{array}$ & $\begin{array}{l}\text { Three phase } \\
2000.230 \text { VAC } \\
50-60 \mathrm{~Hz} \\
7.5 \mathrm{kVA}(1.6 \mathrm{~kW})\end{array}$ \\
\hline
\end{tabular}

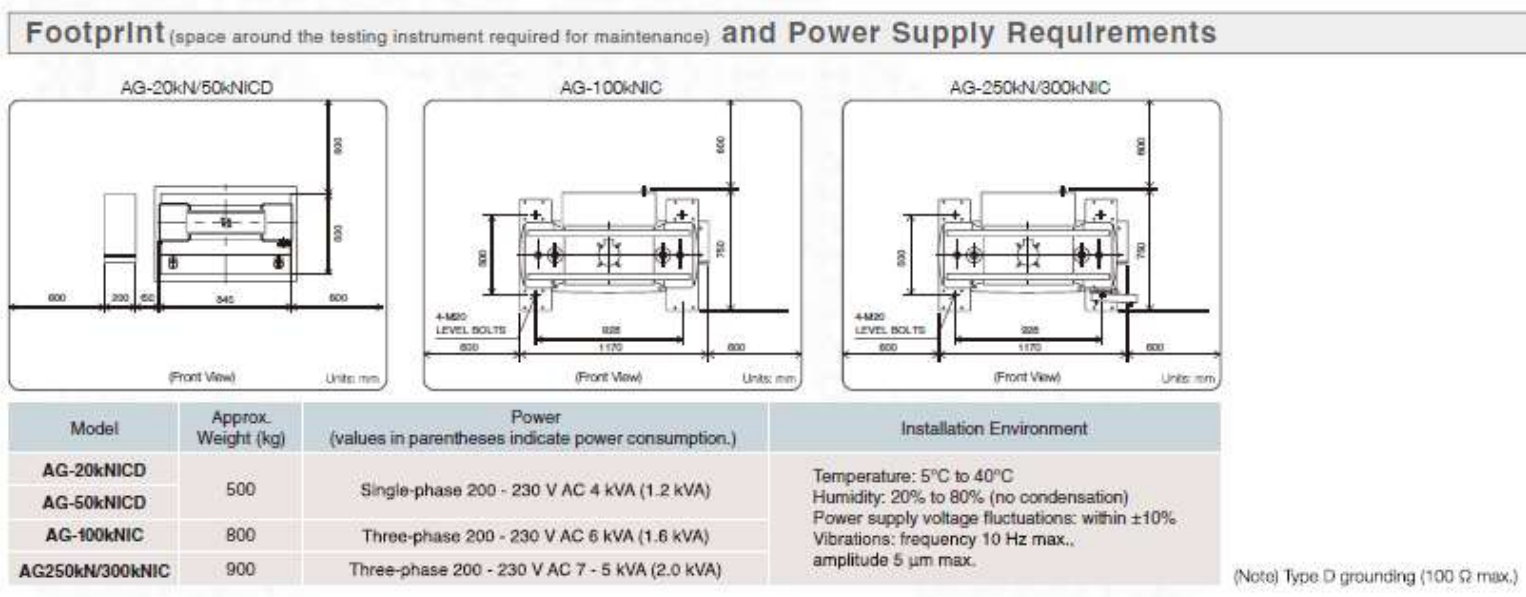




\section{Appendix C - CFS Specifications Sheet}

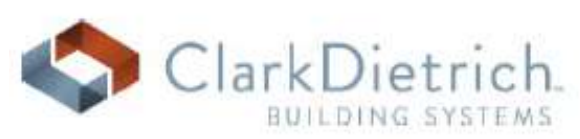

\section{Product Submittal Sheet}

Tech Support: $888-437-3244$

Engineering Services: 877-832-3206
Sales: $800-543-7140$ clarkdietrich.com
Product category: Product name:
S162 (1-5/8" Flange Structural Stud) 600 S162-43 (33ksi, CP60) P - Punched 43 mils (18ga)
Coating: CP60 per ASTM C955 Color coding: Yellow

Geometric Properties

Web depth $\quad 6.000$ in

Flange width $\quad 1.625$ in

Stiffening lip $\quad 0.500$ in

Design thickness 0.0451 in

Yield strength, Fy $33 \mathrm{ksi}$

Ultimate, Fu

$45.0 \mathrm{ksi}$

$\begin{array}{ll}\text { Punchout width } & 1.50 \text { in } \\ \text { Punchout length } & 4.00 \text { in } \\ \text { Min. steel thickness } & 0.0428 \text { in } \\ \text { Fy with Cold-Work, Fya } & 36.3 \mathrm{ksi}\end{array}$

Fy with Cold-Work, Fya $36.3 \mathrm{ksi}$

Gross Section Properties of Full Section, Strong Axis

Cross sectional area (A)

Member weight per foot of length

$0.447 \mathrm{in}^{2}$

$1.52 \mathrm{lb} / \mathrm{ft}$

Moment of inertia (lx)

Section modulus ( $\mathrm{Sx}$ )

Radius of gyration ( $R x$ )

2.316 in $^{4}$

Gross moment of inertia (ly)

Gross radius of gyration (Ry)

0.148 in $^{4}$

0.576 in

Effective Section Properties, Strong Axis

Effective Area (Ae)

Moment of inertia for deflection (Ix)

Section modulus ( $\mathrm{Sx}$ )

Allowable bending moment (Ma)

Allowable moment based on distortion buckling (Mad)

Allowable shear force in web (solid section)

Allowable shear force in web (perforated section)

Unbraced length $(\mathrm{Lu})$

$$
\begin{aligned}
& 0.256 \mathrm{in}^{2} \\
& 2.316 \mathrm{in}^{4} \\
& 0.767 \mathrm{in}^{3} \\
& 16.68 \mathrm{in}-\mathrm{k} \\
& 14.47 \mathrm{in}-\mathrm{k} \\
& 1416 \mathrm{lb} \\
& 1240 \mathrm{lb} \\
& 39.0 \mathrm{in}
\end{aligned}
$$

Torsional Properties

St. Venant torsion constant $(\mathrm{J} \times 1000)$

Warping constant ( $\mathrm{CW}$ )

Distance from shear center to neutral axis (Xo)

Distance between shear center and web centerline $(\mathrm{m})$

Radii of gyration (Ro)

Torsional flexural constant (Beta)

ASTM \& Code Standards:

- AISI North American Specification [NASPEC] S100-07 with 2010 supplement

- *Effective properties incorporate the strength increase from the cold work of forming

- Gross properties are based on the cross section away from the punchouts

- Structural framing is produced to meet or exceed ASTM C955

- Sheet steel meets or exceeds mechanical and chemical requirements of ASTM A1003

- ClarkDietrich's structural and nonstructural framing comply with the SFIA Code Compliance

Certification Program, ICC-ES ESR-1166P and ATI CCRR-0206

- For installation \& storage information refer to ASTM C1007

- SDS \& Product Certification Information is available at www. clarkdietrich.com
05.40.00 (Cold-Formed Metal Framing)

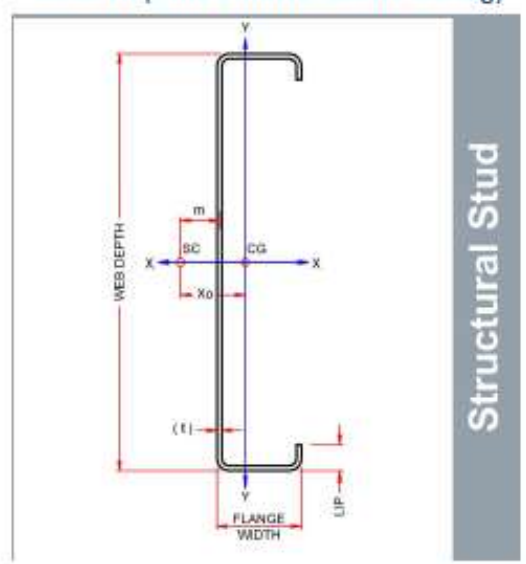

Used in framing applications:

- Load-bearing walls

- Curtain walls

- Tall interior walls

- Floor \& ceiling joists

- Trusses

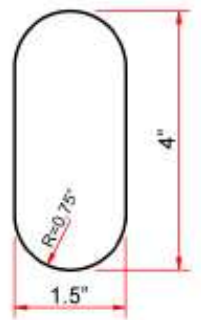

Structural

Punchout

East market punchout spacing: 12 " from lead end then 24 " o.c.

West market punchout spacing: 24 " from lead end then 24 " o.c.

Sustainability Credits:

For more details and LEED letters contact Technical Services at 888-437-3244 or visit www.clarkdietrich.com/LEED

LEED v4 MR Credit - Building Product Disclosure and Optimization: EPD (up to 2 points) - Sourcing of Raw Materials (1 point) - Material Ingredients (1 point) - Construction and Demolition Waste Management (up to 2 points) - Innovation Credit (up to 2 points).

LEED 2009 Credit MR 2 \& MR 4 - ClarkDietrich's steel products are 100\% recyclable and have a minimum recycled content of 34.2\% (19.8\% post-consumer and $14.4 \%$ pre-consumer). If seeking a higher number to meet Credit MR 5, please contact us at (info@clarkdietrich.com / 888-437-3244) 


\section{Appendix D - Celesco SP2-12 Specifications Sheet}

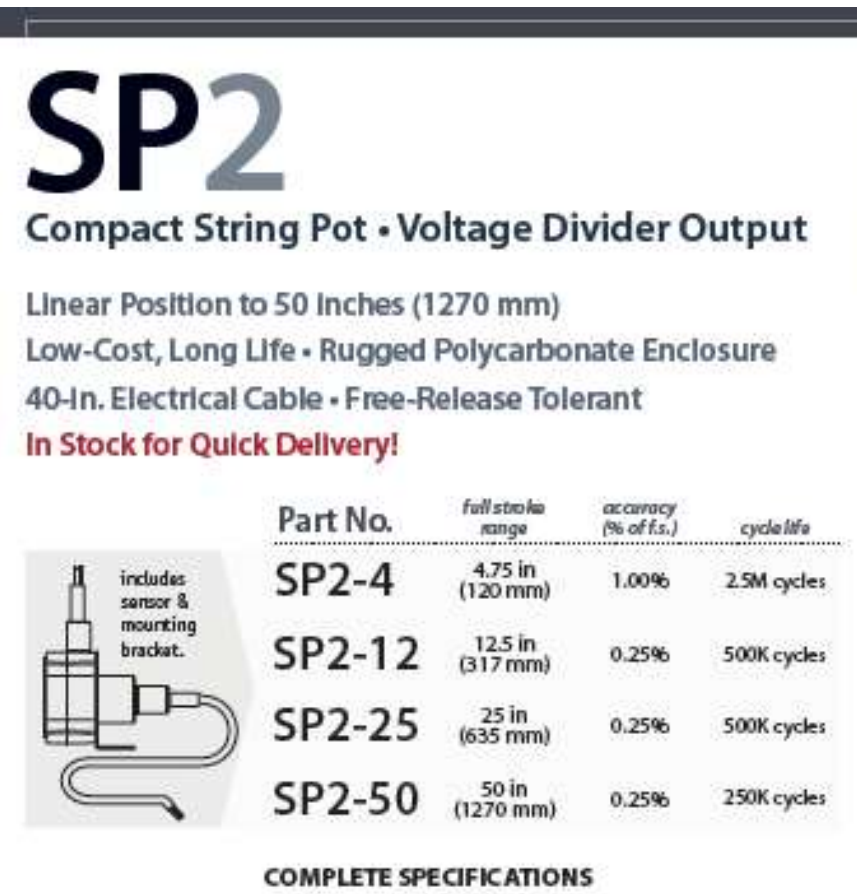

Full Stroke Range Options

$0-4.75,0-12.5,0-25,0-50$ inches

Output Signal

voltage divider (potentiometer)

Accuracy \pm 0.25 to $\pm 1.00 \%$ (see part na above)

Repeatability $\pm 0.05 \%$ full stroke

Resolution essentially infinite

Measuring Cable

0.019-in. dia. mylon-coated stainless steel

Measuring Cable Tension $7 \mathrm{oz} .(1,9 \mathrm{~N}) \pm 25 \%$

Maximum Cable Acceleration

$15 \mathrm{~g}$

Enclosure Material

polycarbonate

Sensor

plastic-hybrid precision potentiometer

Weight $5 \mathrm{oz}$. (w/o mounting bracket) max.

\section{ELETRACAL}

Input Resistance

$10 \mathrm{Kohms}, \pm 10 \%$

Power Rating, Watts 2.0 at $70^{\circ} \mathrm{F}$ derated to 0 at $250^{\circ}$

Recommended Maximum Input Voltage

$30 \mathrm{~V}(\mathrm{AC} / \mathrm{DC})$

Output Signal Change Over Full Stroke Range $94 \% \pm 4 \%$ of input voltage Electrical Connection $\quad 40$-inch long, 24 guage shielded electical cable

\section{ENVIRONMENTAL}

Enclosure

IP 50

Operating Temperature

vibration

$0^{\circ}$ to $160^{\circ} \mathrm{F}\left(-18^{\circ}\right.$ to $\left.71^{\circ} \mathrm{C}\right)$

up to $10 \mathrm{~g}$ to $2000 \mathrm{~Hz}$ maximum

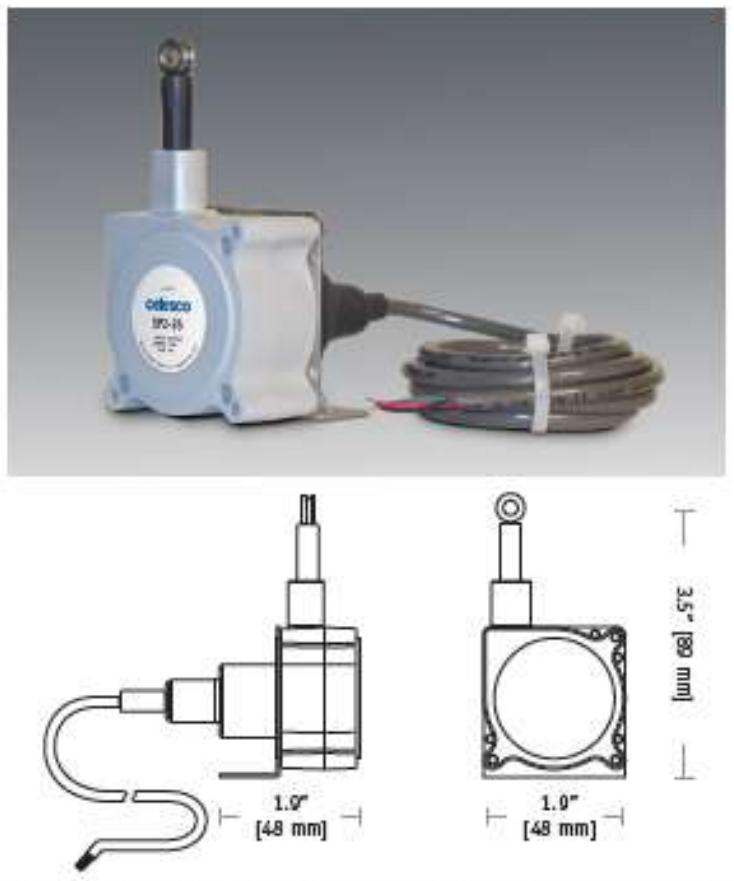

The SP2 String Pot from Celesco is a compact, economical and water resistant device that utilizes a flexible cable, a spring-loaded spool and a potentiometer to detect and measure linear position.

The SP2 is identical to the SP1 except for an added 40 -inch electrical cable with a watertight rubber strain relief. The SP2 has been compactly designed for tight spaces and high cycle applications and generously allows for measuring cable misalignment. With 4 different ranges and a handy mounting bracket, the SP2 is a perfect solution for many applications from light industrial to OEM.

$\underline{\text { Output Signat: }}$

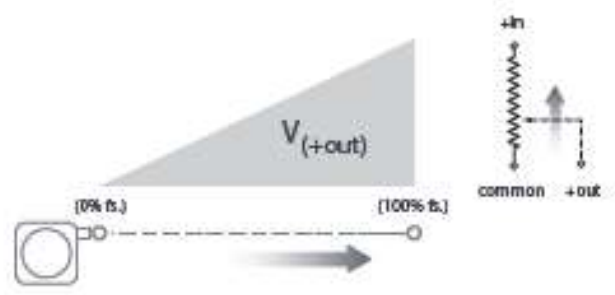




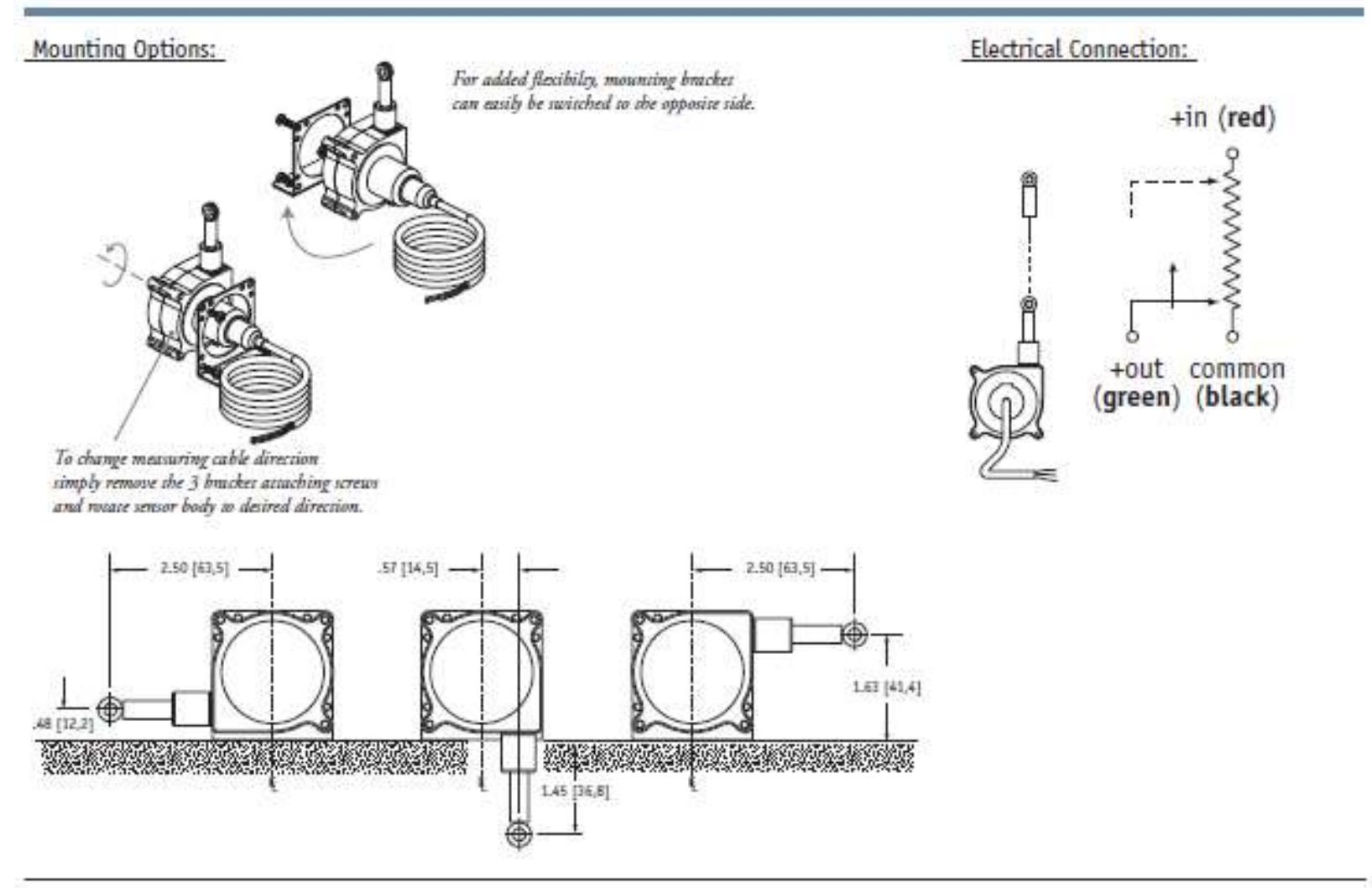

Outline Drawing (w/o bracket):

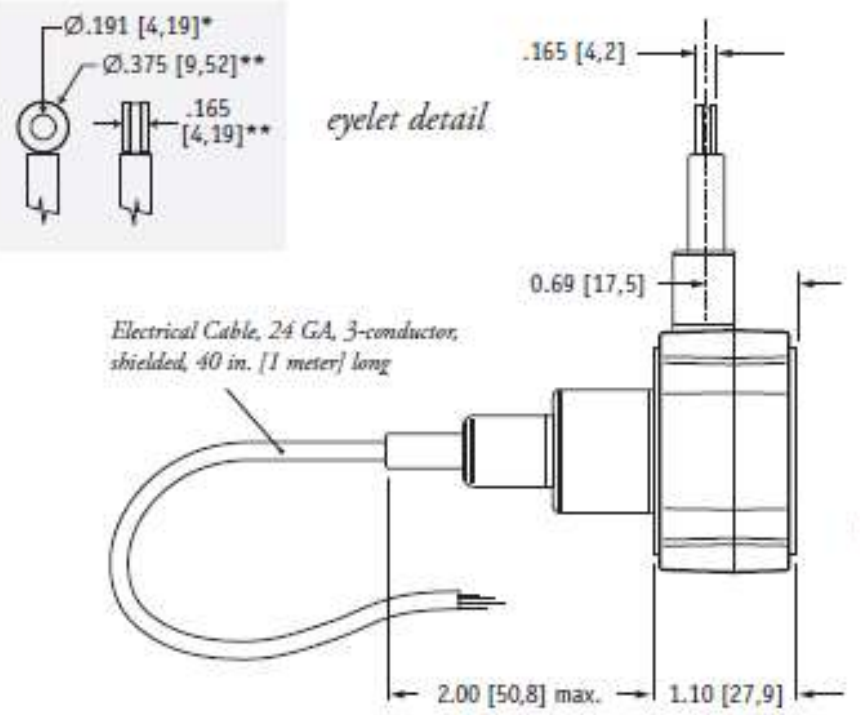

DIMENSIONS ARE IN INCHES [MM]

tolerances are $0.04 \mathrm{IN}$. [1,0 MM] unless otherwise noted.

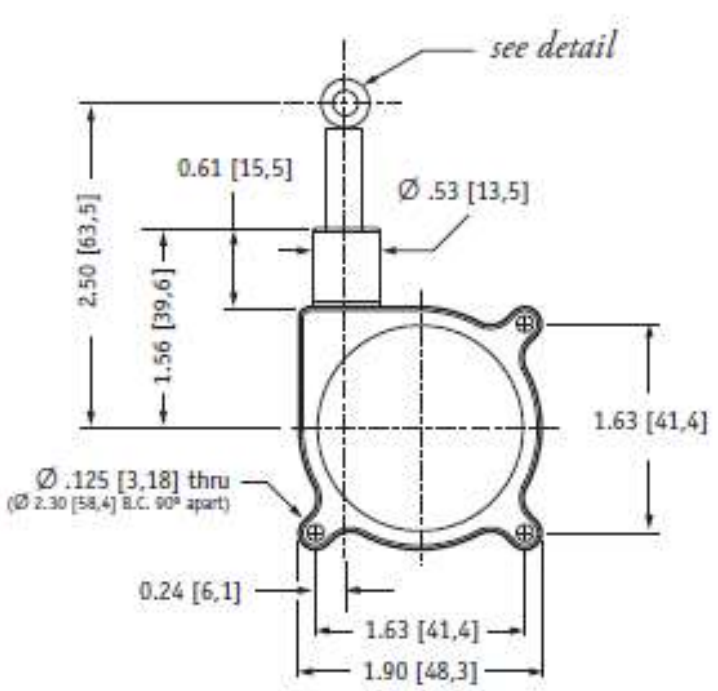

* tolerance $=+, 005-, 001[+0,1-0,0]$

$*$ tolerance $=+.005-0.05[+0,1-0,1]$ 
lutline Drawing (with bracket):
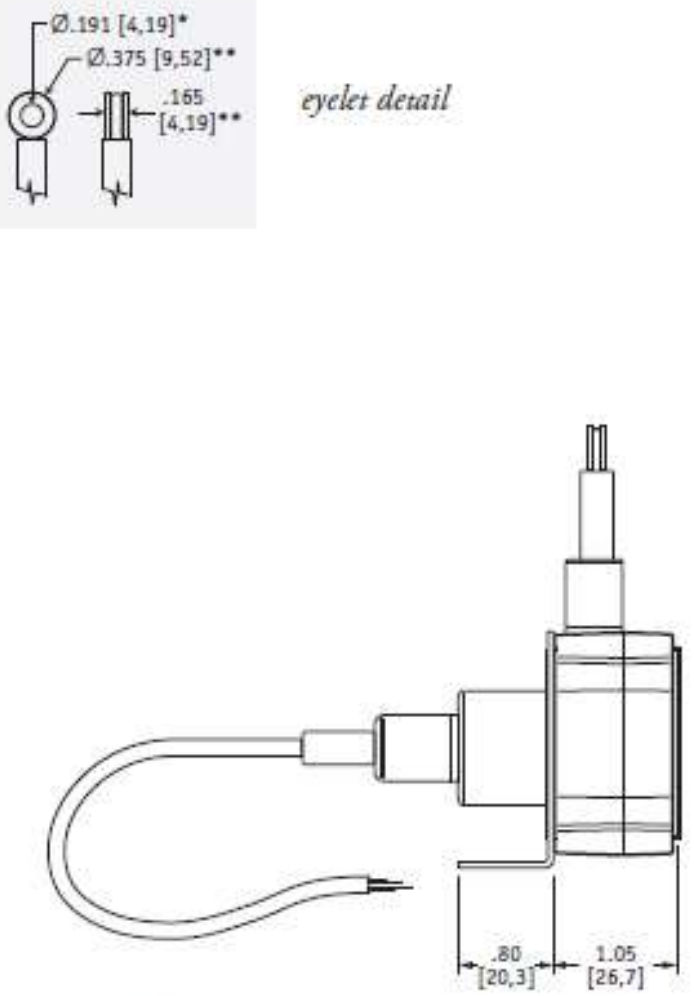

DIMENSYONS AGE IN BNOHES IMMI

tolerances are $0.04 \mathrm{IN}$. [1,0 MMl unless otherwore noted.
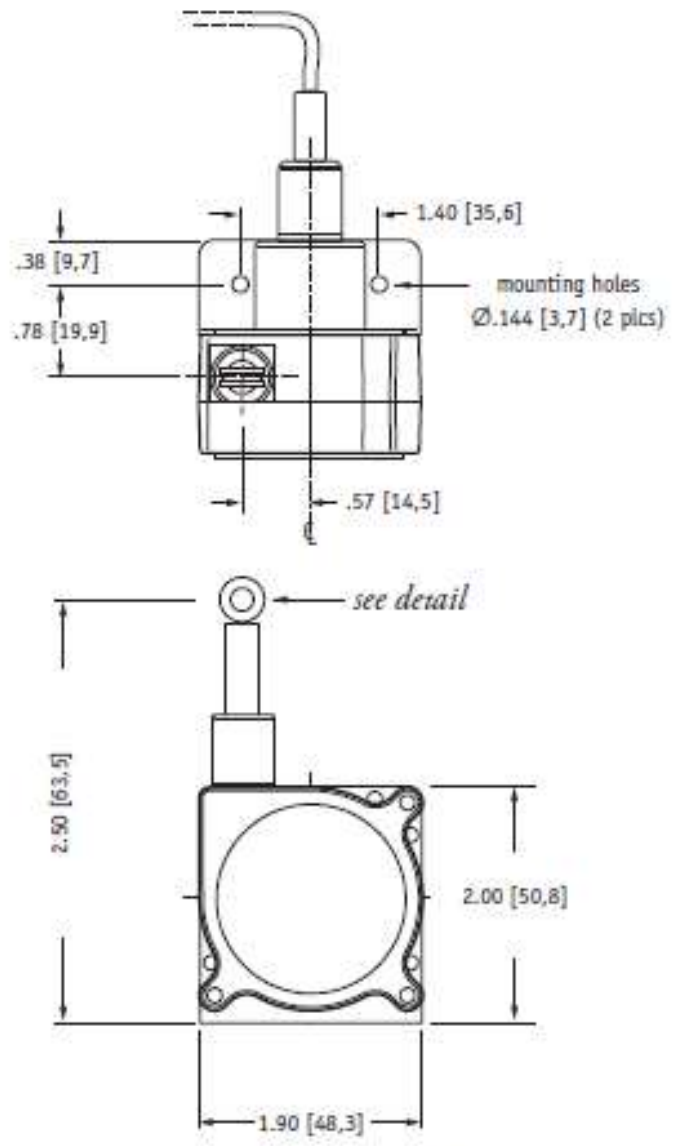

- tolerance $=+005-0001[+0,1-0,0]$ $*$ tolerance $=+0005-0005[+0,1-0,1]$ 